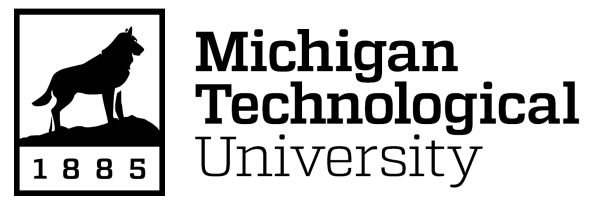

Michigan Technological University Digital Commons @ Michigan Tech

\title{
A broadly protective thermostable next generation HPV vaccine based on a concatemer peptide and a consensus peptide of $L 2$ displayed on bacteriophage virus-like particles
}

Lukai Zhai

Michigan Technological University, Izhai@mtu.edu

Copyright 2019 Lukai Zhai

Recommended Citation

Zhai, Lukai, "A broadly protective thermostable next generation HPV vaccine based on a concatemer peptide and a consensus peptide of L2 displayed on bacteriophage virus-like particles", Open Access Dissertation, Michigan Technological University, 2019.

https://doi.org/10.37099/mtu.dc.etdr/848

Follow this and additional works at: https://digitalcommons.mtu.edu/etdr

Part of the Immunology and Infectious Disease Commons 


\title{
A BROADLY PROTECTIVE THERMOSTABLE NEXT GENERATION HPV VACCINE BASED ON A
}

\section{CONCATEMER PEPTIDE AND A CONSENSUS PEPTIDE}

\section{OF L2 DISPLAYED ON BACTERIOPHAGE VIRUS-LIKE}

PARTICLES

By

Lukai Zhai

\author{
A DISSERTATION \\ Submitted in partial fulfillment of the requirements for the degree of \\ DOCTOR OF PHILOSOPHY \\ In Biological Sciences
}

MICHIGAN TECHNOLOGICAL UNIVERSITY

2019

(c) 2019 Lukai Zhai 
This dissertation has been approved in partial fulfillment of the requirements for the Degree of DOCTOR OF PHILOSOPHY in Biological Sciences.

Department of Biological Sciences

Dissertation Advisor: Dr. Ebenezer Tumban

Committee Member: Dr. Stephen M. Techtmann.

Committee Member: Dr. Xiaoqing Tang

Committee Member: $\quad$ Dr. Hairong Wei

Department Chair: Dr. Chandrashekhar P. Joshi 


\section{Table of Contents}

Preface

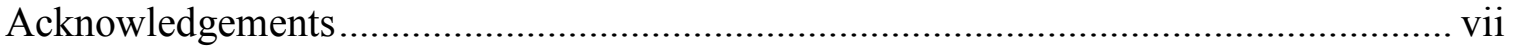

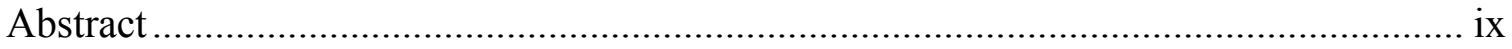

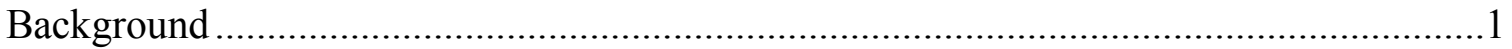

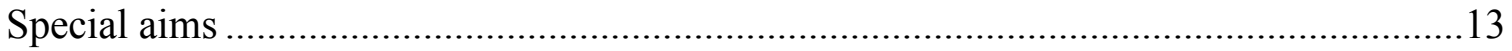

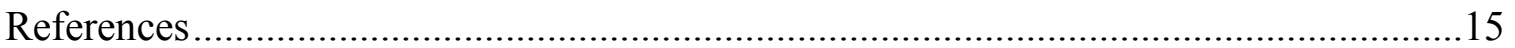

Chapter 1 A Novel Candidate MS2 Phage VLP Vaccine Displaying a tandem HPV L2 Peptide offers Similar Protection in Mice to Gardasil-9 ..................................................20

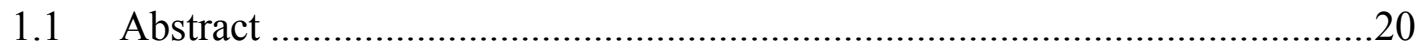

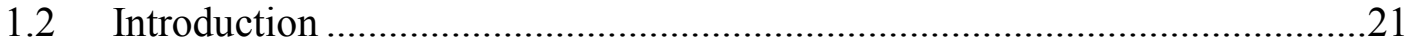

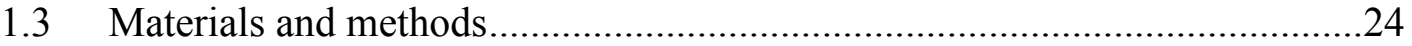

1.3.1 Cloning, expression and purification of MS2-L2 VLPs ....................24

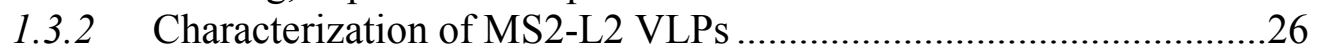

1.3.3 Immunization of mice and characterization of antibody responses..27

1.3.4 Pseudovirus production and purification ........................................28

1.3.5 Cervicovaginal infection with HPV PsVs........................................29

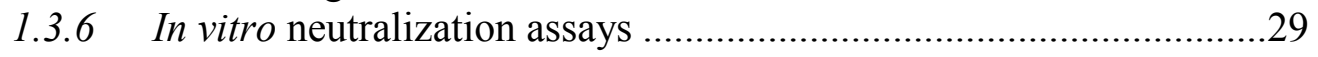

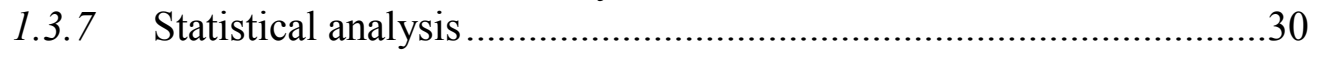

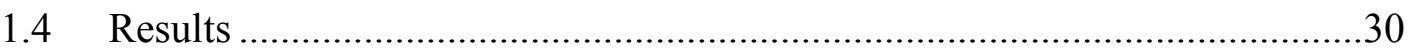

1.4.1 Insertion of multiple L2 epitopes on MS2 coat protein does not

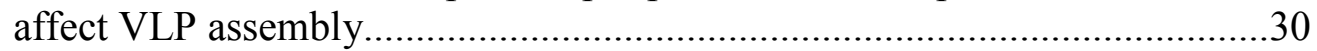

1.4.2 MS2 VLPs displaying multiple L2 epitopes are immunogenic .........35

1.4.3 MS2 VLPs displaying multiple L2 epitopes offered broad protection against HPV PsVs, at levels similar to Gardasil-9 vaccine............39

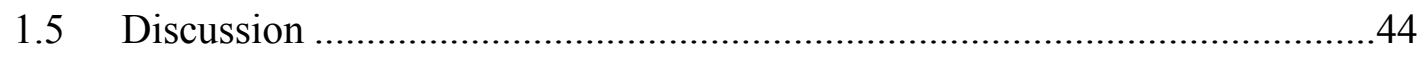

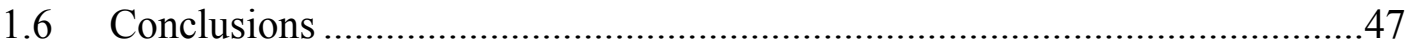

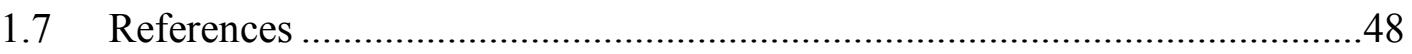

Chapter 2 Oral immunization with bacteriophage MS2-L2 VLPs protects against oral and genital infection with multiple HPV types associated with head \& neck cancers and

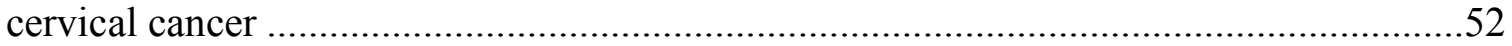

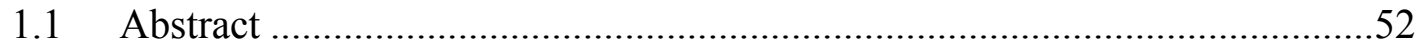




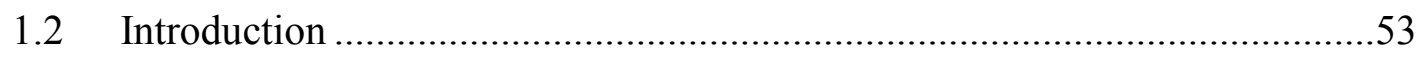

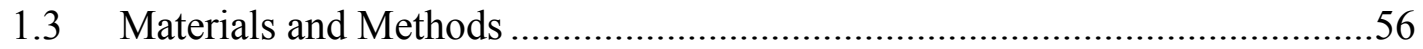

1.3.1 Production of MS2-L2 VLPs .....................................................56

1.3.2 Spray-freeze drying of VLPs into dry powder formulation................56

1.3.3 Assessing the thermostability of SFD VLPs....................................58

1.3.4 Immunization of mice and assessing antibody responses..................58

1.3.5 Oral and vaginal infection with HPV pseudoviruses (PsVs) ............60

1.3.6 Statistical analysis ........................................................................61

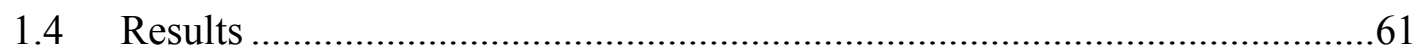

1.4.1 Buccal immunization with mixed MS2-L2 VLPs plus mucosal adjuvants elicits protective immune responses at the vaginal and oral regions

1.4.2 Mixed MS2-L2 VLPs can be SFD without a mixture of cholera toxin/MPLA adjuvants

1.4.3 SFD mixed VLPs are thermostable at room temperature for up to 60 days and elicit protective responses

……………………………….....

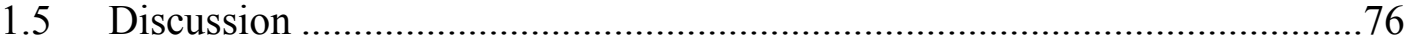

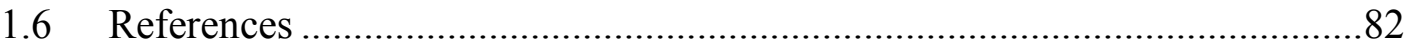

Chapter 3 Novel Expression of Coat Proteins from Thermophilic Bacteriophage ФIN93 and Evaluation for Assembly into Virus-like Particles ..................................................87

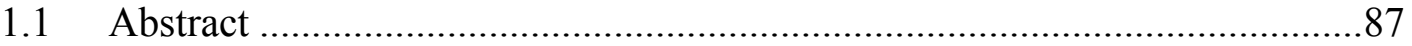

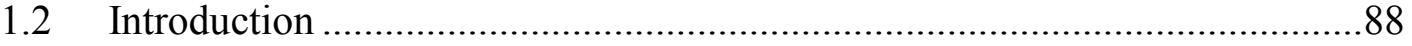

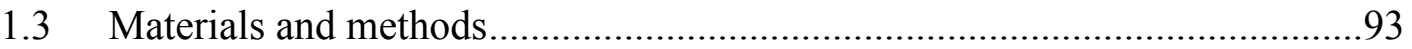

1.3.1 Generation of expression vectors....................................................93

1.3.2 Coat protein expression and purification ..........................................99

1.3.3 Generation of bacteriophage ФIN93 ……….................................95

1.3.4 Transmission electron microscopy (TEM) ........................................96

1.3.5 Generation of sera for immunoassays .............................................96

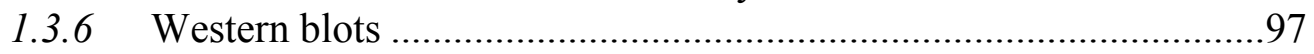

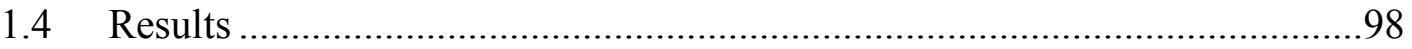

1.4.1 ORF13 and ORF14 can be successfully expressed in E. coli ...........98

1.4.2 Truncated ORF13 and ORF14 can be co-expressed and purified

from $E$ coli .................................................................................

1.4.3 Truncated ORF13 and ORF14 form structures that resemble

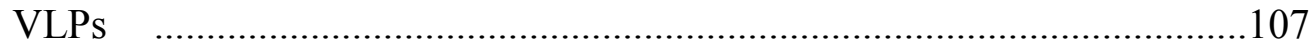

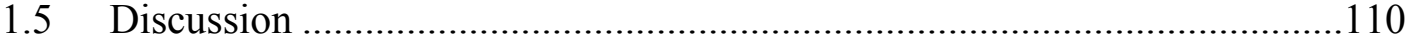

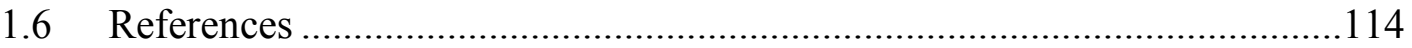


Summary

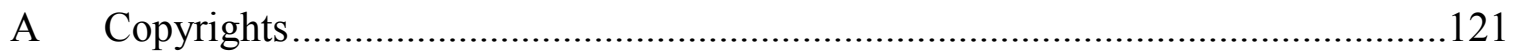




\section{Preface}

The In vitro neutralizing assays in Chapter 1 were conducted by Susana Pang in Dr. John Schiller's lab (Laboratory of Celluar Oncology, National Cancer Institute, National Institute of Health). Sera used in this experiment were collected in Michigan Technological University and were sent to our collaborator for further studies. The HPV pseudovirus challenge experiments in Chapter 1 were conducted by Julianne Peabody in Dr. Bryce Chackerian's lab (Department of Molecular Genetics and Microbiology, University of New Mexico School of Medicine). The data were published in "Antiviral Research 147 (2017) 116-123". The Spray-freeze drying formulation into dry powder was conducted by $\mathrm{Dr}$. Nitesh Kunda in Dr. Pavan Muttil's lab (Department of Pharmaceutical Sciences, College of Pharmacy, University of New Mexico). We sent the liquid VLPs samples to them and they sent us the lyophilized VLPs samples. Data in Chapter

2 has been published in the journal of Antiviral Research (2019) (https://doi.org/10.1016/j.antiviral.2019.03.012). 


\section{Acknowledgements}

I would like to thank, sincerely, my advisor, Dr. Ebenezer Tumban for his kind guidance and help during my research. He is knowledgeable \& patient, and also a good mentor who showed me how to do research and communicate with others.

Also, I would like to thank my other committee members: Dr. Stephen Techtmann, Dr. Xiaoqing Tang and Dr. Hairong Wei for their insights, suggestions and directions on my research. Special thank you to Dr. Tang and Dr. Techtmann for allowing me to use their lab equipment, which made my research very successful. Special thank you to Dr. Wei for offering a Bioinformatics class, which helped enrich myself my knowledge.

I cannot forget the help from all my colleagues in our department. Thanks to Dr. Joshi (Department Chair), Tori Connors, Raquel Heitor, Travis Wakeham, Emily Betterly (retired), Patricia Asselin (retired), and Jeffrey Lewin for their administrative support. I would also like to thank my colleagues in Tumban Lab (Rupsa Basu, Tahiyat Alothaim, Rashi Yadav, Dana Anderson, and Ellie Bruckner) for their assistance towards my research. Thanks to Owen Mills, Pinaki Mukherjee and Anjana Asthana (Materials Sciences and Engineering) for TEM imaging. I would also like to thank Dr. Sara Zimmer (University of Minnesota 
School of Medicine, Duluth) for providing us with access to IVIS equipment; thanks also to Heidi and lan for helping euthanize mice.

Finally, I am very thankful and highly indebted to my parents (Yingchun Zhai and Cuiping Zhao), my wife (Mengmeng Qiao), my daughter (Alex), my son (George), and my upcoming daughter (Olivia). I cannot imagine what will happen without their support and encouragement. I would like to thank my grandma who passed away in 2018. She loved me so much and was always proud of me. You are always the best grandma and I love you so much. 


\section{Abstract}

Current human papillomavirus (HPV) vaccines (Cervarix and Gardasil-9) are highly immunogenic and derived from the major capsid proteins (L1) of different HPV types. L1 is not conserved among different HPV types. Thus, these L1based vaccines protect mostly against the HPV types included in the vaccines with minimal cross-protection against non-vaccine HPV types. In addition to this, the vaccines require refrigeration during transportation and storage. To broaden protection against diverse HPV infection, we targeted epitopes (17-31, 69-86, and 108-122) on the major capsid protein (L2) of HPV, which are conserved among different HPV types for vaccine design. We explored the display of these L2 epitopes, individually or as concatemers, on the surface of a highly immunogenic bacteriophage MS2 virus-like particle (VLP) platform. VLPs are empty viral shells without a viral genome. They are derived from viral structural proteins such as envelope proteins or capsid proteins. VLPs cannot replicate, they are non-infectious, and are highly immunogenic; thus, they are safe and effective platforms for vaccine designs. Mice immunized with the MS2-L2 candidate HPV vaccine (a mixture of MS2 VLPs: one displaying a concatemer of peptides from HPV16L2 \& HPV31L2 and the other displaying a consensus peptide, epitope 69-86, from the alignment of 23 HPV types) elicited high-titer antibodies that protected mice from genital infection with nine diverse HPV types; the VLPs also protected mice from oral infection with five diverse HPV types. To 
improve the thermostability of the MS2-L2 VLPs, the candidate vaccine was formulated into powder by spray-freeze drying technique. Spray-freeze dried VLPs stored at room temperature for two months were still immunogenic and offered protection against HPV infection. Mixed MS2-L2 VLPs is a candidate next generation HPV vaccine. We also explored, in this dissertation, the potential of developing a novel thermostable VLP platform based on a thermophilic bacteriophage, $\Phi$ IN93. Our results seem to suggest that co-expression of two truncated versions of coat proteins from $\Phi I N 93$ have potential to form structures that resemble VLPs. 


\section{Background}

\section{Immunity, vaccination and virus-like particles (VLPs):}

The human body is well protected from infectious pathogens such as bacteria and viruses by the complex immune system. The immune system is divided into the innate immune system (innate immunity) and the adaptive immune system (adaptive immunity). Innate immunity provides the first line of defense against general pathogens. It does not show specificity to a particular antigen (antigenindependent), its response is immediate (from minutes to hours) after foreign invasion, and it does not have memory responses. Three components provide innate immunity: physical (skin) \& chemical barriers (mucus, tears and saliva), phagocytes (blood monocytes, neutrophils and macrophages), and pattern recognition molecules [1]. When innate immunity fails to clear off invasions, adaptive immunity is activated. Adaptive immunity has different features compared to innate immunity: i) it takes longer time (several days) for the response to be mounted; ii) it is more specific to the antigens (antigendependent); iii) it generates memory to the invaded pathogens, which means adaptive immunity can rapidly recognize and response to the same antigens following reinfection (with the same pathogen) with the help of the existing memory cells or antibodies [2]. Adaptive immunity contains more complex components such as $T$ and B lymphocytes ( $T$ cells and B cells) and antibodies. Antibody response or humoral immunity is one of the two main responses of 
adaptive immunity (antibodies are produced by B cells). The other response, cellmediated immunity is mounted by $\mathrm{T}$ cells. As shown in Figure 1, the generation and secretion of antibodies involves collaboration of a series of immune cells: antigen-presenting cells (APCs) such as macrophages, B cells, and dendritic cells ingest pathogens, digest the pathogens, and present antigens from the pathogen, on cell surfaces in association with the major histocompatibility complex (MHC) class II molecules. CD4 T cells interact with APCs, which displayed the antigens in association with MHC II. CD4 T cells are then activated and they release cytokines such as IL-4, IL-5 and IL-6. The released cytokines or the cross-linking of $B$ cell receptors can lead to B cells activation and differentiation into plasma B cells (secrete antibodies) and memory B cells which provide a rapid and long-lasting response on reinfection with the same pathogen $[3,4]$. Innate and adaptive immunities do not work independently, but rather are complementary in maintaining host defense. While some pathogens can be eliminated by the immune system, some will develop ways to escape from host defense network to cause deadly diseases or cancers after infection. Thus, vaccination became an important strategy to prevent some diseases and cancers. 


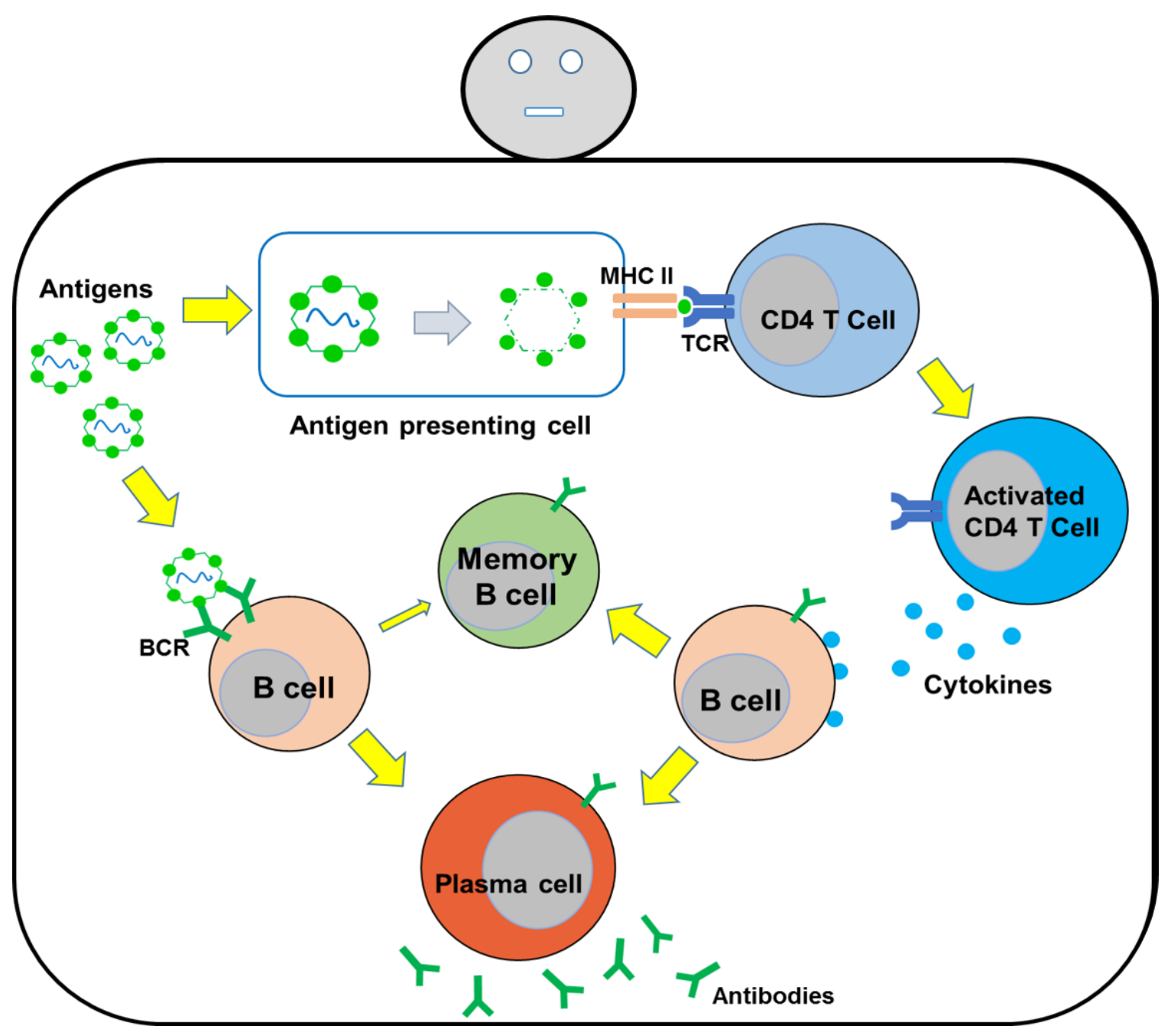

Fig. 1. Generation and secretion of antibodies through $T$ cell and $B$ cell activation. Antigen invasion (green) can trigger phagocytosis whereby antigens are phagocytosed and digested by antigen presenting cells (APCs). APCs then display the processed antigens on surface together with MHC II molecules. Antigens on MHC II are presented to receptors on CD4 T cells causing CD4 T cells activation. The activated CD4 T cells release cytokines to further activate naïve B cells as well as the CD4 T cells. Activated B cells differentiate into antibody secreting plasma cells (release antibodies against the antigen) and 
memory B cells (for a rapid and effective response against reinfection with the same antigen). In addition to this pathway, the antigens also can directly bind to B cells by cross-linking with B cell receptors, leading to B cell activation. The activated B cells differentiate into plasma cells. This type of B cell activation is associated with little or no memory to the response.

Vaccination is defined as the administration of an antigen to the body to enable the body to develop an immune response with the ultimate goal of to preventing the body from being infected by the infectious agent from which the antigen was derived. In other words, a vaccine is an imitation of real pathogen (organism) or they are antigens derived from a pathogen but without the potential to infect or cause a disease. They organism can be live but attenuated, it can be inactivated; alternatively, the vaccine can be an antigen, which is a subunit or part of a real pathogen or it could be a toxoid (non-toxic form of a toxin) derived from pathogens; either of them can activate the host adaptive immune response to offer protection against the real pathogen invasion [5, 6]. Adjuvants are often used as part of a vaccine to enhance activation of the innate immune system and thus protection. Diverse classes of compounds can be used as adjuvants including aluminum salts, emulsions, saponins, liposomes and micro-particles [7]. Adjuvants can enhance the immune responses through diverse mechanisms such as formation of a depot at the injection site for slow and constant stimulation, up-regulation of cytokines \& chemokines for recruitment of innate 
immune cells, increase in antigen presentation to APCs, and activation and maturation of APCs [8]. Safety and high immunogenicity are considered as two important factors for developing a new vaccine. For example, attenuated vaccines are highly immunogenic because the viruses are still alive and usually one or two doses can achieve long-lasting protection; however, for people who have weakened immune system or transplanted organs, live viruses might cause diseases in vaccinees. The inactivated vaccines are safe for patients but need more boosts to achieve and maintain a high level immunogenicity. Among all these types of vaccines, multi-protein structured vaccines, based on virus-like particles (VLPs) seem to be attracting a lot of attention as an approach in developing next-generation preventive vaccines against infections agents [9].

VLPs are empty viral shells without viral genome formed by viral structural proteins such as envelope proteins or capsid proteins. These structural proteins can spontaneously assemble to form VLPs without the viral genomes; VLPs therefore cannot replicate, they are non-infectious, and thus, they are safe for vaccine designs. They are highly immunogenic; the sizes and the icosahedral structures make them easy for APCs to recognize and take them up for processing and antigen presentation to CD4 T cells. Also, repetitive copies of antigens displayed on VLPs enable them to trigger strong immune responses especially the cross-linking of B cell receptors on the surface of B cells. VLPS have been used to develop vaccines against human papillomaviruses (HPVs) $[10,11]$ and hepatitis B virus (HBV) [12]. VLPs derived from HPV are highly 
immunogenic and protect against HPV-associated cancers (described in detail below).

\section{HPV, HPV vaccines, and limitations:}

HPVs are non-enveloped DNA viruses, which infect human stratified epithelial cells. More than $200 \mathrm{HPV}$ types have been identified and among them, 42 types are transmitted sexually $[13,14]$. HPVs are the most common sexually transmitted infections [15]. Ninety percent of HPV infections are cleared within 24 months after infection [16]. However, persistent infection with mucosal types can lead to neoplasias [17]. HPV can be divided into two groups based on their association with neoplasias: low-risk types and high-risk types. Infections with the low-risk types (such as types $6,11,40,42,43,44,54,61,72,81$ ) are associated with genital warts as well as recurrent respiratory papillomatosis (RRP). HPV types 6 and 11 alone are associated with about $90 \%$ of genital warts and about 95\% of RRP [18-21]. On the other hand, infections with the high-risk types (such as $16,18,26,31,33,35,39,45,51,52,53,56,58,59,66,68,70,73,82)$ are associated with cancers such as cervical [18, 22], penile [23, 24], vulvar, anal, and vaginal [25-27] cancers as well as head and neck squamous cell carcinomas (including oral, oropharyngeal, and laryngeal cancers) [28].

Currently, two prophylactic vaccines, Cervarix (bivalent HPV), and Gardasil-9 (nonavalent HPV), have been approved by the Food and Drug Administration (FDA) in the United States to protect against HPV infections [29]. These vaccines 
are composed of virus-like particles (VLPs) derived from the major capsid protein (L1) of HPV. The HPV vaccines are highly immunogenic. For example, as shown in Figure 2, the Gardasil 9 protects against $\sim 90 \%$, worldwide average, of cervical cancer cases caused by HPV16, 18, 31, 33, 45, 52, 58 and it also protects against $\sim 90 \%$ of genital warts cases caused by HPV6 and 11 [30]. Gardasil-9 is also expected to protect against $\sim 80-85 \%$ cases of HPV-associated vaginal cancers, $90-95 \%$ of HPV-associated anal cancers, $85-90 \%$ of HPV-associated vulvar cancers [30], and $\sim 86 \%$ of penile cancers [24]. However, the current vaccines still have some limitations.

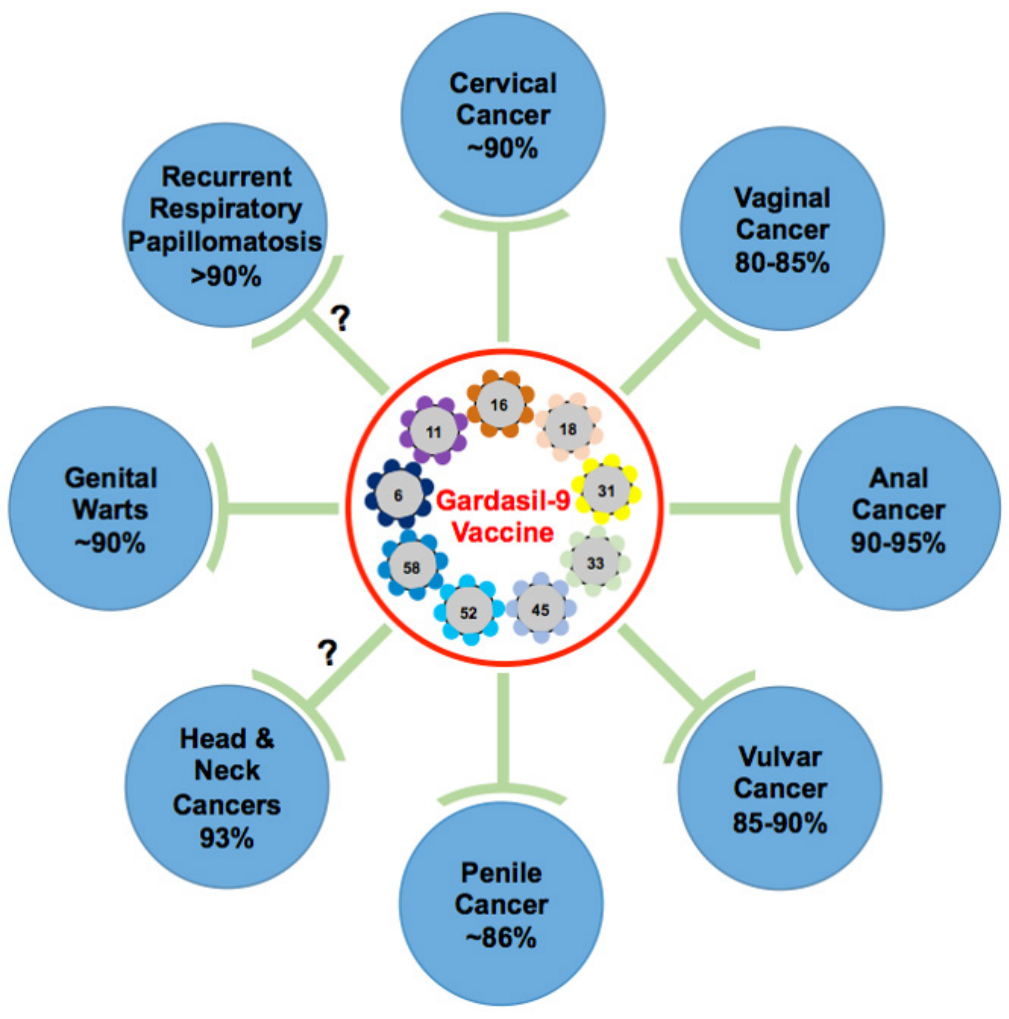

Fig. 2. Worldwide estimated percentages of HPV-associated cancers, HPVassociated warts, and papillomatosis to be protected by Gardasil-9. 
Estimates are based on the prevalence and the sum of percent contributions of vaccine HPV types to different HPV-associated (cervical, vaginal, anal, vulvar, penile, head and neck) cancers, genital warts including recurrent respiratory papillomatosis. For example, $90 \%$ protection against cervical cancer is based on the fact that HPV16 is associated with ( 55.4\%), HPV18 (16.1\%), HPV45 (4.7\%), HPV31 (3.8\%), HPV33 (4.1\%), HPV52 (2.8\%), and HPV58 (3.0\%) of cervical cancer cases worldwide.

First, they offer protection mostly against HPV types included in the vaccines but with less or no protections against non-vaccine HPVs. This is because they are derived from L1 proteins, which are not conserved among HPV types; they protect mostly against the HPV types included in the vaccines with little crossprotection against non-vaccine HPV types (e.g. HPV31, 45, 58) [31-35]. People who are infected with HPV, especially HIV patients, are able to be infected with multiple HPV types: up to $10 \mathrm{HPVs}$ were found in one HIV-infected patient [36]. Thus, an optimal HPV vaccine should protect against more cancer-causing HPVs to decrease the risk of developing HPV-associated cancers. Secondly, since little is known about the ability of current vaccines to protect against oral HPV infections, it is important and necessary to go further to study the efficacy of the vaccine against diverse oral HPVs infections. Thirdly, the current vaccines are thermosensitive; thus, refrigeration and temperature monitoring facilities are required for the vaccines. Refrigeration equipment is not available worldwide 
especially in the developing countries and regions, where there are higher rates of HIV infections.
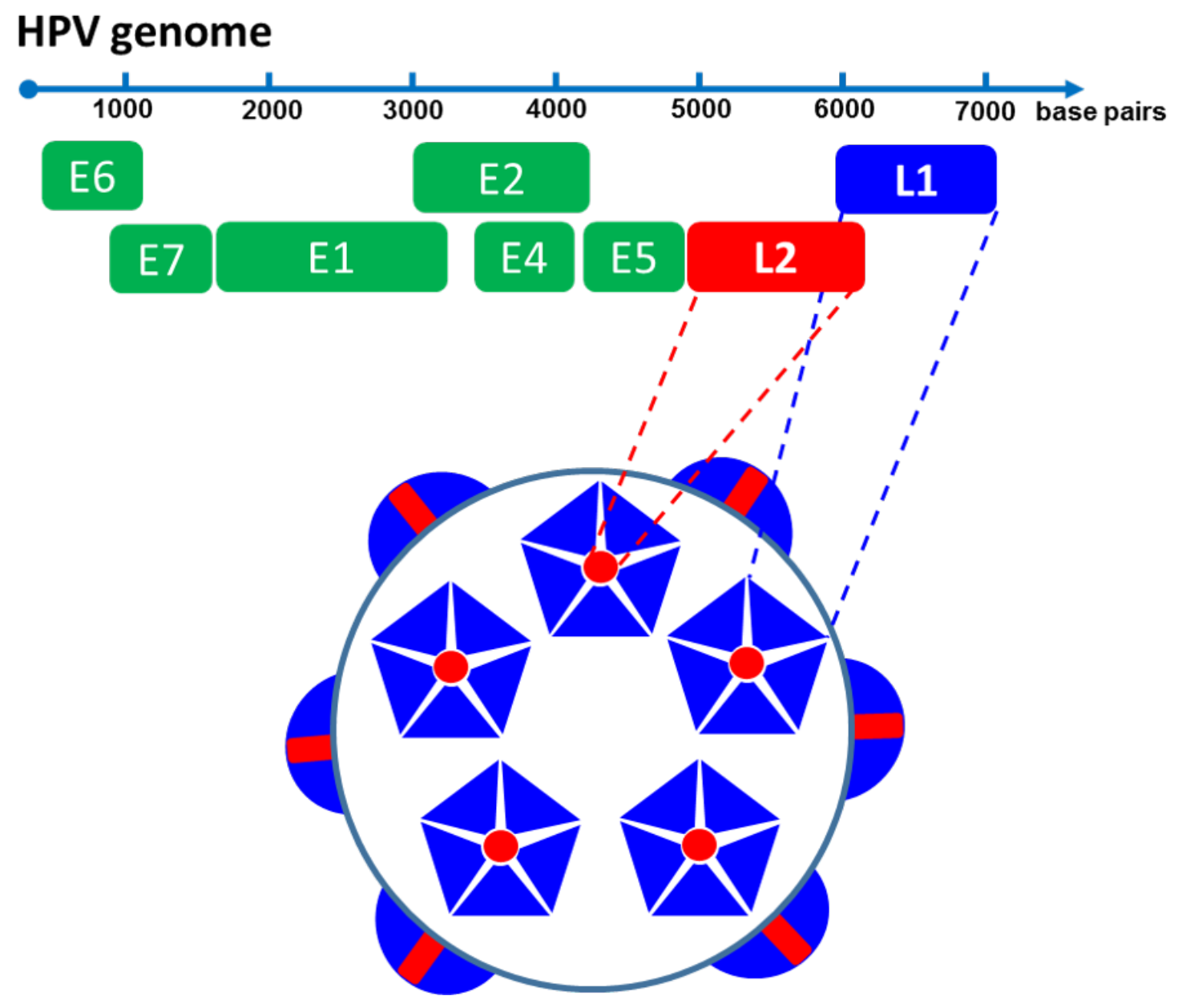

Fig. 3. HPV genome and capsid structure model. HPV genome is circular, but it is shown in the linear form (top image) for simplicity. Genes coding for early proteins (E1, E2, E4, E5, E6 and E7), which are non-structural proteins are shown in green. Genes coding for late proteins are L1 and L2; L1 (shown in blue) forms pentamers and each pentamer has one L2 (shown in red) at the vertex of 
each pentamer. The icosahedral capsid (bottom; surrounds the genome) is composed of major capsid protein (L1) and minor capsid protein (L2).

With this in consideration, other studies have been looking into designing a next generation HPV vaccine, targeting the minor capsid protein, L2, shown in Figure 3. The minor capsid protein, especially the $\mathrm{N}$-terminus, is highly conserved among diverse HPV types [37, 38]. Nevertheless, normal infection does not induce protective anti-L2 antibody responses because L2 is only transiently exposed on the capsid. During HPV infection, the capsid binds to heparan sulfate proteoglycan (HSPG) on the basement membrane; the capsid then undergoes a series of conformational changes thus transiently exposing the $\mathrm{N}$-terminal portion of L2 [39, 40]. This conformational change allows the virus to bind to and infect epithelial cells. If neutralizing antibodies, following immunization with L2 antigens are available, they can bind to exposed-neutralizing L2 epitopes thus preventing the infection [39, 40] (Fig. 4). Neutralizing L2 antibodies can cross-protect against diverse HPV types [41-43].The L2 protein, unlike the L1 protein, cannot form VLPs and thus, it is less immunogenic. Thus, different approaches have been explored to enhance the immunogenicity of L2 protein; these include conjugation of an L2 peptide to thioredoxin [44, 45], construction of L2 concatemer proteins derived from different HPV types [46, 47], and the display of L2 peptides on different types of VLPs [48-52]. While these approaches enhance crossprotection against diverse HPV types, they do not offer complete protection 
against all cancer-causing HPV types. VLPs derived from viruses that infect bacteria (bacteriophages e.g. MS2, PP7 and QB) have also been used as platforms to multivalently display less immunogenic peptides from other pathogens in order to increase the immunogenicity of the peptides $[49,53]$. In this dissertation, I focused on developing a candidate L2 vaccine against HPV based on a bacteriophage MS2 VLP platform. In addition to this, I explored the potential to develop a novel thermostable VLP platform based on a virus, ФIN93, which infects a thermophilic bacterium.

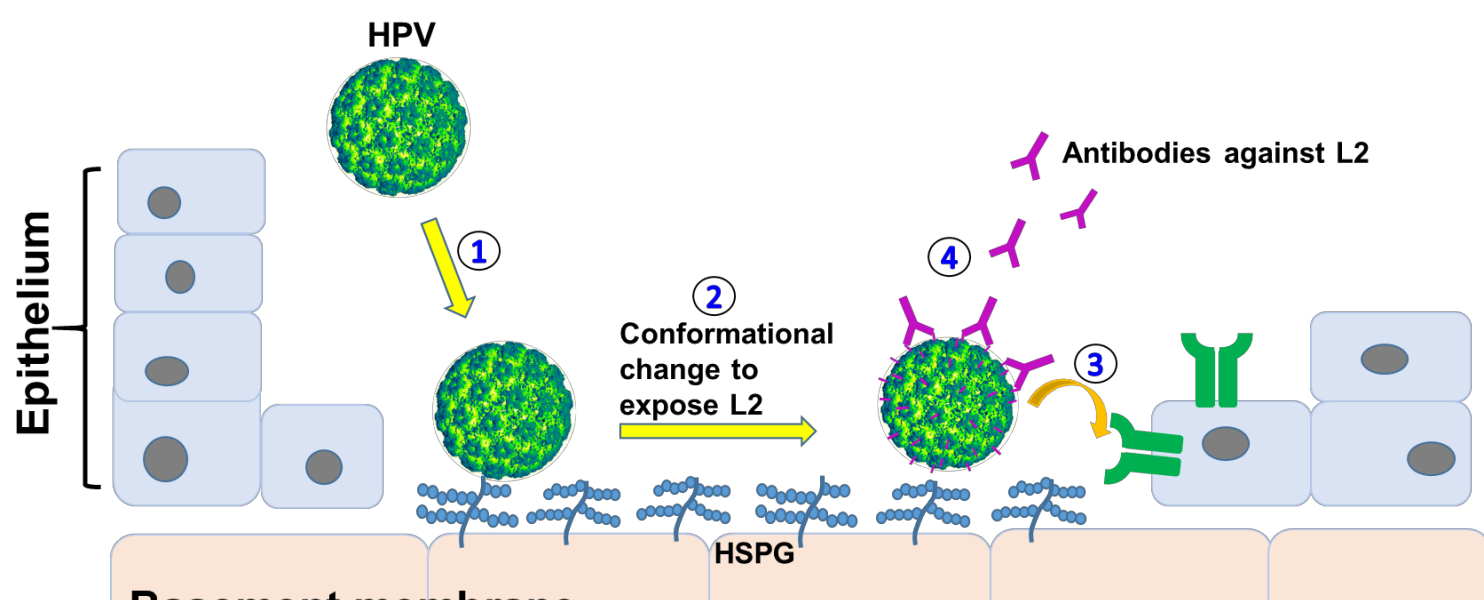

Basement membrane

Fig. 4. Schematic (adapted from [39]) illustrating HPV infection and how L2 antibodies targeting L2 protein prevents HPV infection. Micro-trauma or a cut allows HPVs to: 1) bind to heparan sulfate proteoglycan (HSPG) on basement membrane cells. 2) After conformational change, pre-buried L2 will be shortly exposed and cleaved for another conformational change, which allows the viruses to 3) recognize receptors (integrin proteins) on epithelial cells and 
infection of the cells are initiated. 4) In the presence of anti-L2 antibodies, binding to the receptor is blocked and infection is prevented. 


\section{Special aims}

The goals of my dissertation were to develop a candidate prophylactic HPV vaccine, which can protect against more high-risk HPVs infections (including protection from oral HPV infections) and to formulate the candidate vaccine into a thermostable product that can be transported and stored without the need to refrigerate the vaccine. In a previous study, an HPV16 L2 epitope containing amino acids (aa) 17-31 displayed on MS2 bacteriophage VLPs offered protection against up to $11 \mathrm{HPV}$ types (HPV5, 6, 16, 31, 33, 35, 39, 45, 51, 53, and 58) [49].

However, there was suboptimal protection against some of these HPVs including those associated with HNCs. To broaden and enhance protection, in this dissertation, we attempted to display more epitopes on the same VLPs already displaying HPV16 L2 epitopes. Additionally, we assessed oral immunity/protection following oral immunization with our L2 phage VLPs together with a combination of different mucosal adjuvants. Furthermore, we used sprayfreeze drying technique to convert the liquid VLPs into a thermostable dry powder vaccine. We also assessed whether coat proteins from a thermophilic phage ФIN93 can assemble into VLPs. Our hypotheses are: i) immunization with multi-epitope L2 VLPs can offer broader protection against more HPV types; ii) a spray-freeze dried VLPs powder vaccine will be more stable for storage at room temperature; iii) coat proteins of $\Phi \mathrm{IN} 93$, expressed in $E$. coli, can assemble into VLPs. 
Aim 1) Develop and test a candidate vaccine with multiple epitopes displayed on MS2 bacteriophage VLPs. Sequences of all high-risk HPVs and some wartcausing low-risk HPVs were aligned and two consensus epitopes that have the potential to broaden protection against diverse HPVs were chosen and used to design a candidate HPV vaccine (Chapter 1).

Aim 2) Assess the ability to enhance oral immune response using a combination of mucosal adjuvants. Mucosal adjuvants such as cholera toxin (CT) and monophosphoryl lipid A (MPLA) are able to stimulate signaling pathways associated with immune responses and thus they may enhance oral immune responses (Chapter 2)

Aim 3) Use the spray-freeze drying technique to formulate L2 vaccine with/without mucosal adjuvants to a thermostable powder. This strategy can avoid the problems of vaccine refrigeration during transportation and storage in developing countries (last part of Chapter 2)

Aim 4) Develop a novel VLP platform based on thermophilic bacteriophage ФIN93 coat proteins (Chapter 3) 


\section{References}

1. Turvey, S.E. and D.H. Broide, Innate immunity. J Allergy Clin Immunol, 2010. 125(2 Suppl 2): p. S24-32.

2. Bonilla, F.A. and H.C. Oettgen, Adaptive immunity. J Allergy Clin Immunol, 2010. 125(2 Suppl 2): p. S33-40.

3. Hoffman, W., F.G. Lakkis, and G. Chalasani, B Cells, Antibodies, and More. Clin J Am Soc Nephrol, 2016. 11(1): p. 137-54.

4. Zhu, J. and W.E. Paul, CD4 T cells: fates, functions, and faults. Blood, 2008. 112(5): p. 1557-69.

5. Clem, A.S., Fundamentals of vaccine immunology. J Glob Infect Dis, 2011. 3(1): p. 73-8.

6. NIH, Vaccine Types. Available at: https://www.niaid.nih.gov/research/vaccinetypes. 2019.

7. Guy, B., The perfect mix: recent progress in adjuvant research. Nat Rev Microbiol, 2007. 5(7): p. 505-17.

8. Awate, S., L.A. Babiuk, and G. Mutwiri, Mechanisms of action of adjuvants. Front Immunol, 2013. 4: p. 114.

9. Roldao, A., et al., Virus-like particles in vaccine development. Expert Rev Vaccines, 2010. 9(10): p. 1149-76.

10. FDA, F.D.A approved Products Gardasil 9. Available at: https://www.fda.gov/BiologicsBloodVaccines/Vaccines/ApprovedProducts/ucm 42 6445.htm. 2018.

11. FDA, FDA approved products Cervarix. Available at: https://www.fda.gov/biologicsbloodvaccines/vaccines/approvedproducts/ucm 1869 57.htm. 2018.

12. FDA, Hepatitis B Vaccine (Recombinant). Available at:

https://www.fda.gov/BiologicsBloodVaccines/Vaccines/ApprovedProducts/ucm09 4041.htm Page Last Updated: 03/26/2018 2018.

13. Zhai, L. and E. Tumban, Gardasil-9: A global survey of projected efficacy. Antiviral Res, 2016. 130: p. 101-9. 
14. Karolinska, I., INTERNATIONAL HUMAN PAPILLOMAVIRUS (HPV) Reference Center. Avaiable at: http://www.nordicehealth.se/hpvcenter/reference clones/. 2018.

15. Schwarz, K., et al., Efficient homologous prime-boost strategies for T cell vaccination based on virus-like particles. Eur J Immunol, 2005. 35(3): p. 816-21.

16. WHO. Human papillomavirus (HPV) and cervical cancer fact sheet. 2015 [cited 2015 November, 18]; Available from: http://www.who.int/mediacentre/factsheets/fs380/en/.

17. Crow, J.M., HPV: The global burden. Nature, 2012. 488(7413): p. S2-3.

18. Munoz, N., et al., Epidemiologic classification of human papillomavirus types associated with cervical cancer. N Engl J Med, 2003. 348(6): p. 518-27.

19. Lindeberg, H. and L. Johansen, The presence of human papillomavirus (HPV) in solitary adult laryngeal papillomas demonstrated by in-situ DNA hybridization with sulphonated probes. Clin Otolaryngol Allied Sci, 1990. 15(4): p. 367-71.

20. Dickens, P., et al., Human papillomavirus 6, 11, and 16 in laryngeal papillomas. J Pathol, 1991. 165(3): p. 243-6.

21. Sanchez, G.I., et al., Human papillomavirus genotype detection in recurrent respiratory papillomatosis (RRP) in Colombia. Head Neck, 2013. 35(2): p. 22934.

22. Matsukura, T. and M. Sugase, Relationships between 80 human papillomavirus genotypes and different grades of cervical intraepithelial neoplasia: association and causality. Virology, 2001. 283(1): p. 139-47.

23. de Sousa, I.D., et al., Prevalence of human papillomavirus in penile malignant tumors: viral genotyping and clinical aspects. BMC Urol, 2015. 15: p. 13.

24. Miralles-Guri, C., et al., Human papillomavirus prevalence and type distribution in penile carcinoma. J Clin Pathol, 2009. 62(10): p. 870-8.

25. Serrano, B., et al., Human papillomavirus genotype attribution for HPVs 6, 11, 16, 18, 31, 33, 45, 52 and 58 in female anogenital lesions. Eur J Cancer, 2015.

26. de Sanjose, S., et al., Worldwide human papillomavirus genotype attribution in over 2000 cases of intraepithelial and invasive lesions of the vulva. Eur J Cancer, 2013. 49(16): p. 3450-61.

27. Hoots, B.E., et al., Human papillomavirus type distribution in anal cancer and anal intraepithelial lesions. Int J Cancer, 2009. 124(10): p. 2375-83. 
28. Kreimer, A.R., et al., Human papillomavirus types in head and neck squamous cell carcinomas worldwide: a systematic review. Cancer Epidemiol Biomarkers Prev, 2005. 14(2): p. 467-75.

29. Tumban, E., et al., Preclinical refinements of a broadly protective VLP-based $H P V$ vaccine targeting the minor capsid protein, L2. Vaccine, 2015. 33(29): p. 3346-53.

30. Merck. FDA Approves Merck's HPV Vaccine, GARDASIL ${ }^{\circledR 9}$, to Prevent Cancers and Other Diseases Caused by nine HPV types. 2015 [cited 2015 August, 28]; Available from: http://www.mercknewsroom.com/news-release/prescriptionmedicine-news/fda-approves-mercks-hpv-vaccine-gardasil9-prevent-cancers-an.

31. Brown, D.R., et al., The impact of quadrivalent human papillomavirus (HPV; types 6, 11, 16, and 18) L1 virus-like particle vaccine on infection and disease due to oncogenic nonvaccine HPV types in generally HPV-naive women aged 1626 years. J Infect Dis, 2009. 199(7): p. 926-35.

32. Smith, J.F., et al., Antibodies from women immunized with Gardasil crossneutralize HPV 45 pseudovirions. Hum Vaccin, 2007. 3(4): p. 109-15.

33. Wheeler, C.M., et al., The impact of quadrivalent human papillomavirus (HPV; types 6, 11, 16, and 18) L1 virus-like particle vaccine on infection and disease due to oncogenic nonvaccine HPV types in sexually active women aged 16-26 years. J Infect Dis, 2009. 199(7): p. 936-44.

34. Joura, E.A., et al., A 9-valent HPV vaccine against infection and intraepithelial neoplasia in women. N Engl J Med, 2015. 372(8): p. 711-23.

35. Toft, L., et al., Comparison of the immunogenicity of Cervarix(R) and Gardasil(R) human papillomavirus vaccines for oncogenic non-vaccine serotypes $H P V-31, H P V-33$, and HPV-45 in HIV-infected adults. Hum Vaccin Immunother, 2014. 10(5): p. 1147-54.

36. Levi, J.E., et al., High prevalence of human papillomavirus (HPV) infections and high frequency of multiple HPV genotypes in human immunodeficiency virusinfected women in Brazil. J Clin Microbiol, 2002. 40(9): p. 3341-5.

37. Gambhira, R., et al., A protective and broadly cross-neutralizing epitope of human papillomavirus L2. J Virol, 2007. 81(24): p. 13927-31.

38. Kondo, K., et al., Neutralization of HPV16, 18, 31, and 58 pseudovirions with antisera induced by immunizing rabbits with synthetic peptides representing segments of the HPV16 minor capsid protein L2 surface region. Virology, 2007. 358(2): p. 266-72. 
39. Kines, R.C., et al., The initial steps leading to papillomavirus infection occur on the basement membrane prior to cell surface binding. Proc Natl Acad Sci U S A, 2009. 106(48): p. 20458-63.

40. Selinka, H.C., et al., Inhibition of transfer to secondary receptors by heparan sulfate-binding drug or antibody induces noninfectious uptake of human papillomavirus. J Virol, 2007. 81(20): p. 10970-80.

41. Roden, R.B., et al., Minor capsid protein of human genital papillomaviruses contains subdominant, cross-neutralizing epitopes. Virology, 2000. 270(2): p. 254-7.

42. Alphs, H.H., et al., Protection against heterologous human papillomavirus challenge by a synthetic lipopeptide vaccine containing a broadly crossneutralizing epitope of L2. Proc Natl Acad Sci U S A, 2008. 105(15): p. 5850-5.

43. Pastrana, D.V., et al., Cross-neutralization of cutaneous and mucosal Papillomavirus types with anti-sera to the amino terminus of L2. Virology, 2005. 337(2): p. 365-72.

44. Rubio, I., et al., Potent anti-HPV immune responses induced by tandem repeats of the HPV16 L2 (20 -- 38) peptide displayed on bacterial thioredoxin. Vaccine, 2009. 27(13): p. 1949-56.

45. Seitz, H., et al., A three component mix of thioredoxin-L2 antigens elicits broadly neutralizing responses against oncogenic human papillomaviruses. Vaccine, 2014. 32(22): p. 2610-7.

46. Jagu, S., et al., Concatenated multitype L2 fusion proteins as candidate prophylactic pan-human papillomavirus vaccines. J Natl Cancer Inst, 2009. 101(11): p. 782-92.

47. Jagu, S., et al., Vaccination with multimeric L2 fusion protein and L1 VLP or capsomeres to broaden protection against HPV infection. Vaccine, 2010. 28(28): p. 4478-86.

48. Schellenbacher, C., R. Roden, and R. Kirnbauer, Chimeric L1-L2 Virus-Like Particles as Potential Broad-Spectrum Human Papillomavirus Vaccines. Journal of Virology, 2009. 83(19): p. 10085-10095.

49. Tumban, E., et al., VLPs displaying a single L2 epitope induce broadly crossneutralizing antibodies against human papillomavirus. PLoS One, 2012. 7(11): p. e49751.

50. Nieto, K., et al., Development of AAVLP(HPV16/31L2) particles as broadly protective HPV vaccine candidate. PLoS One, 2012. 7(6): p. e39741. 
51. Tyler, M., et al., Immunization with a consensus epitope from human papillomavirus $L 2$ induces antibodies that are broadly neutralizing. Vaccine, 2014. 32(34): p. 4267-74.

52. McGrath, M., et al., Development of human papillomavirus chimaeric L1/L2 candidate vaccines. Arch Virol, 2013. 158(10): p. 2079-88.

53. Tumban, E., et al., A pan-HPV vaccine based on bacteriophage PP7 VLPs displaying broadly cross-neutralizing epitopes from the HPV minor capsid protein, L2. PLoS One, 2011. 6(8): p. e23310. 


\section{Chapter 1}

\section{A Novel Candidate MS2 Phage VLP Vaccine Displaying a tandem HPV L2 Peptide offers Similar Protection in Mice to Gardasil-9}

\subsection{Abstract}

Human papillomaviruses (HPVs) cause approximately $5 \%$ of cancer cases worldwide. Fortunately, three prophylactic vaccines have been approved to protect against HPV infections. Gardasil-9, the most recent HPV vaccine, is predicted to offer protection against the HPV types that cause $\sim 90 \%$ of cervical cancer, $86 \%$ of HPV-associated penile cancers, and $\sim 93 \%$ of HPV-associated head \& neck cancers. As an alternative to Gardasil-9, we developed and tested a novel candidate vaccine targeting conserved epitopes in the HPV minor capsid protein, L2. We displayed a tandem HPV31/16L2 peptide (amino acid 17-31) or consensus peptides from HPV L2 (amino acid $69-86$ or 108-122) on the surface of bacteriophage MS2 virus-like particles (VLPs). Mice immunized with the MS2 VLPs displaying the tandem peptide or immunized with a mixture of VLPs (displaying the tandem peptide and consensus peptide 69-86) elicited high titer antibodies against individual L2 epitopes. Moreover, vaccinated mice were protected from cervicovaginal infection with HPV pseudoviruses 16, 18, 31, 33, 45, and 58 at levels similar to mice immunized with Gardasil-9. These results 
suggest that immunization with a tandem, L2 peptide or a low valency mixture of L2 peptide-displaying VLPs can provide broad protection against multiple HPV types.

\subsection{Introduction}

Human papillomaviruses (HPVs) are the most common sexually transmitted infections; approximately 40 HPV types can be transmitted sexually and they cause neoplasias such as genital warts and cancers [1, 2]. Persistent infection with high-risk HPV (HR-HPV) types (HPV16, 18, 26, 31, 33, 35, 39, 45, 51, 52, $53,56,58,59,66,70,73,82$ ) is associated with $\sim 94 \%$ of anal cancers, $\sim 63 \%$ of penile cancers, $\sim 74 \%$ of vaginal cancers, $\sim 5-20 \%$ of head \& neck squamous cell carcinomas, and nearly all cases of cervical cancers [3-5]. Infections with low-risk HPV types (HPV6, 11, 43, and 44) are associated with genital warts [6-8]. HPVassociated cancers can be initiated by infection with a single HR-HPV type or by infection with multiple HR-HPV types [9, 10]; a situation that occurs especially in human immunodeficiency virus (HIV) and acquired immunodeficiency syndrome (AIDS) patients. HIVIAIDS patients are more susceptible to HPV-associated cancers compared to non-HIV infected patients $[9,11-15]$. Thus, these patients need broad protection from infections by multiple HPV types. 
Two prophylactic vaccines (Cervarix, and Gardasil-9) have been approved to protect against certain types of HPV infections. The vaccines are composed of virus-like particles (VLPs) derived from HPV major capsid protein (L1). The vaccines are highly immunogenic. However, because L1 neutralizing epitopes are not highly conserved among HPV types, L1 vaccines protect mostly against the HPV types included in the vaccines, with minimal cross-protection against non-vaccine HPV types [16-20]. For example, Gardasil-9 offers protection against the HR-HPV types (HPV16, $18,31,33,45,52,58$ ) that cause $\sim 93 \%$ of head and neck cancers, $\sim 90 \%$ of cervical cancers, $90-95 \%$ of anal cancers and more than $80 \%$ of vaginal, penile and vulvar cancers. The vaccine also protects against HPV6 and 11, types that cause $90 \%$ of genital warts. [4]. As such, women who are vaccinated with Gardasil-9 vaccine (and also the other HPV vaccines) are still advised to continue screening for other HPV types not included in the vaccine. To broaden protection, researchers have focused on developing next-generation HPV vaccines targeting the HPV minor capsid protein (L2) [2123]. The minor capsid protein, especially the $\mathrm{N}$-terminus, is highly conserved among diverse HPV types [24, 25]. Nevertheless, normal infection does not induce protective anti-L2 antibody responses because L2 is only transiently exposed on the capsid. During HPV infection, the capsid binds to heparan sulfate proteoglycan (HSPG) on the basement membrane; the capsid then undergoes a series of conformational changes thus transiently exposing the $\mathrm{N}$-terminal portion of $L 2[26,27]$. This conformational change allows the virus to bind to and infect epithelial cells. If neutralizing antibodies, following immunization with L2 antigens 
are available, they can bind to exposed-neutralizing L2 epitopes thus preventing the infection [26, 27]. Neutralizing L2 antibodies can cross-protect against diverse HPV types [28-30]. However, L2-based immunogens generally elicit much lower antibody titers than L1 VLPs because, unlike L1, L2 cannot selfassemble into VLPs. Different approaches have been explored to enhance the immunogenicity of L2 protein; these include conjugation of an L2 peptide to thioredoxin [21, 31], construction of L2 concatemer proteins derived from different HPV types [22, 32], and the display of L2 peptides on different types of VLPs [33-37]. While these approaches enhance cross-protection against diverse HPV types, they do not offer complete protection against all cancer-causing HPV types. In a previous study, we displayed a conserved epitope (representing amino acid 17-31) from HPV16 L2, on the surface of bacteriophage MS2 VLPs. MS2-16L2 VLPs elicited strong antibody response in mice and offered complete protection against HPV16 pseudovirus (PsV) 16 as well as sub-optimal crossprotection against other HPV PsV types [34]. In another study, we showed that immunization with bacteriophage VLPs displaying a consensus L2 epitope (representing amino acid 65-85 derived from an alignment of different HR-HPV types), enhanced cross-neutralization, albeit at low titers, against diverse HPV PsV types (PsV 16, 31, 18, 45 and 58) compared to immunization with VLPs displaying a similar epitope derived from HPV16 [36]. These results suggested that the immunogenicity as well as the spectrum of protection against diverse HPV types could be enhanced by displaying conserved or consensus L2 epitopes on the surface of bacteriophage VLPs. In this study, we assessed the 
spectrum of protection against diverse HPV types following immunization with a mixture of two MS2-L2 VLPs in comparison to immunization with Gardasil-9.

\subsection{Materials and methods}

\subsubsection{Cloning, expression and purification of MS2-L2 VLPs}

Polymerase chain reaction (PCR) was used, as previously described [38], to insert different HPV L2 epitopes on the N-terminus of the single-chain dimer of MS2 bacteriophage coat protein. Plasmid pDSP62 (which expresses the singlechain dimer of MS2 coat protein) was used as a PCR template (Fig. 1).

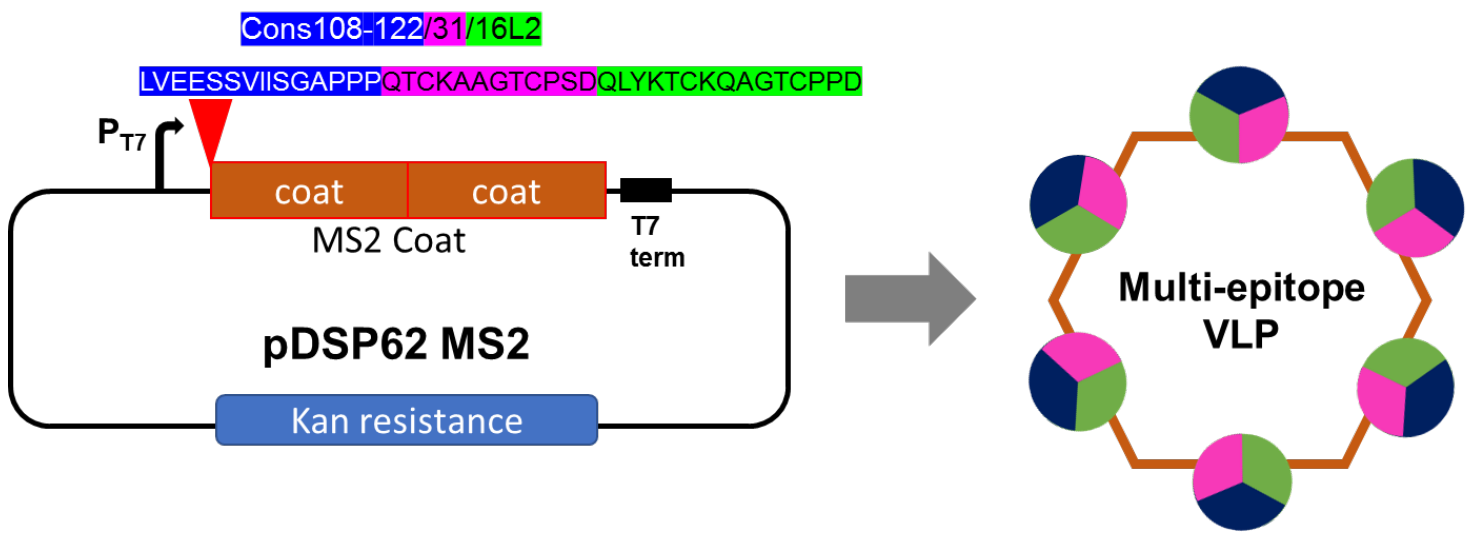

Fig. 1. Schema showing insertion of 16 L2 epitope at N-terminus of MS2 bacteriophage and assembly of VLPs. 
To get a consensus L2 sequence, amino acid sequences of all HR-HPVs and some low-risk ones (HPVs 6, 11, 34, 43 and 59) were analyzed and aligned by Jalview software and T-coffee program (Fig. 2). The following HPV L2 peptides (Table 1) representing amino acids (aa) sequences were inserted: a tandem peptide (aa 20-31 from HPV31 L2 \& aa 17-31 from HPV16 L2), aa 69-86 from a consensus (cons)L2 sequence, aa 108-122 from a consensus (cons)L2 sequence, and a multivalent epitope representing consL2(108-122)/HPV31L2 (20-31)/HPV16L2(17-31).

These L2 sequences were engineered into forward PCR primers. A reverse primer, E3.2 (5' CGGGCTTTGTTAGCAGCCGG 3'), which anneals downstream of a unique BamHI site in the pDSP62 plasmid was used for all PCR amplifications above. Amplified MS2-L2 PCR fragments were cloned into pDSP62 plasmid using $\mathrm{Ncol}$ and $\mathrm{BamHI}$ restriction sites and the plasmids were then transformed into C41 E. coli bacteria. All constructs were sequenced to confirm insertions. To express recombinant MS2-L2 proteins, transformed C41 cells were grown at $37^{\circ} \mathrm{C}$ until the cells reached an optical density (OD)600 of 0.6 . Protein expression was induced with $0.5 \mathrm{mM}$ isopropyl $\beta-\mathrm{D}-1$ thiogalactopyranoside for 4 hours or overnight. Cell pellets were collected and lysed using $0.2 \%$ lysozyme solution. Soluble MS2-L2 VLPs were purified by gel filtration on Sepharose CL-4B column. 
Table 1: HPV L2 epitopes inserted on MS2 VLPs

\begin{tabular}{|l|l|l|}
\hline Epitope Name & Epitope Sequence \\
\hline 16L2 (aa 17-31) & QLYKTCKQAGTCPPD \\
\hline $31 \mathrm{~L}$ (aa 17-31) & QLYQTCKAAGTCPSD \\
\hline 31L2 (aa 20-31)/16L2 (aa 17-31) & QTCKAAGTCPSDQLYKTCKQAGTCPPD \\
\hline Consensus L2(aa 69-86) & RTGYVPLGTRPPTVVDVT \\
\hline Consensus L2(aa 108-122) & LVEESSVIISGAPPP \\
\hline $\begin{array}{l}\text { Consensus L2(aa 108-122)I } \\
\text { 31L2 (aa 20-31)/16L2 (aa 17-31) }\end{array}$ & \begin{tabular}{l} 
LVEESSVIISGAPPPQTCKAAGTCPSDQL \\
\hline
\end{tabular} \\
\hline
\end{tabular}

\subsubsection{Characterization of MS2-L2 VLPs}

Transmission electron microscopy (TEM) was used to assess whether all constructs assembled into VLPs in a way as previously described [38]. To examine whether the L2 epitopes were displayed on the MS2 bacteriophage VLPs, enzyme-linked immunosorbent assay (ELISA) and Western blot were performed. Western blotting was conducted as follows: 100 ng of MS2-L2 VLPs or control MS2 VLPS were run on an SDS-PAGE gel and transferred to polyvinylidene fluoride membranes. The membranes were blocked and 1:5,000 dilution of anti-HPV16 L2 (aa 1-88) serum [34] or MS2 serum was added and incubated for 2 hours. The membranes were washed and 1:10,000 dilution of 
horseradish peroxide (HRP)-conjugated goat anti-mouse IgG antibodies added for 1 hour. The membranes were then washed and developed using a mixture of SuperSignal West Pico (Lumino/Enhance and Stable Peroxide) solutions. To confirm the Western blot results, ELISA was conducted as follows: Briefly, ELISA plates were coated with $500 \mathrm{ng}$ of purified MS2-L2 VLPs. The wells were blocked and serial dilutions of anti-HPV16 L2 (aa 1-88) serum was added. The plates were incubated for 2 hours and 1:5,000 dilution of HRP-conjugated goat antimouse IgG antibodies was added for 1 hour. The plates were developed by adding 3, 3', 5, 5'-tetramethylbenzidine (TMB) and the reactivity was determined at $\mathrm{OD}_{450 .}$

\subsubsection{Immunization of mice and characterization of antibody responses}

All animal work was conducted in accordance with Institutional Animal Care and Use Committee (IACUC) guidelines. Four Balb/c mice (per group) were immunized intramuscularly (i.m.) with $5 \mu$ g each of MS2-16L2 VLPs (displaying aa 17-31 from HPV16) [34], MS2-31L2 VLPs (displaying aa 17-31 from HPV31) [36], MS2-31/16L2 VLPs (displaying tandem L2 peptide 20-31 and 17-31 from HPV31 and HPV16, respectively), MS2-consL2(69-86), MS2-consL2(108-122), MS2consL2(108-122)/31L2/16L2, or immunized with a mixture of VLPs [Mixed MS2L2 VLPs: $5 \mu \mathrm{g}$ MS2-consL2(108-122)/31L2/16L2 plus 5 $\mathrm{g}$ of MS2-consL2(6986)]. All VLPs were mixed with alum hydroxide adjuvant prior to immunizations 
and immunizations were done twice at two-week intervals. Anti-L2 IgG antibody responses in sera were tested by L2 peptide-ELISA using synthetic HPV16L2 (17-31), HPV31L2 (17-31), consL2(69-86), and consL2(108-122) as target antigens. The peptides were conjugated to streptavidin using biotin or SMPH [Succinimidyl 6-((beta-maleimidopropionamido)hexanoate)] and were then used to coat ELISA plates. ELISAs were conducted as described above and the titers of antibodies were determined as the reciprocal of the highest sera dilution with an $\mathrm{OD}_{450}$ greater than 2-fold compared to that of control sera at the same dilution.

\subsubsection{Pseudovirus production and purification}

HPV PsV types (PsV: 16, 33, 45, 58) encapsidating a reporter plasmid [pClucf: encodes both green fluorescence protein (GFP) and luciferase] were produced in 293TT cells as previously described [39]. Briefly, 293TT cells were transfected with a mixture of two plasmids (each HPV shell and a pCluf). Forty-eight hours after transfection, cells were lysed and mature PsV was purified on a cesium chloride gradient by ultracentrifugation at $20,000 \mathrm{rpm}$ for 17 hours or $40,000 \mathrm{rpm}$ for 4 hours. 


\subsubsection{Cervicovaginal infection with HPV PsVs}

Mice were intramuscularly immunized twice each with $5 \mu \mathrm{g}$ of MS2 control VLPs, MS2 VLPs displaying L2 peptides or with Mixed MS2-L2 VLPs at two-week intervals. In addition to these, another group of mice was immunized with $5 \mu \mathrm{g}$ of Gardasil-9. All immunizations were done with alum hydroxide adjuvant. Two weeks after the last immunization, mice were subcutaneously treated with $3 \mathrm{mg}$ of Depo-Provera. After five days, mice were vaginally challenged with $\sim 6.4 \times 10^{6}$ infectious unit (IU) of PsV. Forty-eight hours post-PsV challenge, mice were vaginally instilled with $0.4 \mathrm{mg}$ of luciferin and imaged with a Caliper IVIS Lumina II as previously described [38].

\subsubsection{In vitro neutralization assays}

Neutralization assays were performed as previously described [40]. Briefly, HPV PsV18 and PsV33 encapsidating a reporter plasmid (pfwB: expresses GFP) were made in 293TT cells as above. HPV PsV18 and PsV33 were titered in pgsa-745 cells and virus titers that lead to $20 \%$ and $75 \%$ infectivity (expression of GFP relative to control cells), respectively, were used in the neutralization assay as followings: extracellular matrix (ECM) from MCF10A cells was deposited in 96-

well plates followed by the addition of the PsVs. The ECM-PsVs were incubated overnight followed by the addition of serial-dilutions of sera collected from 
immunized mice or addition of growth media as control. The plates were incubated for 6 hours and pgsa-745 cells were added. Forty-eight hours later, PsV infectivity/neutralizations were assessed by flow cytometry based on the expression levels of GFP in infected cells. The reciprocal of the highest sera dilution that inhibited $50 \%$ of PsV infection relative to control sera was considered the neutralization titer.

\subsubsection{Statistical analysis}

Statistical analyses for ELISA and PsV challenges were determined by unpaired two-tailed t-test and unpaired one-tailed t-test, respectively.

\subsection{Results}

\subsubsection{Insertion of multiple L2 epitopes on MS2 coat protein does not affect VLP assembly}

We had previously shown that immunization with MS2 bacteriophage VLPS displaying HPV16L2 (17-31) offered complete protection against HPV PsV16 but suboptimal cross-protection against other high-risk HPV PsV types. To enhance protection against these other HPV types, we explored several strategies. First, we constructed recombinant coat proteins displaying a tandem L2 peptide (aa 
20-31 from HPV31 and aa 17-31 HPV16) or consensus L2 sequences (representing aa 69-86 or aa 108-122) at the N-terminus of the MS2 coat protein. The consensus sequence was obtained by aligning amino acid sequences from 19 HR-HPV types plus 4 low-risk types using Jalview software (version 2.9.0b2) and T-coffee program (Fig. 2). In a second strategy, we inserted multiple epitopes [consL2(108-122) and the tandem 31L2/16L2 peptide] on the MS2 coat protein.

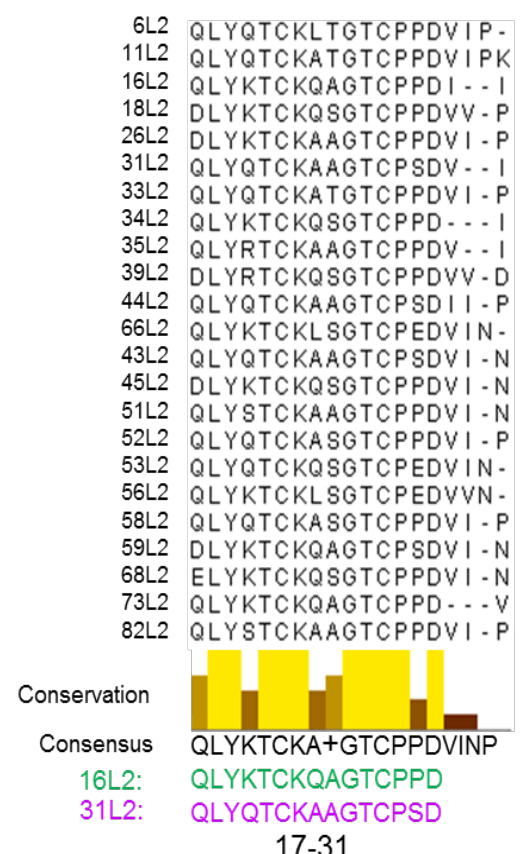

- TGGRTGYVPLGTSAKPSIT - SGP - - GGRAGYIPLGSSPKPAITGGPA G - TGGRTGYIPLGTRPPTAT - - DTL - - TGGRTGYIPLGGRSNTVVD - VGP - SGGRTGYIPLGGGGRPSVV - DIG G - TGGRTGYVPLSTRPSTVS - EAS - SGGRTGYVPIGTDPPTAAI - PLQ SGTGGRTGYVPLPTTTPS - - R - PVE G - TGGRSGYVPLGTTPPTA - A - TNI - TGGRTGYI PLGGRPNTVVD - VSP - - TGGRTGYIPLQSTPRPDIP - SVP - . SGGRAGYVPLGSRPSTIVD - VTP

- TGGRTGYVPLTTGRTGIVP - KVT - - SGGRTGYVPLGGRSNTVVD - VGP - SGGRTGYIPLGGGGRPGVV - DIA - - SGGRAGYVPLSTRPPTSSI - TTS

- - TGGRTGYIPLGTRPSTVVD - VTP - SGGRAGYVPLGSRPSTIVD - VTP - - TGGRTGYVPLGSTPPSEAI - PLQ - - TGGRTGYIPLGGRTNTIVD - VSP - TGGRTGYI PLGGKPNTVVD - VSP SGSGGRTGYVPLSTGTPS - - K - PVE - - TGGRTGYIPLGGGGRPGVV-DIA

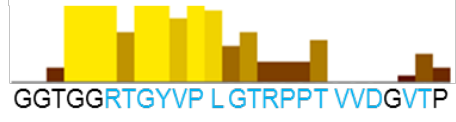
$69-86$

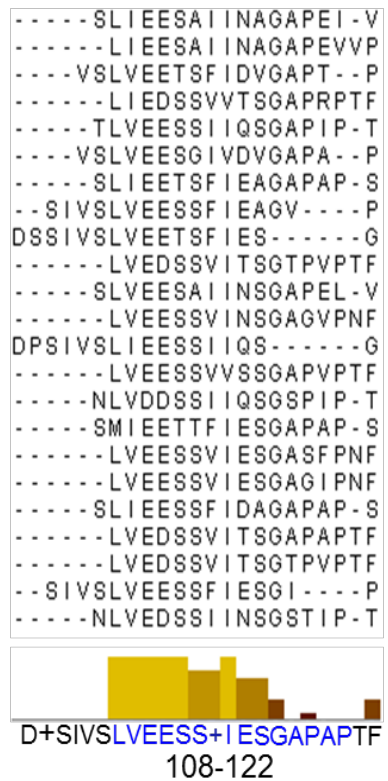

108-122

Fig. 2. Consensus sequence of HPVs L2 proteins. Consensus sequences were obtained by aligning HR-HPV types (HPVs 16, 18, 26, 31, 33, 34, 35, 39, 45, 51-53, 56, 58, 59, 66, 68, 73 and 82) and low-risk HPV types (HPVs 6, 11, 43, and 44) using Jalview software (http://www.jalview.org/) and T-coffee program (an plugin of Jalview software). Highly conserved amino acids 
(conservation) are shown in yellow/gold tall bars whereas less conserved amino acids are shown in tan/chocolate short bars. Glycine $(G)$ at position 85 was not included in designing consensus (69-86) peptide because only HPV 11 had G at this position. "+" at position 114 was replaced with valine (V) since most HPVs have $V$ at this site. Glutamic acid $(E)$ at 116 and Alanine $(A)$ at 121 were replaced with isoleucine $(\mathrm{I})$ and proline $(\mathrm{P})$, respectively.

The results of TEM analysis indicated that proteins produced from all these recombinant constructs assembled into VLPs (Fig. 3 and Table 1). 

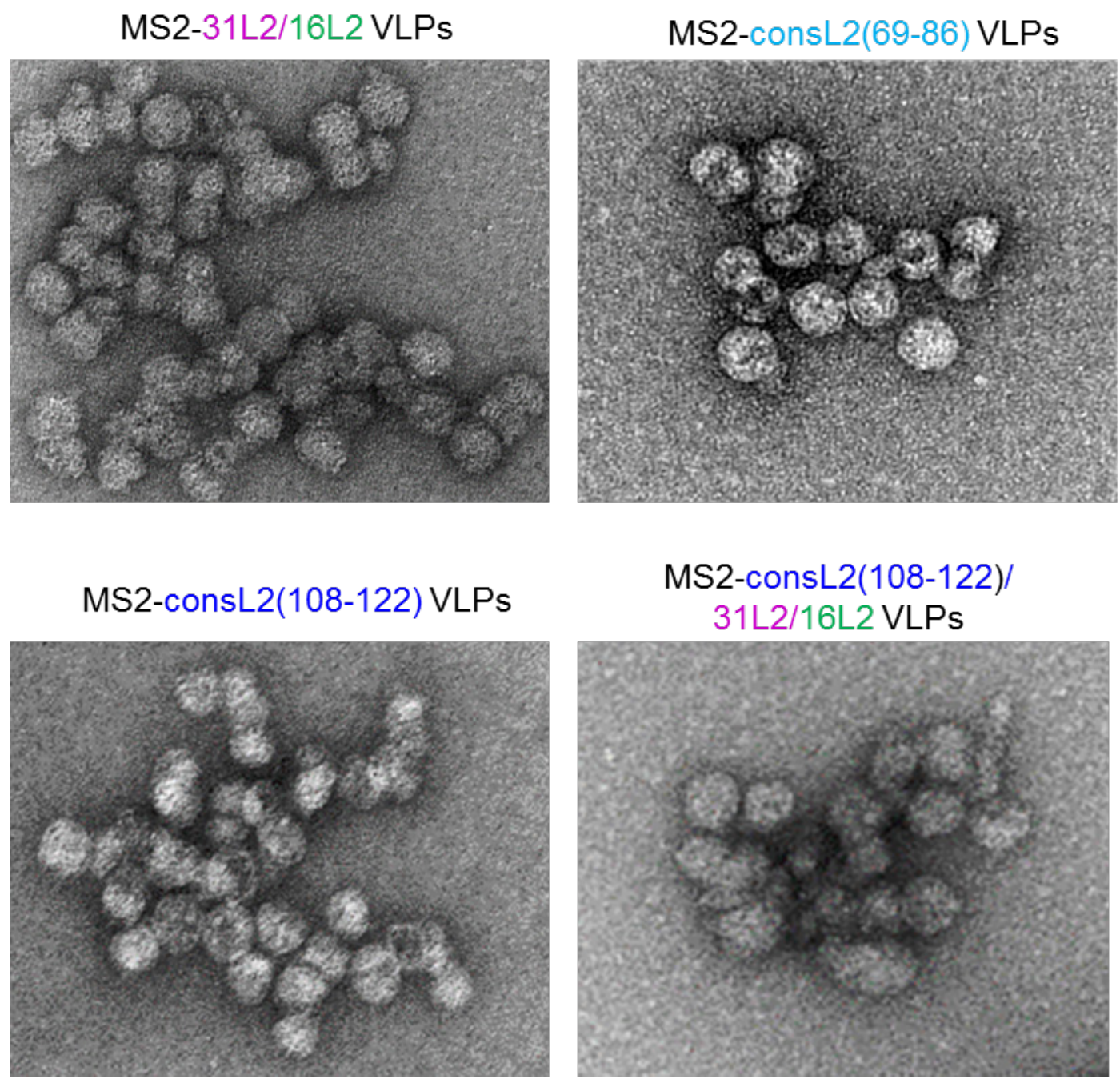

Fig. 3. Transmission electron microscopy (TEM) images of MS2-L2 VLPs that were assembled from recombinant proteins containing various L2 epitopes. All images were taken at magnification of $70,000 \mathrm{X}$.

To confirm that the coat proteins contained L2, VLPs were analyzed by Western blot using anti-MS2 and anti-HPV16 L2 (aa 1-88) serum. As shown in Fig. 4A, anti-HPV 16L2 serum reacted with all VLPs except with MS2-consL2(108-122) 
and control MS2 VLPs as expected. As expected, anti-MS2 serum reacted with each VLP. The varying sizes of recombinant MS2-L2 protein bands reflect the differences in the sizes of inserted L2 epitopes.

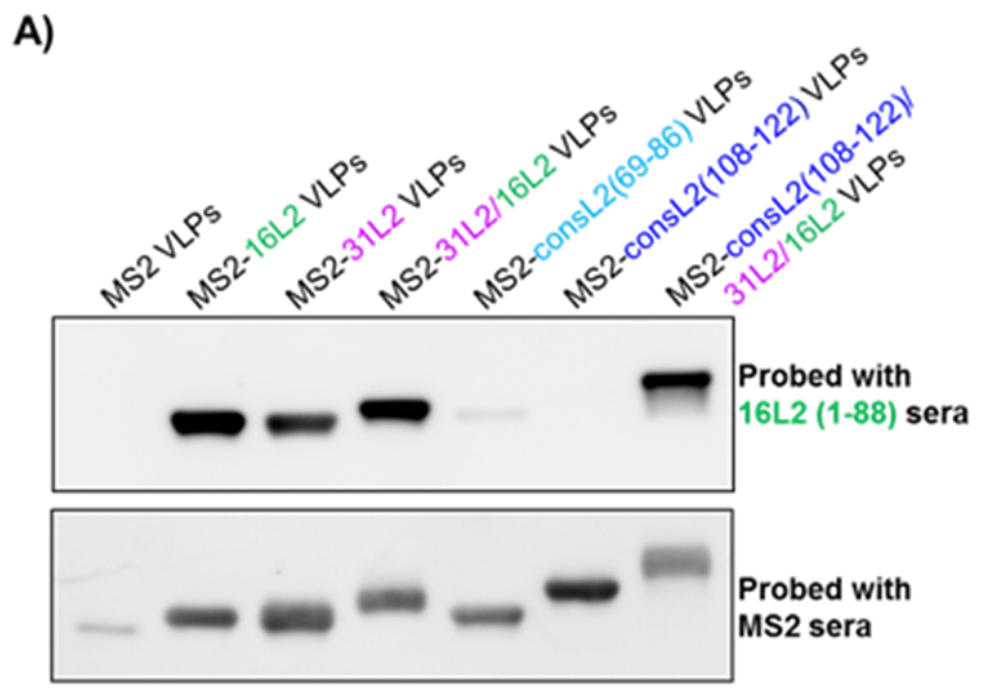

B)
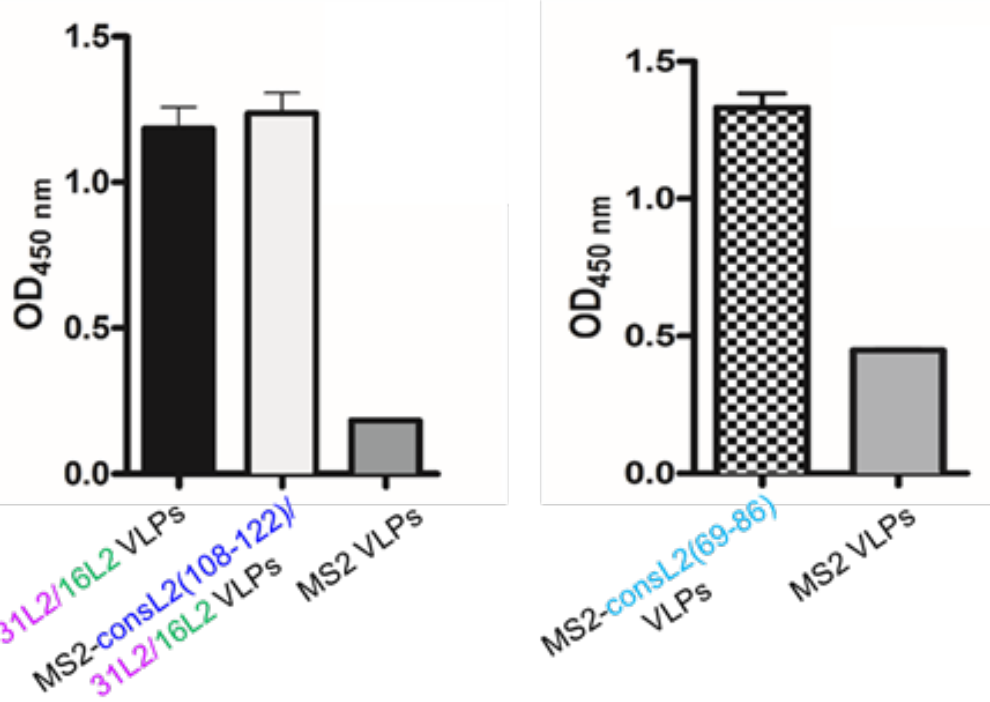

Fig. 4. Characterization of L2 peptides on MS2 VLP. A) Reactivity of HPV16 L2 (aa 1-88) serum and MS2 serum with MS2-L2 VLPs or MS2 VLPs in Western 
blots. One hundred ng of VLPs were loaded to 10\% SDS-PAGE gel and 16L2 (188) serum (top) and MS2 serum (bottom) were used as primary antibodies at a dilution of 1:5,000. B) Reactivity of HPV16 L2 (aa 1-88) serum with MS2-L2 VLPs or MS2 VLPs. ELISA plates were coated with $500 \mathrm{ng}$ of VLPs and reacted with the serum at a dilution of 1:10,240 (left) and 1:640 (right). The average ODs450 for 4 mice are shown. Error bars stand for standard error of the mean (SEM).

To assess if the L2 peptides were actually displayed on intact VLPs, an ELISA was conducted using MS2-L2 VLPs or control MS2 VLPs as target antigens. As shown in Fig. 4B, anti-HPV16 L2 serum (at a 1:10,240 dilution) reacted with MS2-31/16L2 VLPs and MS2-consL2(108-122)/31L2/16L2 VLPs, and, to a lesser extent (at a 1:640 dilution) with MS2-consL2(69-86) VLPs. These data suggest that the peptides are displayed on the surface of VLPS.

\subsubsection{MS2 VLPs displaying multiple L2 epitopes are immunogenic}

To assess the immunogenicity of MS2 VLPs displaying the L2 peptides, mice were immunized with two doses ( $5 \mu \mathrm{g} /$ dose) of purified MS2-L2 VLPs or control MS2 VLPs. Another group of mice was immunized twice with a mixture of VLPs [Mixed MS2-L2 VLPs; MS2-consL2(108-122)/31L2/16L2 plus MS2-consL2(6986)] in order to assess whether immunizing with multiple L2 VLPs could enhance 
the spectrum of protection. In general, all of the VLPs elicited high-titer antibody responses. Sera collected from mice immunized with MS2-16L2, MS2-31L2, MS2-31/16L2, and MS2-consL2(108-122)/31L2/16L2 VLPs had high antibody titers $\left(>10^{4}\right)$ against HPV16 and HPV31 L2 peptides (Figs. 5A-B). Moreover, mice immunized with MS2-consL2(69-86) VLPs had high IgG titers against consL2(69-86) peptide (Fig. 5C). In contrast, VLPs displaying the consL2(108122) peptide were less immunogenic and induced lower antibody titers $\left(<10^{3}\right)$ (Fig. 5D). Mice immunized with Mixed MS2-L2 VLPs had similar antibody titers $\left(>10^{4}\right)$ against HPV16 L2, HPV31 L2 and consL2(69-86) peptides as mice immunized with individual VLPs (Figs. 5A, B and C), suggesting that mixing the VLPs did not compromise the immunogenicity of individual L2 epitopes.

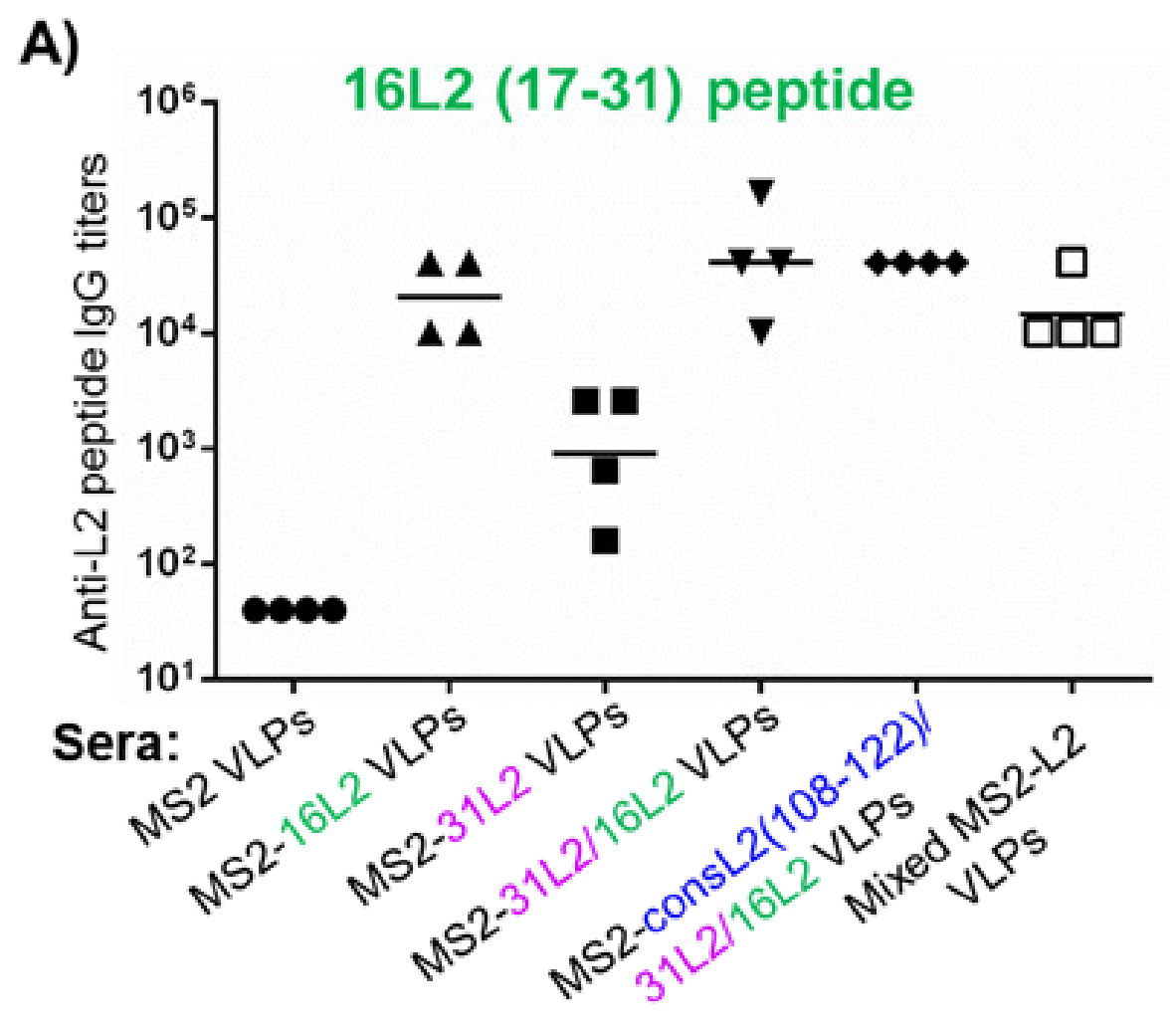


B)
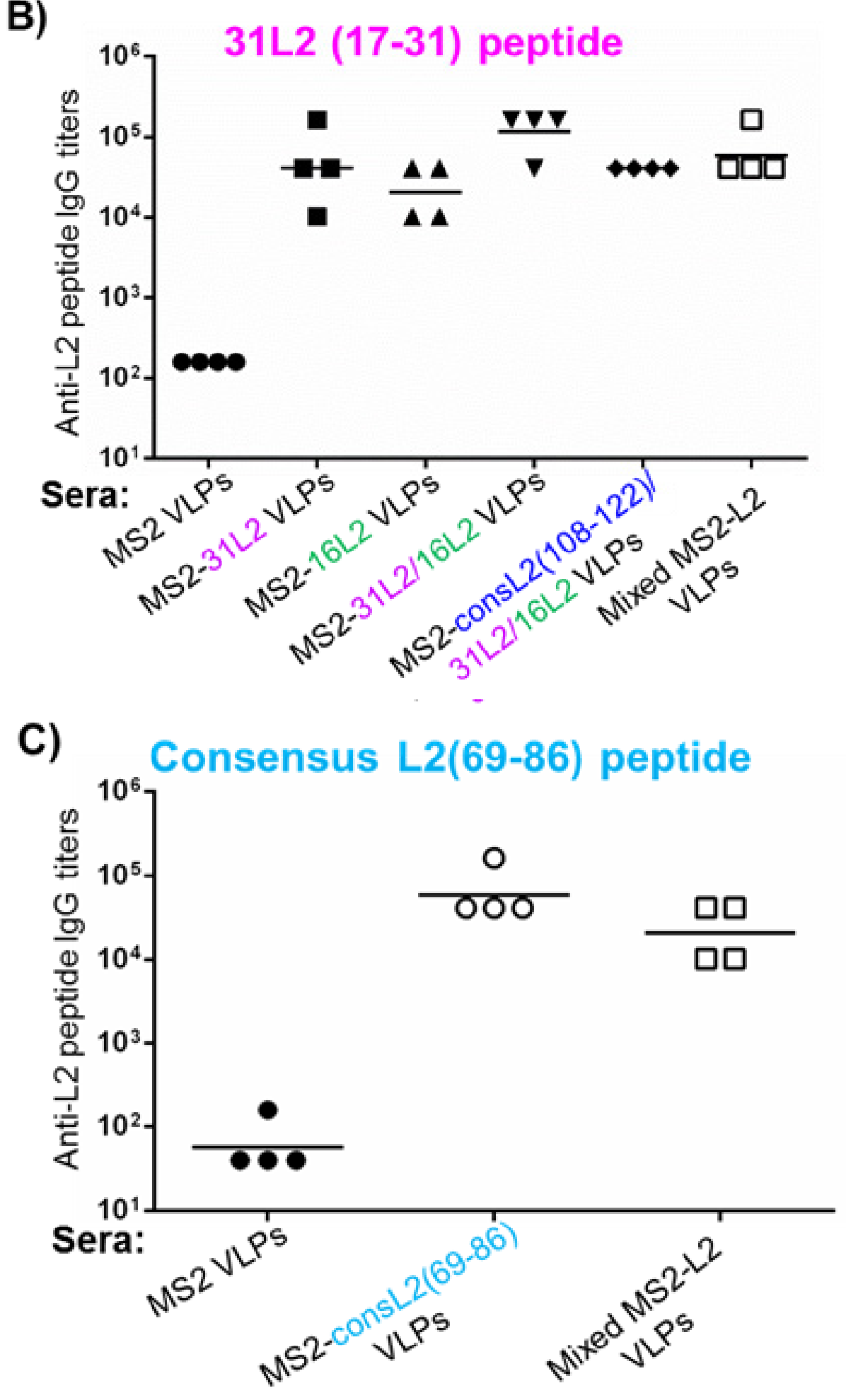


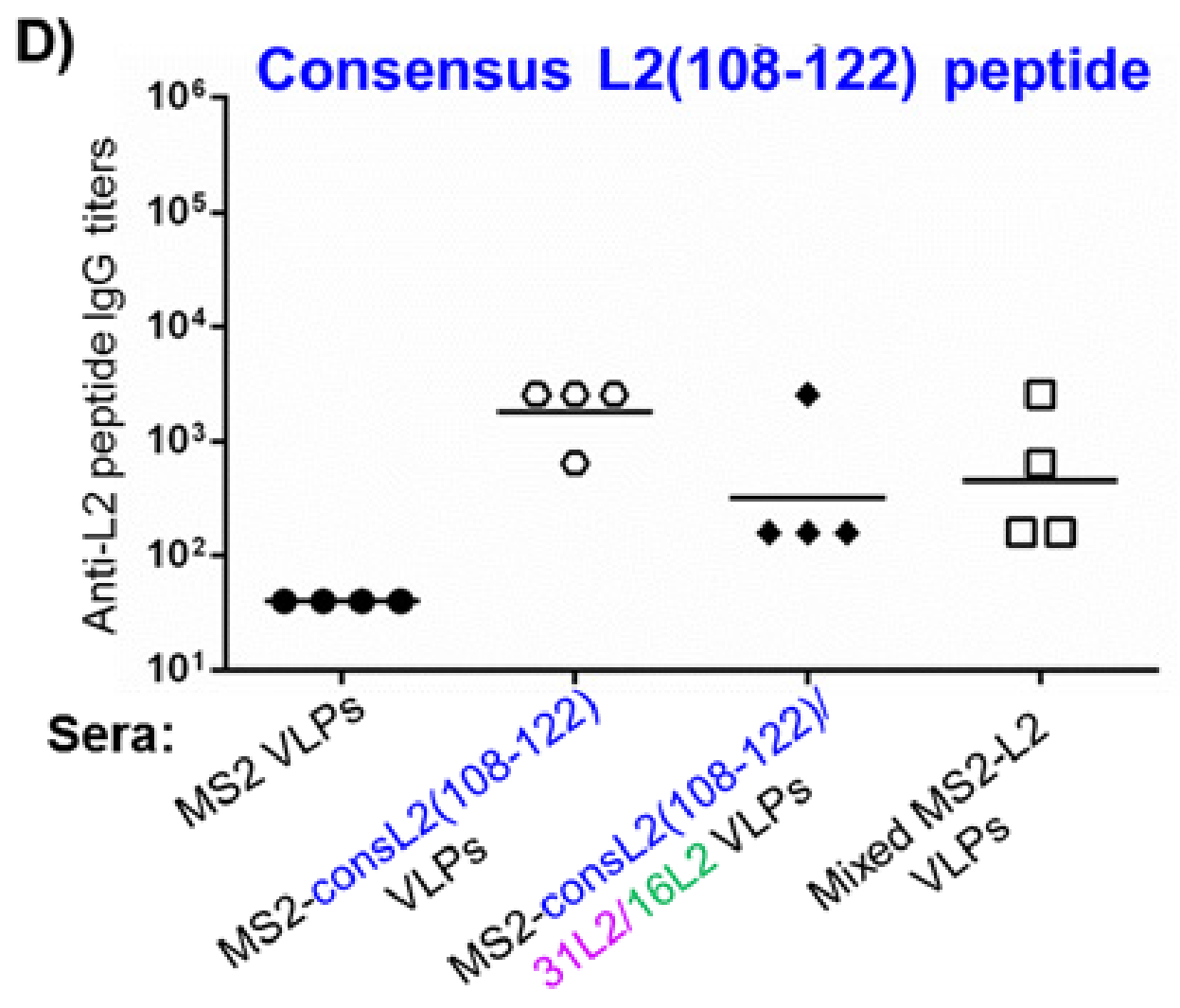

Fig. 5. Immunogenicity of MS2-L2 VLPs in mice. Mice were immunized twice with $5 \mu \mathrm{g}$ of MS2-L2 VLPs or control MS2 VLPs at two-week intervals. Sera were collected two weeks after the last immunization and anti-L2 peptide IgG titers were determined by end-point dilution ELISA using: A) 16L2 (17-31) peptide, B) 31L2 (17-31) peptide, C) consensus L2(108-122) peptide, and D) consensus L2(69-86) peptide as target peptides. Titers were determined as the reciprocal of highest sera dilutions at which reactivity of experimental sera was at least twice that of control MS2 sera. "Mixed MS2-L2 VLPs" serum was collected from mice immunized with a mixture of consL2(108-122)/31L2/16L2 and consL2(69-86) VLPs. Each datum (circles, squares, rectangles, and triangles, etc.) represents 
titer in an individual mouse and lines stand for the geometric mean for each group.

\subsubsection{MS2 VLPs displaying multiple L2 epitopes offered broad protection against HPV PsVs, at levels similar to Gardasil-9 vaccine}

To determine whether immunization with MS2-L2 VLPs conferred protection from genital infection with various HPV types, immunized mice were vaginally infected with $\operatorname{HPV} \operatorname{PsV}(16,31,45$, and 58) and protection efficacies were compared to those of mice immunized with Gardasil-9 or control MS2 VLPs. We assessed cross-protection against HPV PsV31 and 58 because in a previous study [34] we observed suboptimal cross-protection against these PsVs following immunization with MS2-16L2 VLPs. Mice immunized with MS2-16L2, MS2-31L2, MS231/16L2, MS2-consL2(108-122)/31L2/16L2, and Mixed MS2-L2 VLPs showed protection against HPV PsV31, at levels similar to Gardasil-9 (which contains HPV31 VLPs) vaccine-immunized mice (Fig. 6A); Moreover, almost complete protection were observed against PsV58, PsV45, and PsV16 challenge (Figs. 6B-6D). Mice immunized with MS2-consL2(69-86) VLPs showed only slight protection (not significant) against the HPV PsV types tested, and MS2consL2(108-122) was not protective. Mixed MS2-L2 VLPs offered the best protection against all PsV types except against PsV58. 
A)

Mice infected with HPV PsV31

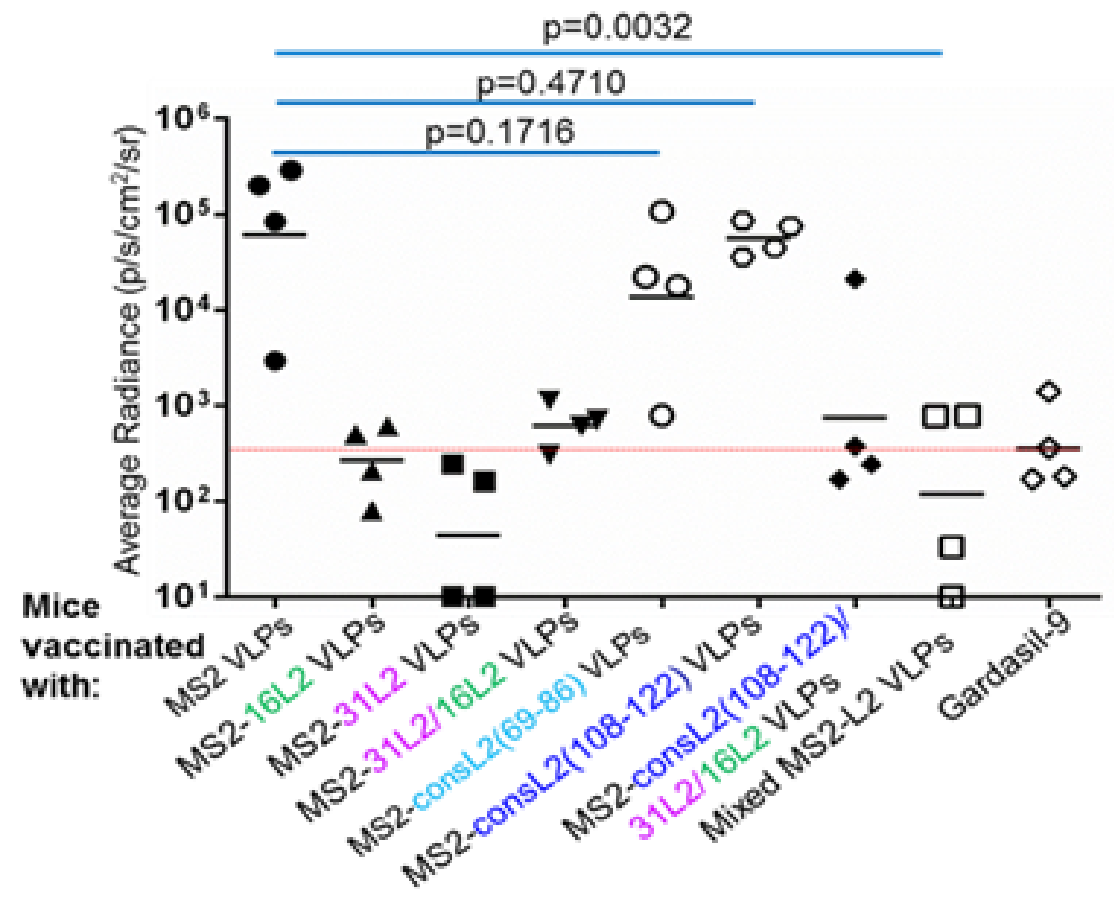

B)

Mice infected with HPV PsV58

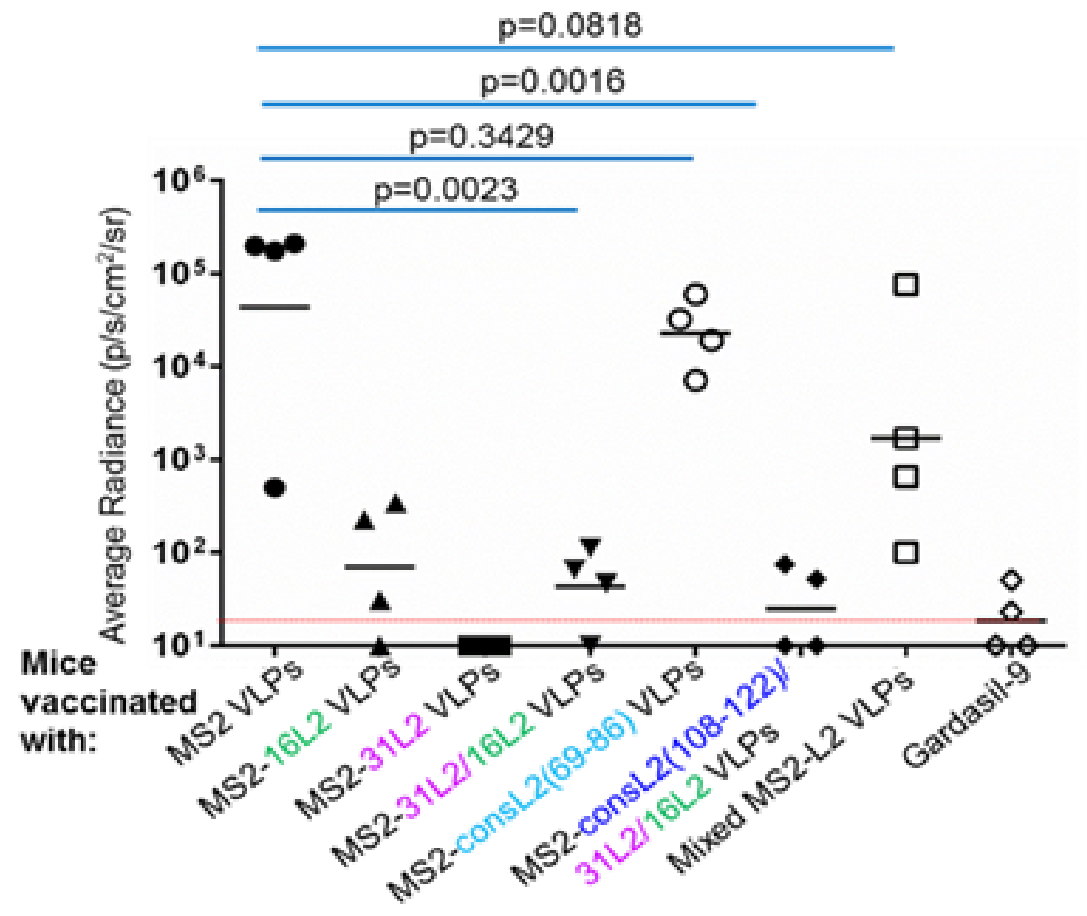




\section{C) Mice infected with HPV PsV45}
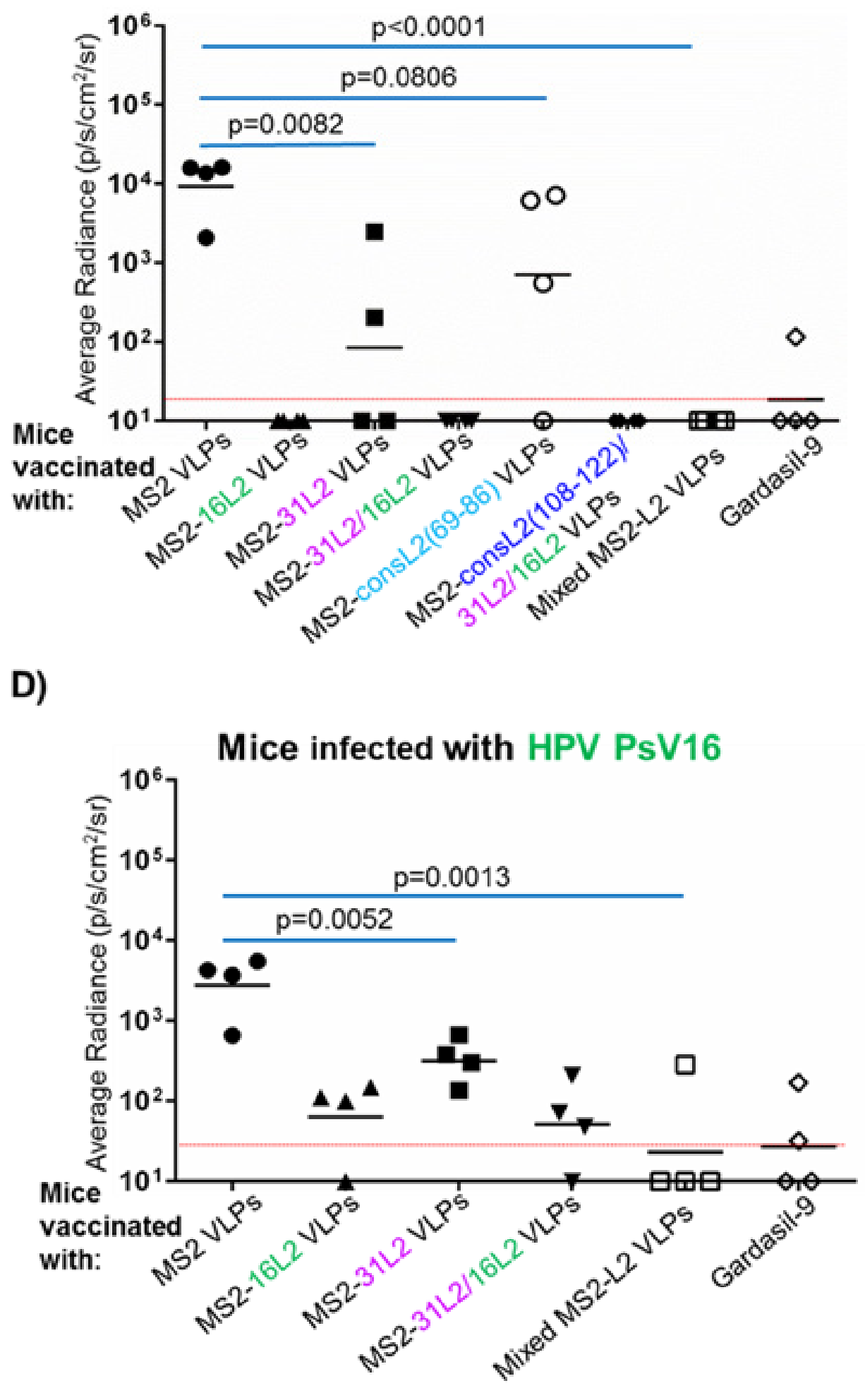
Fig. 6. Mice immunized with MS2-L2 VLPs elicit protective antibody responses against HPV PsV31, 45, 58, and 16. Mice vaccinated with MS2-L2 VLPs or MS2 control VLPs were vaginally challenged with $\sim 6.4 \times 10^{6} \mathrm{IU}$ of HPV PsVs. Forty-eight hours post-challenge, luciferin was instilled vaginally and images were taken 3 minutes post-luciferin instillation except in $4 \mathrm{~A}$ were images were taken 10 minutes post-luciferin instillation. The average radiance $\left(\mathrm{p} / \mathrm{s} / \mathrm{cm}^{2} / \mathrm{sr}\right)$ of luciferase expression at the genitals was determined using Living Image 3.2 software. Each datum represents the radiance value of an individual mouse and the lines stand for the average geometric mean for each group. Red dashed lines highlight MS2-L2 VLPs efficacy in comparison to Gardasil-9 vaccine.

The in vitro neutralization assay is an alternative method that can be used to test the neutralization efficacy (i.e. predict protection potentials) of candidate HPV vaccines. To test the neutralizing potential of our MS2-L2 VLPs with other HPV types, sera from mice immunized with VLPs (MS2-31/16L2 and Mixed MS2L2) that offered the best protection against vaginal infection were used in an in vitro neutralization assay against PsV18 and PsV33. Compared to control MS2 sera, sera from mice immunized with MS2-31/16L2 or Mixed MS2-L2 VLPs neutralized PsV18 and PsV33 at levels similar to sera from mice immunized with Gardasil-9 (Fig. 7). These results show that MS2-31/16L2 and Mixed MS2-L2 
VLPs sera are protective in vivo and in vitro against infection by diverse HPV types.

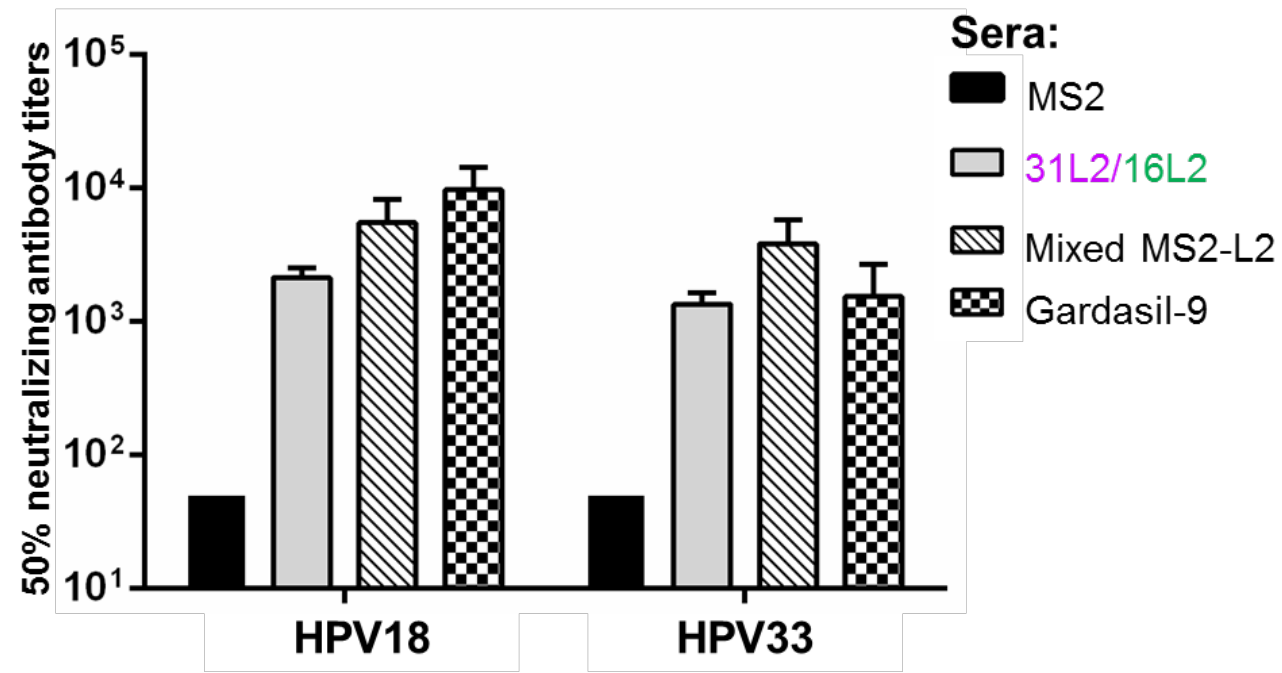

Fig. 7. MS2-L2 sera neutralize HPV PsV18 and PsV33. Titers of HPV PsV18 and PsV33 that led to $20 \%$ and $75 \%$ infectivity, respectively, of pgsa- 745 cells were separately incubated with serial-dilutions of sera collected from mice immunized with MS2-L2 VLPs or controls. Incubated PsV and sera were then used to infect pgsa-745 cells. Forty-eight hours after infection, PsV neutralization (based on GFP expression levels) was determined by flow cytometry. Bars indicate the reciprocal of the highest sera dilution at which at least $50 \%$ HPV PsV was neutralized compared to controls with no sera. MS2 control sera neutralizing titers were $<50$. 


\subsection{Discussion}

Current HPV vaccines protect mostly against the HPV types included in the vaccines [4]. Given the fact that protection from HPV infections is not $100 \%$, patients vaccinated with any of the HPV vaccines are still recommended to continue cervical cancer screening. The recommended screening is very crucial for HIVIAIDS patients given the immunocompromised nature of their immune system, their propensity to be co-infected with up to 10 HR-HPV types [12, 13], and the risk for their HPV infections to progress to invasive cancer 6 to 15 years earlier than non-HIV patients [41, 42]. Thus, there is a need to develop an HPV vaccine with the potential to offer complete protection against HPV-associated cancers, especially in HIVIAIDS patients. We had previously reported that a thermostable bacteriophage MS2 VLPs displaying peptide 17-31 from HPV16 offered complete protection against HPV PsV16 and other HPV PsVs, but suboptimal protection against two important heterologous HPV types (HPV31 and HPV58) [34, 43]. To enhance protection against some of these heterologous HPV types, we generated for the first time, VLPS [MS2-31/16L2 and MS2consL2(108-122)/31L2/16L2] displaying concatemers of two or three L2 epitopes, respectively. In addition to these, we developed VLPs [MS2-consL2(69-86), MS2-consL2(108-122)] displaying consensus sequences. Anti-HPV16 L2 serum reacted with all the MS2-L2 VLPs (confirming display of peptides on VLPs) except for VLPs displaying consL2(108-122) (Figs. 2A and 2B). Lack of reactivity with MS2-consL2(108-122) VLPs was expected because the HPV16 L2 (aa 1-88) 
serum does not include consL2(108-122) epitope. The reactivity of anti-HPV16 L2 serum with MS2-consL2(69-86) VLPs (compared with other L2-VLPs) was low. This could be explained by the fact that HPV16 L2, from which the serum was generated is $80 \%$ identical to $31 \mathrm{~L} 2$ (at aa 17-31) unlike peptide $69-86$ of HPV16 L2, which is only $72 \%$ identical to consL2(69-86).

Mice immunized with VLPs displaying concatemers, consensus sequences [except MS2-consL2(108-122)], and Mixed MS2-L2 VLPs [MS2consL2(108-122)/31L2/16L2 plus MS2-consL2(69-86)] elicited high anti-L2 antibody titers (Fig. 3), which protected/neutralized six HPV PsV types (16, 18, $31,33,45,58)$ at levels similar to Gardasil-9 vaccine (Figs. 4 and 5). Mixed MS2L2-immunized mice offered the best protection except against PsV58; we are not sure why partial protection was observed given the fact that 31L2 and 16L2 (1731) share $\sim 87 \%$ and $80 \%$ amino acid identity, respectively, with $58 \mathrm{~L} 2$ at the same epitope. MS2-16L2 VLPs in this study offered good protection (although a little less compared to MS2-31L2 VLPs) against PsV31 and PsV58, whereas we had observed less protection in a previous study [34]. It is likely that mice in our previous study were challenge with higher PsV dose compared to this study. For example, control MS2 mice challenged with PsV31 in our previous study had a higher geometric mean average radiance (GMAR 10 ${ }^{5.5}$ ) compared to MS2 control mice in this study with GMAR of $10^{4.8}$. Irrespective of thesedifferences, these results suggest that immunization with a tandem L2 peptide or a mixture of L2 peptides does not compromise the immunogenicity of individual epitopes. 
While robust responses were observed with the VLPs displaying peptide 17-31 (single or tandem peptide), little protection was observed in mice immunized with VLPs displaying peptide consL2(69-86) and no immune responses were observed in mice immunized with VLPs displaying peptide consL2(108-122). It was surprising that no significant protection was observed in mice immunized with the MS2-consL2(69-86) given the fact that mice had high anti-L2 antibody titers against this peptide. A previous study had shown that sera (at 1:1000 dilution) from mice immunized with $Q \beta$ bacteriophage VLPs displaying a similar conjugated consensus L2 peptide neutralized HPV PsV31, 45, 58 [36]. The discrepancy in the results could be explained by the fact that the previous study used a slightly longer consensus sequence (65-85), which included 4 additional amino acids (GTGG) that are highly conserved amongst HPV types. We attempted here to insert (genetically) the same epitope on the coat protein of MS2; however, no expression of the fusion protein was detected (data not shown). With respect to consensus peptide 108-122, we think MS2-consL2(108122) was not immunogenic because the peptide may not have been properly displayed on the VLPs; previous studies had shown that the isolated peptide contains neutralizing epitopes [25, 36]. Unfortunately, we could not confirm genetic display on MS2 due to lack of polyclonal antibodies that include peptide 108-122. 


\subsection{Conclusions}

In summary, we have shown that inserting a concatemer of two or three L2 peptides on MS2 coat proteins does not affect the ability of the coat proteins to assemble into VLPs. Additionally, the L2 epitopes are displayed on the VLPs and immunizations with a mixture of MS2 VLPs displaying multiple L2 epitopes do not compromise the immunogenicity of each individual epitope on the VLPs. MS2 VLPs displaying the tandem L2 peptide, (20-31) from HPV31 and (17-31) from HPV16, cross-protected/neutralized selected HR-HPV PsV types, suggesting that this is an excellent approach to achieve broader protection against more HPV types. Moreover, mixing MS2-consL2(108-122)/31L2/16L2 with MS2consL2(69-86) VLPs offered protection/neutralization at levels similar to Gardasil9 vaccine, suggesting that these MS2-L2 VLPs are candidates for low valence yet broadly cross-protective HPV vaccines that should be assessed further for protection against more HPV types especially those that may be more common in HIV patients. 


\subsection{References}

1. Schwarz, K., et al., Efficient homologous prime-boost strategies for T cell vaccination based on virus-like particles. Eur J Immunol, 2005. 35(3): p. 816-21.

2. Matsukura, T. and M. Sugase, Relationships between 80 human papillomavirus genotypes and different grades of cervical intraepithelial neoplasia: association and causality. Virology, 2001. 283(1): p. 139-47.

3. Crow, J.M., HPV: The global burden. Nature, 2012. 488(7413): p. S2-3.

4. Zhai, L.K. and E. Tumban, Gardasil-9: A global survey of projected efficacy. Antiviral Research, 2016. 130: p. 101-109.

5. Boscolo-Rizzo, P., et al., New insights into human papillomavirus-associated head and neck squamous cell carcinoma. Acta Otorhinolaryngol Ital, 2013. 33(2): p. 77-87.

6. Munoz, N., et al., Epidemiologic classification of human papillomavirus types associated with cervical cancer. N Engl J Med, 2003. 348(6): p. 518-27.

7. Dickens, P., et al., Human papillomavirus 6, 11, and 16 in laryngeal papillomas. J Pathol, 1991. 165(3): p. 243-6.

8. Sanchez, G.I., et al., Human papillomavirus genotype detection in recurrent respiratory papillomatosis (RRP) in Colombia. Head Neck, 2013. 35(2): p. 22934.

9. Schmitt, M., et al., Abundance of Multiple High-Risk Human Papillomavirus (HPV) Infections Found in Cervical Cells Analyzed by Use of an Ultrasensitive HPV Genotyping Assay. Journal of Clinical Microbiology, 2010. 48(1): p. 143149.

10. Schmitt, M., et al., Multiple human papillomavirus infections with high viral loads are associated with cervical lesions but do not differentiate grades of cervical abnormalities. J Clin Microbiol, 2013. 51(5): p. 1458-64.

11. Munoz, N., et al., Against which human papillomavirus types shall we vaccinate and screen? The international perspective. International Journal of Cancer, 2004. 111(2): p. 278-285.

12. Levi, J.E., et al., High prevalence of human papillomavirus (HPV) infections and high frequency of multiple HPV genotypes in human immunodeficiency virus- 
infected women in Brazil. Journal of Clinical Microbiology, 2002. 40(9): p. 33413345 .

13. McKenzie, N.D., et al., HPV in HIV-Infected Women: Implications for Primary Prevention. Front Oncol, 2014. 4: p. 179.

14. Beachler, D.C., et al., Risk factors for oral HPV infection among a high prevalence population of HIV-positive and at-risk HIV-negative adults. Cancer Epidemiol Biomarkers Prev, 2012. 21(1): p. 122-33.

15. Ortiz, A.P., et al., Human papillomavirus-related cancers among people living with AIDS in Puerto Rico. Prev Chronic Dis, 2014. 11: p. E80.

16. Brown, D.R., et al., The impact of quadrivalent human papillomavirus (HPV; types 6, 11, 16, and 18) L1 virus-like particle vaccine on infection and disease due to oncogenic nonvaccine HPV types in generally HPV-naive women aged 1626 years. J Infect Dis, 2009. 199(7): p. 926-35.

17. Joura, E.A., et al., A 9-valent HPV vaccine against infection and intraepithelial neoplasia in women. N Engl J Med, 2015. 372(8): p. 711-23.

18. Smith, J.F., et al., Antibodies from women immunized with Gardasil crossneutralize HPV 45 pseudovirions. Hum Vaccin, 2007. 3(4): p. 109-15.

19. Toft, L., et al., Comparison of the immunogenicity of Cervarix(R) and Gardasil(R) human papillomavirus vaccines for oncogenic non-vaccine serotypes $H P V-31, H P V-33$, and HPV-45 in HIV-infected adults. Hum Vaccin Immunother, 2014. 10(5): p. 1147-54.

20. Wheeler, C.M., et al., The impact of quadrivalent human papillomavirus (HPV; types 6, 11, 16, and 18) L1 virus-like particle vaccine on infection and disease due to oncogenic nonvaccine HPV types in sexually active women aged 16-26 years. J Infect Dis, 2009. 199(7): p. 936-44.

21. Seitz, H., et al., A three component mix of thioredoxin-L2 antigens elicits broadly neutralizing responses against oncogenic human papillomaviruses. Vaccine, 2014. 32(22): p. 2610-7.

22. Jagu, S., et al., Concatenated multitype L2 fusion proteins as candidate prophylactic pan-human papillomavirus vaccines. J Natl Cancer Inst, 2009. 101(11): p. 782-92.

23. Schellenbacher, C., R. Roden, and R. Kirnbauer, Chimeric L1-L2 virus-like particles as potential broad-spectrum human papillomavirus vaccines. J Virol, 2009. 83(19): p. 10085-95. 
24. Gambhira, R., et al., A protective and broadly cross-neutralizing epitope of human papillomavirus L2. J Virol, 2007. 81(24): p. 13927-31.

25. Kondo, K., et al., Neutralization of HPV16, 18, 31, and 58 pseudovirions with antisera induced by immunizing rabbits with synthetic peptides representing segments of the HPV16 minor capsid protein L2 surface region. Virology, 2007. 358(2): p. 266-72.

26. Kines, R.C., et al., The initial steps leading to papillomavirus infection occur on the basement membrane prior to cell surface binding. Proc Natl Acad Sci U S A, 2009. 106(48): p. 20458-63.

27. Selinka, H.C., et al., Inhibition of transfer to secondary receptors by heparan sulfate-binding drug or antibody induces noninfectious uptake of human papillomavirus. J Virol, 2007. 81(20): p. 10970-80.

28. Roden, R.B., et al., Minor capsid protein of human genital papillomaviruses contains subdominant, cross-neutralizing epitopes. Virology, 2000. 270(2): p. 254-7.

29. Alphs, H.H., et al., Protection against heterologous human papillomavirus challenge by a synthetic lipopeptide vaccine containing a broadly crossneutralizing epitope of L2. Proc Natl Acad Sci U S A, 2008. 105(15): p. 5850-5.

30. Pastrana, D.V., et al., Cross-neutralization of cutaneous and mucosal Papillomavirus types with anti-sera to the amino terminus of L2. Virology, 2005. 337(2): p. 365-72.

31. Rubio, I., et al., Potent anti-HPV immune responses induced by tandem repeats of the HPV16 L2 (20 -- 38) peptide displayed on bacterial thioredoxin. Vaccine, 2009. 27(13): p. 1949-56.

32. Jagu, S., et al., Vaccination with multimeric L2 fusion protein and L1 VLP or capsomeres to broaden protection against HPV infection. Vaccine, 2010. 28(28): p. 4478-86.

33. Schellenbacher, C., R. Roden, and R. Kirnbauer, Chimeric L1-L2 Virus-Like Particles as Potential Broad-Spectrum Human Papillomavirus Vaccines. Journal of Virology, 2009. 83(19): p. 10085-10095.

34. Tumban, E., et al., VLPs displaying a single L2 epitope induce broadly crossneutralizing antibodies against human papillomavirus. PLoS One, 2012. 7(11): p. e49751.

35. Nieto, K., et al., Development of AAVLP(HPV16/31L2) particles as broadly protective HPV vaccine candidate. PLoS One, 2012. 7(6): p. e39741. 
36. Tyler, M., et al., Immunization with a consensus epitope from human papillomavirus L2 induces antibodies that are broadly neutralizing. Vaccine, 2014. 32(34): p. 4267-74.

37. McGrath, M., et al., Development of human papillomavirus chimaeric L1/L2 candidate vaccines. Arch Virol, 2013. 158(10): p. 2079-88.

38. Tumban, E., et al., A pan-HPV vaccine based on bacteriophage PP7 VLPs displaying broadly cross-neutralizing epitopes from the HPV minor capsid protein, L2. PLoS One, 2011. 6(8): p. e23310.

39. Buck, C.B., et al., Generation of HPV pseudovirions using transfection and their use in neutralization assays. Methods Mol Med, 2005. 119: p. 445-62.

40. Day, P.M., et al., A human papillomavirus (HPV) in vitro neutralization assay that recapitulates the in vitro process of infection provides a sensitive measure of HPV L2 infection-inhibiting antibodies. Clin Vaccine Immunol, 2012. 19(7): p. 1075-82.

41. Moodley, J.R., et al., HIV and pre-neoplastic and neoplastic lesions of the cervix in South Africa: a case-control study. BMC Cancer, 2006. 6: p. 135.

42. Moodley, M., J. Moodley, and I. Kleinschmidt, Invasive cervical cancer and human immunodeficiency virus (HIV) infection: a South African perspective. Int J Gynecol Cancer, 2001. 11(3): p. 194-7.

43. Tumban, E., et al., Preclinical refinements of a broadly protective VLP-based $H P V$ vaccine targeting the minor capsid protein, L2. Vaccine, 2015. 33(29): p. 3346-53. 


\section{Chapter 2}

\section{Oral immunization with bacteriophage MS2-L2 VLPs protects against oral and genital infection with multiple HPV types associated with head \& neck cancers and cervical cancer}

\subsection{Abstract}

Human papillomaviruses (HPVs) are the most common sexually transmitted infections. HPVs are transmitted through anogenital sex or oral sex. Anogenital transmission/infection is associated with anogenital cancers and genital warts while oral transmission/infection is associated with head and neck cancers (HNCs) including recurrent respiratory papillomatosis. Current HPV vaccines protect against HPV types associated with $\sim 90 \%$ of cervical cancers and are expected to protect against a percentage of HNCs. However, only a few studies have assessed the efficacy of current vaccines against oral HPV infections. We had previously developed a mixed MS2-L2 candidate HPV vaccine based on bacteriophage MS2 virus-like particles (VLPs). The mixed MS2-L2 VLPs consisted of a mixture of two MS2-L2 VLPs displaying: i) a concatemer of L2 peptide (epitope 20-31) from HPV31 \& L2 peptide (epitope 17-31) from HPV16 and ii) a consensus L2 peptide representing epitope 69-86. The mixed MS2-L2 
VLPs neutralized/protected mice against six HPV types associated with $\sim 87 \%$ of cervical cancer. Here, we show that the mixed MS2-L2 VLPs can protect mice against additional HPV types; at the genital region, the VLPs protect against HPV53 and at the oral region, the VLPs protect against HPV16, 35, 39, and 58. Including our colleague's data (data not shown), mixed MS2-L2 VLPs protect against eleven oncogenic HPV types associated with $\sim 95 \%$ of cervical cancer. The VLPs also have the potential to protect, orally, against the same oncogenic HPVs, associated with $\sim 99 \%$ of HNCs. Moreover, mixed MS2-L2 VLPs are thermostable at room temperature for up to 60 days after spray-freeze drying and they are protective against oral HPV infection.

\subsection{Introduction}

Human papillomaviruses (HPVs) are non-enveloped DNA viruses with more than 220 different types identified to date [1-3]. Approximately, 40 of these HPV types are transmitted sexually through anogenital-to-anogenital sex or anogenital-tooral sex [4, 5], and 19 HPV types can cause cancers. Anogenital HPV infections are associated with cervical cancer, vaginal cancer, penile cancer, anal cancer, and genital warts [6-10] whereas oral HPV infections are associated with head and neck cancers (HNCs; oral, oropharyngeal, laryngeal cancers, etc.) including recurrent respiratory papillomatosis (RRP) [11-15]. Twenty-five percent of HNCs are caused by HPVs [16]; HPV type 16 is associated with more than $70 \%$ of 
HPV-associated HNCs (HPV+HNCs). HPV18 is associated with $14-17 \%$ of $\mathrm{HPV}+\mathrm{HNCs}$ while the remaining $\mathrm{HPV}+\mathrm{HNC}$ cases are caused by other oncogenic HPV types $(31,33,35,45$, etc.) $[11,17-19]$. The prevalence of $\mathrm{HPV}+\mathrm{HNC}$ varies from one geographical region to another; $21.1-40.8 \%$ in Europe, $\sim 32.4 \%$ in Asia, $24.3-26.3 \%$ in North America, $3.7-21.1 \%$ in Central \& South American, and $1.0-2.5 \%$ in Africa [17, 19]. Two prophylactic vaccines (Gardasil-9 and Cervarix; Gardail-4 has been discontinued) are currently being used to protect against HPV infections [6, 20, 21]. Amongst these vaccines, Gardasil-9 offers the broadest level of protection against HPV types (HPV16, 18, $31,33,45,52,58)$ that cause $\sim 90 \%$ of cervical cancers worldwide and HPV types (HPV6 and 11) that cause $90 \%$ of genital warts/RRP. Despite the broadness of protection offered by Gardasil-9 vaccine, vaccinated individuals are still advised to continue cervical cancer screening to make sure they are not infected with cancer-causing HPV types not included in the vaccine. The HPV types (e.g. HPV35, 39, 53, 56, etc.) associated with $\sim 10 \%$ of cervical cancer not protected by current vaccines are significantly important especially if this involves patients infected with human immunodeficiency virus (HIV) or are suffering from acquired immunodeficiency syndrome (AIDS). Additionally, there is no data on the efficacy of Gardasil-9 vaccine against oral HPV infections.

To enhance the spectrum of protection and to circumvent these problems, we developed, in a previous study [22], two bacteriophage MS2 VLPs: i) MS231L2/16L2 VLP displaying a concatemer of HPV31 L2 (amino acid 20-31) \& HPV16 L2 (amino acid 17-31) on its surface; ii) MS2-consL2(69-86) VLP 
displaying a consensus sequence (amino acid 69-86) derived from the alignment of 19 cancer-causing HPV types and 4 warts-causing HPV types. L2 (the minor capsid protein) is one of the two capsid proteins of HPV; L2, especially the Nterminus, is highly conserved among HPV types and is a target for nextgeneration HPV vaccines [23-26]. In Zhai et al. 2017, we showed that mice immunized, intramuscularly, with a mixture of the VLPs, MS2-31L2/16L2 and MS2-consL2(69-86), elicited high-titer $\left(>10^{4}\right) \lg G$ antibodies and protected the mice from vaginal challenge with HPV pseudoviruses representing HPV16, 18, 31, 45, and HPV33 at levels similar to Gardasil-9; suboptimal protection was observed against HPV58 [22]; these six HPV types are associated with $\sim 87 \%$ of cervical cancer and $\sim 90 \%$ of HPV+HNCs. To build on that study, we assessed whether oral immunization with the mixed MS2-L2 VLPs in the presence of two mucosal adjuvants (cholera toxin and monophosphoryl lipid A) can protect mice from oral and/or vaginal infection with additional HPV pseudovirus types (HPV35, 39,52 , and 53 ) associated with $\sim 8.9 \%$ of $\mathrm{HPV}+\mathrm{HNC}$ and $\sim 8.0 \%$ of cervical cancer; oral immunization (including other mucosal approaches) with cholera toxin or monophosphoryl lipid A has been shown to elicit protective mucosal and systemic immune responses [27-30]. We also assessed whether the mixed VLPs can be developed into a heat-stable dry powder formulation with mucosal adjuvants; we assessed the thermostability/immunogenicity of the dry powder VLPs stored at room temperature for 60 days. 


\subsection{Materials and Methods}

\subsubsection{Production of MS2-L2 VLPs}

Plasmids encoding recombinant MS2-L2 proteins -- MS2 coat protein with an insertion of a concatemer of HPV L2 epitope containing amino acids (aa) 20-31 from HPV31 L2 and aa 17-31 from HPV16 L2 (MS2-31L2/16L2) or MS2 coat protein with an insertion of a consensus HPV L2 epitope [MS2-consL2(69-86)] were previously described [22]. The plasmids were used to transform C41 Escherichia coli (E. coli) cells. Protein expression and VLPs purification were conducted as previously described [22]. Briefly, transformed bacterial C41 culture was induced with $0.5 \mathrm{mM}$ Isopropyl $\beta$-D-1-thiogalactopyranoside (IPTG) for 3 hours and the bacteria were lysed with $0.2 \%$ lysozyme solution [for MS2consL2(69-86) VLPs] or $10 \mathrm{mM}$ Borax (for MS2-31L2/16L2 VLPs). Soluble VLPs were precipitated with $50 \%$ ammonium sulfate and purified using sepharose cross-linked CL-4B columns.

\subsubsection{Spray-freeze drying of VLPs into dry powder formulation}

Equal concentrations of MS2-31L2/16L2 VLPs and MS2-consL2(69-86) VLPs were mixed together to obtain mixed MS2-L2 VLPs. Half of the mixed MS2-L2 VLPs $(100 \mu \mathrm{g})$ was further mixed with $2 \mu \mathrm{g}$ each of the mucosal adjuvants, cholera toxin (CT) and monophosphoryl lipid A (MPLA); control MS2 VLPs were mixed with the same concentration of adjuvants. The mixed MS2-L2 VLPs and 
MS2 VLPs, with or without mucosal adjuvants, were added to a $3 \% \mathrm{w} / \mathrm{v}$ MTDL excipient solution (containing Mannitol (M, 75\% w/w), Trehalose (T, 7.5\% w/w), Dextran (D, 2.5\% w/w), and L-Leucine (L, 15\% w/w). The VLPs were added at a concentration of $8 \% \mathrm{w} / \mathrm{w}$ to the MTDL excipients and the VLPs-excipients were then spray-freeze dried (SFD) in two steps using a method adapted from Tonnis et al., 2014 and Ali et al., 2014 [31, 32]. In the first step, the VLPs-excipients suspensions were sprayed into a stainless-steel container filled partially with liquid nitrogen. This was achieved by using a two-fluid nozzle $(0.7 \mathrm{~mm})$ which is part of a Büchi B-290 mini spray-dryer; the spraying operating conditions were as following: nitrogen flow (Q) between 10 and $15 \mathrm{~mm}$, and a VLPs-excipients feed rate of $\sim 4 \mathrm{~mL} / \mathrm{min}$. Subsequently, the liquid nitrogen in the steel container was allowed to evaporate and the frozen droplets were transferred into a lyophilizer (FreeZone ${ }^{\circledR}$ Triad $^{\text {TM }}$ Freeze Dry system, Model 74000 Series) [31] for freezedrying (the second step). Freeze-drying was conducted under the following conditions: pre-freeze for $3 \mathrm{~h}$ at $-80{ }^{\circ} \mathrm{C}$, primary drying at $-10{ }^{\circ} \mathrm{C}$ for $24 \mathrm{~h}$ with a ramp of $0.25{ }^{\circ} \mathrm{C} / \mathrm{min}$, followed by secondary drying at $15^{\circ} \mathrm{C}$ for $48 \mathrm{~h}$ with a ramp of $0.25{ }^{\circ} \mathrm{C} / \mathrm{min}$, and vacuum pressure of $1.51 \mathrm{mBar}$. All SFD products were collected in glass scintillation vials and were stored under refrigeration until further use. 


\subsubsection{Assessing the thermostability of SFD VLPs}

Spray-freeze dried VLP powders were loaded into capsules, transferred to amber-colored Wheaton glass bottles and sealed with $20 \mathrm{~mm}$ butyl septa caps. The bottles were then purged with nitrogen gas and crimped with tear-away aluminum seals using a vial seal crimper [33]. The sealed bottles were then stored at $4{ }^{\circ} \mathrm{C}$ or room temperature for 60 days. The powders were then reconstituted in 1X phosphate buffered saline (PBS) and the integrity of VLPs was assessed, in comparison to non-spray-freeze dried VLPs, by transmission electron microscopy (TEM; 30,000X magnification). The immunogenicity of the reconstituted VLPS was assessed by immunizing mice as described below.

\subsubsection{Immunization of mice and assessing antibody responses}

All animal work was conducted following Michigan Technological University Institutional Animal Care and Use Committee (IACUC) guidelines (Protocol number L0264). Groups of female balb/c mice (4-6 mice per group) were immunized thrice orally, by placing VLPs underneath the tongue or by injecting into the buccal region, at two-week intervals with freshly prepared (non-sprayfreeze dried) mixed MS2-L2 VLPs [50 $\mu$ g each of MS2-31L2/16L2 VLPs and MS2-consL2(69-86)] mixed with either $2 \mu \mathrm{g}$ of CT, $2 \mu \mathrm{g}$ of MPLA, a combination of the two adjuvants (same concentrations), or without adjuvants. Other groups of mice were immunized with control MS2 VLPs and same adjuvant combinations for comparison. In all immunizations, $5 \mu \mathrm{g}$ of Gardasil-9 was used 
as controls administered intramuscularly because it does not contain mucosal adjuvants.

To assess the immunogenicity of the spray-freeze dried VLPs, $100 \mu \mathrm{g}$ of the reconstituted SFD mixed MS2-L2 or SFD control MS2 VLPs (all SFD with CT and MPLA adjuvants) were used to immunize mice as described above (same route and schedule). Other groups of mice were immunized with the same concentration of reconstituted SFD VLPs but with additional $2 \mu \mathrm{g}$ each of fresh liquid CT and MPLA adjuvants; the latter will assess whether the activity of the adjuvants were inactivated during the SFD process. The VLPs that were SFD without the adjuvants were immunized (at same concentration) with $2 \mu \mathrm{g}$ each of fresh liquid CT and MPLA adjuvants.

In all immunizations, sera and saliva were collected two weeks after the last immunizations. IgG antibody titers in sera were conducted by peptide-ELISA as previously described [34]. Briefly, 96-well plates were coated, overnight, with 500 ng HPV16 L2 peptide conjugated to streptavidin. The plates were blocked for two hours with $0.5 \%$ non-fat milk in 1X PBS. The plates were incubated with 4fold serial dilutions of serum for two hours. Horseradish peroxidase (HRP)conjugated goat anti-mouse IgG (1:5000 dilution) antibodies were added to the plates for one hour. The wells were washed and developed with $3,3^{\prime}, 5,5^{\prime}-$ Tetramethylbenzidine (TMB) and stopped with $1 \mathrm{M}$ hydrogen chloride solution. Antibody titers were determined (at optical density 450) as the reciprocal of highest sera dilutions at which reactivity of experimental sera was at least twice 
that of control sera. IgA antibody titers in saliva were determined also by peptideELISA with $100 \mu \mathrm{L}$ saliva samples as primary antibodies. HRP-conjugated goat anti-mouse IgA (1:500) antibodies were added for one hour and the plates were developed as described above except without the stop solution. IgA antibodies were determined by comparing the optical density $(405 \mathrm{~nm})$ values of experimental group to those of control group.

\subsubsection{Oral and vaginal infection with HPV pseudoviruses (PsVs)}

HPVs pseudoviruses representing PsVs 16, 35, 39, 53, and 58 were expressed and purified by cesium chloride gradient ultracentrifugation as previously described [26]. The PsVs encode a reporter plasmid that expresses green fluorescence protein and luciferase. For vaginal infection, immunized mice were treated with Depo-provera and PsVs (16 and 53) infection was conducted as previously described [22]. For oral infection, immunized mice were injected at the buccal region with PsVs (16, 35, 39 and 58); $1-7 \times 10^{6}$ infectious unit (IU) of PsVs were used in all infections. Forty-eight hours post-infection, mice that were infected orally were injected in the buccal region with $1 \mathrm{mg}$ of luciferin, while those that were infected vaginally were instilled vaginally with $0.4 \mathrm{mg}$ of luciferin. In both cases, the mice were imaged using IVIS Spectrum at one-minute exposure. Average radiance $\left(\mathrm{p} / \mathrm{s} / \mathrm{cm}^{2} / \mathrm{sr}\right)$ was determined by drawing equally sized regions of interests surrounding the site of PsV instillation. 


\subsubsection{Statistical analysis}

Statistical analyses for ELISAs and of HPV PsV challenge studies were done using unpaired two-tailed t-test and unpaired one-tailed t-test, respectively.

\subsection{Results}

\subsubsection{Buccal immunization with mixed MS2-L2 VLPs plus mucosal adjuvants elicits protective immune responses at the vaginal and oral regions}

To assess which delivery method of oral immunization will elicit immune responses, mice were immunized by placing freshly prepared (non-spray-freeze dried) mixed MS2-L2 VLPs with/without cholera toxin and MPLA in the floor of the mouth or by injecting the buccal area of the mouth with the VLPs. We then assessed $\lg$ and $\lg A$ antibody levels in sera and saliva, respectively. Mice immunized by injecting the floor of the mouth with the VLPs elicited high-titer IgG antibodies in the sera (Fig. 1A) but no detectable IgA in saliva (data not shown). Mice immunized with the mixed MS2-L2 VLPs in the presence of the two adjuvant combinations (mixed MS2-L2 VLPs + CT/MPLA) elicited higher IgG titers $(p<0.0001)$ compared to mice immunized with the same VLPs but with only one of the adjuvants (especially mixed MS2-L2 VLPs + MPLA; $p=0.0140$ ). Mice 
immunized by placing the VLPs in the floor of the mouth did not elicit immune response in the sera or in the saliva (data not shown). Thus, all subsequent immunization studies were conducted by injecting the buccal region of the mouth and with the two-adjuvant combinations (CT/MPLA). 
A)

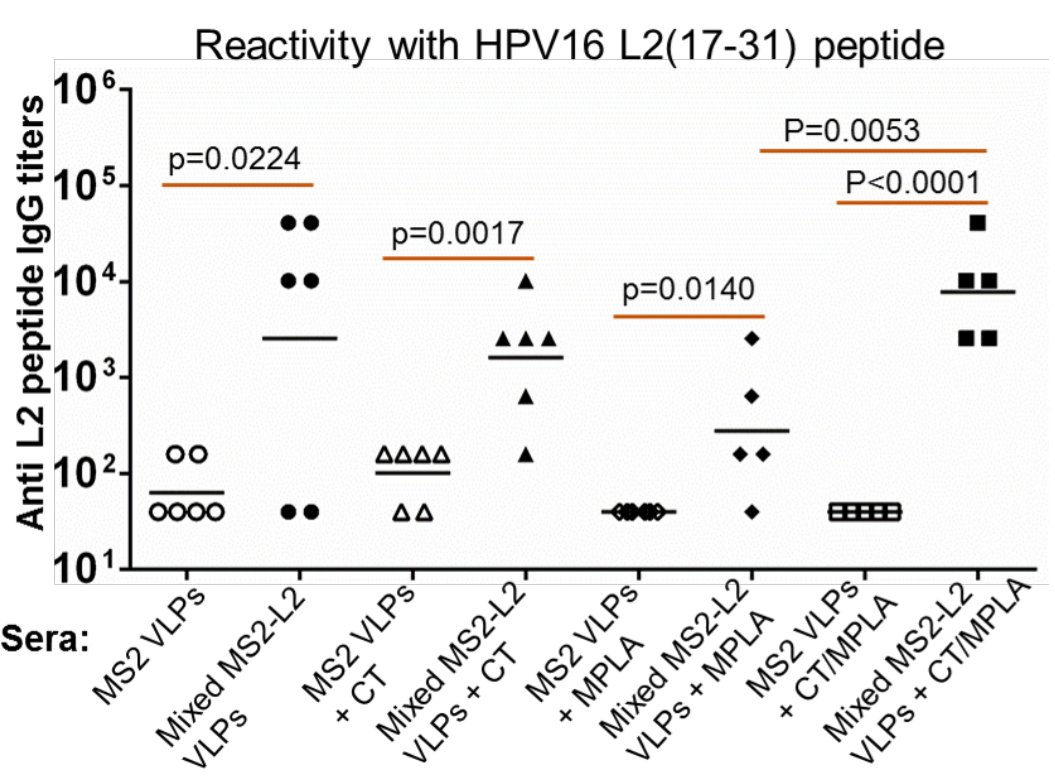

B) Mice vaginally infected with HPV PsV16

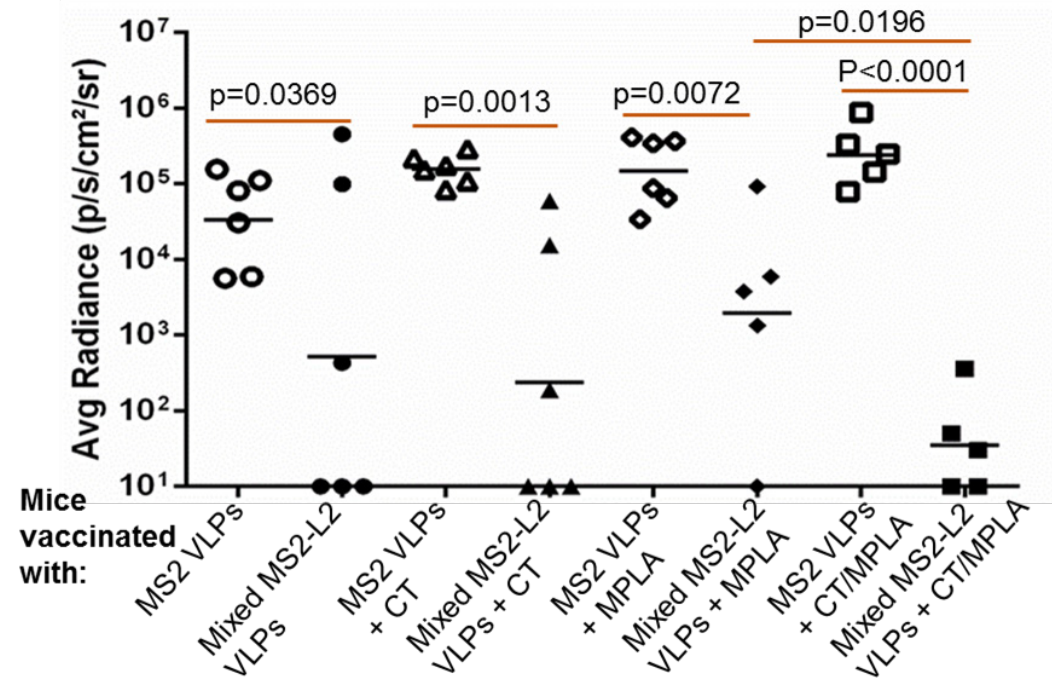


C) Genital protection from HPV PsVs

PsV 53

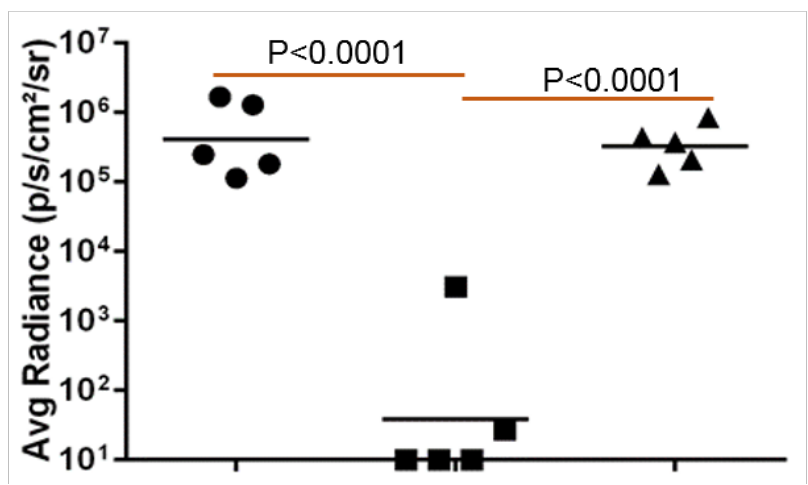

Immunized with MS2 VLPs

Immunized with Mixed MS2-L2 VLPs

$\Delta^{\text {Immunized with Gardasil } 9}$

Fig. 1. Immunogenicity of mixed MS2-L2 VLPs with/without mucosal adjuvants (CT or MPLA) and protection from PsV16 and 53. Mice were immunized (buccal injection) thrice with $100 \mu \mathrm{g}$ of mixed MS2-L2 VLPs or control MS2 VLPs with/without CT, MPLA or with/out the two-adjuvant combinations at two-week intervals. Sera were collected two weeks after the last immunization. A) Anti-L2 peptide IgG titers in sera were determined by end-point dilution ELISA using 16L2 (17-31) peptide as the target peptide. Each datum represents antibody titer in each mouse and the black horizontal lines represent geometric mean for each group. B) The mice in (A) were vaginally challenged with $\sim 3 \times 10^{6}$ IU of HPV PsV16. C) Additional groups of mice were immunized by buccal injection with $100 \mu \mathrm{g}$ of mixed MS2-L2 VLPs, control MS2 VLPs, and $5 \mu \mathrm{g}$ of Gardasil-9 vaccine (immunized intramuscularly). The mice were vaginally challenged with $1.6 \times 10^{6} \mathrm{IU}$ of PsV 53. The average radiance $\left(\mathrm{p} / \mathrm{s} / \mathrm{cm}^{2} / \mathrm{sr}\right)$ of luciferase expression was determined using Living Image 4.5.5 software. Each datum represents the average radiance of an individual mouse and the lines 
represent the geometric mean for each group. The P-values for ELISAs and infection assays were determined by unpaired two-tailed t-test and unpaired onetailed t-test, respectively.

To assess if the immune responses elicited by buccal immunization were protective, we challenged the mice vaginally, using a well-characterized method for HPV infection [34, 35]. As shown in Fig. 1B, mice immunized with mixed MS2L2 VLPs with CT/MPLA showed better levels of protection $(p<0.0001)$ from HPV PsV16 infection compared to mice immunized with only one of the two adjuvants (especially those immunized with MPLA; $p=0.0072$ ). To test if buccal immunization with mixed MS2-L2 VLPs offered cross-protection against other HPV PsVs, vaccinated mice were vaginally infected with high-risk HPV PsV53, which is not included in Gardasil-9 vaccine. Mice immunized with mixed MS2-L2 VLPs offered complete protection against PsV53 while Gargasil-9 offered no protection against PsV53 (Fig. 1C).

Having demonstrated that buccal immunization protected mice from vaginal infection by HPV PsVs 16 and 53, we decided to assess if buccal immunization can protect mice from oral infection with PsV16 and other PsVs (35, 39 and 58). In Fig. 2, buccal immunization with mixed MS2-L2 VLPs + CT/MPLA protected mice from oral infection with PsVs 16, 35, 39 and 58. While mixed MS2-L2 VLPs and Gardasil-9 (immunized intramuscularly) offered similar levels of protection against PsV16, Gardasil-9 offered better protection against PsV58 and mixed 
MS2-L2 VLPs offered best protection against PsV35 and PsV39 (Fig. 2B).

A)
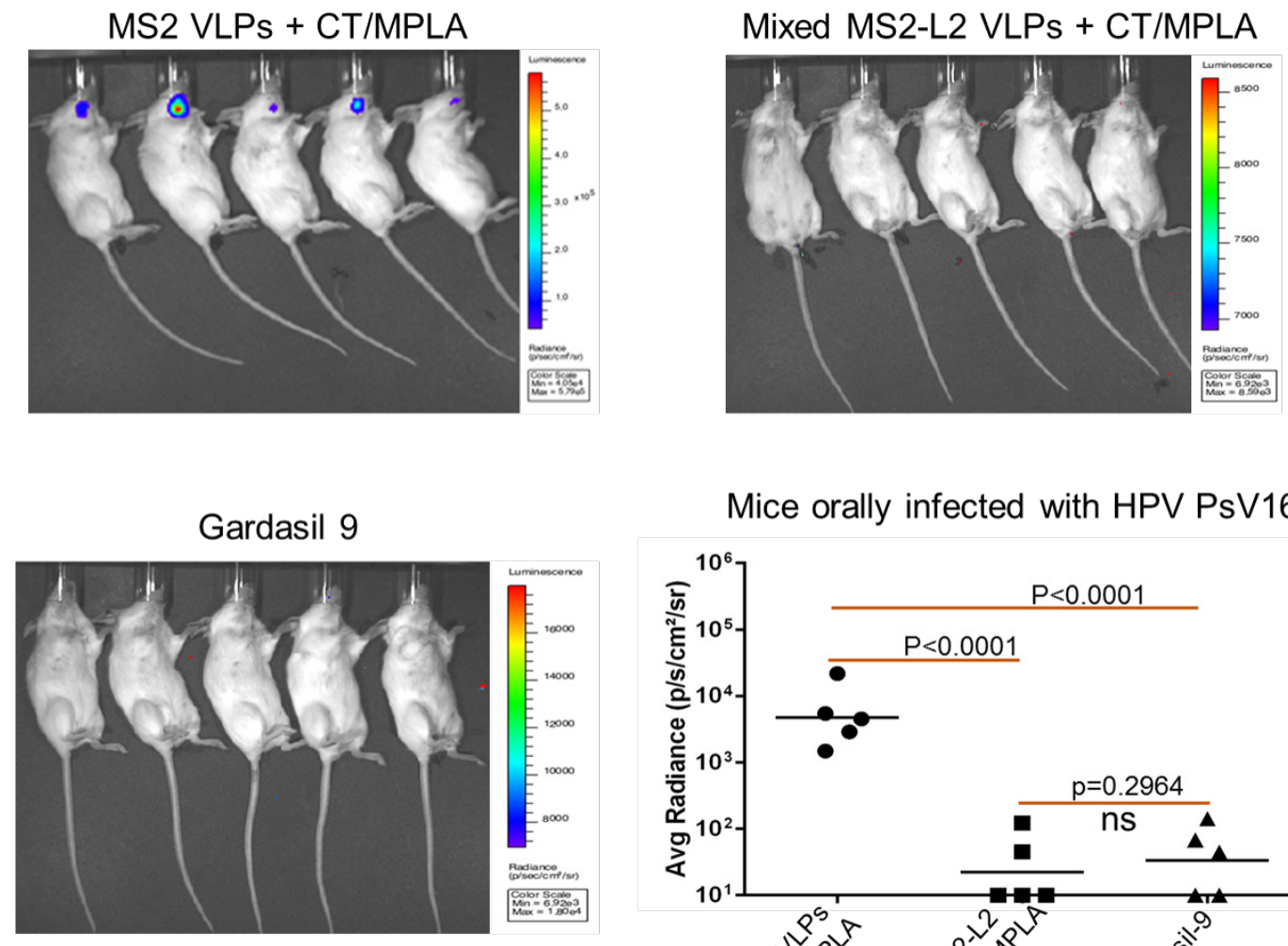

Mice orally infected with HPV PsV16

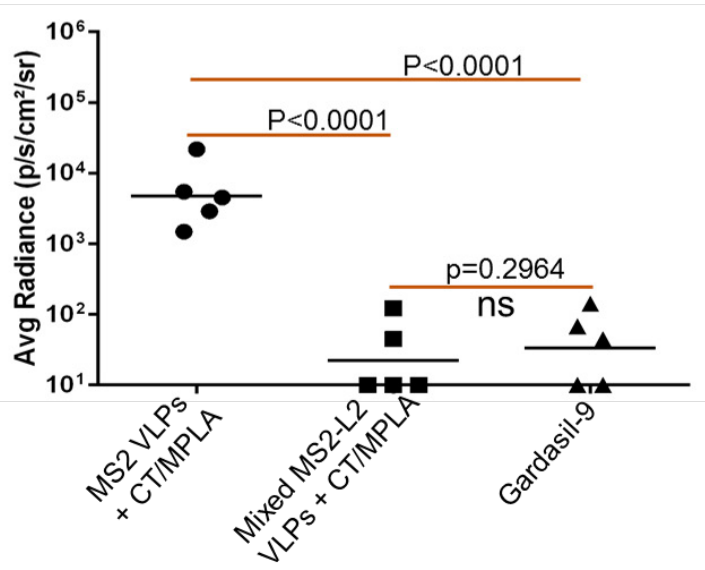


B) Oral protection from HPV PsVs
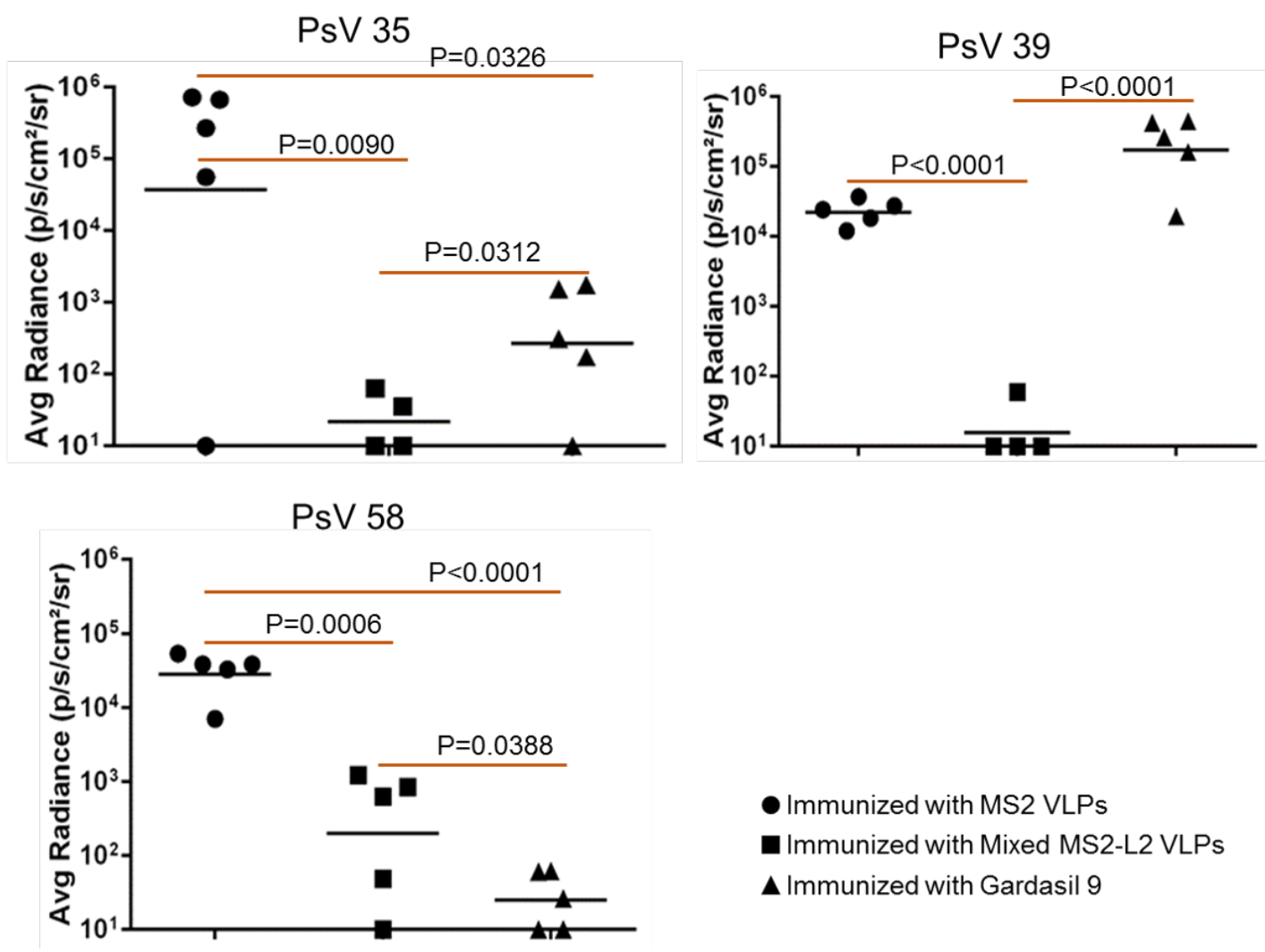

- Immunized with MS2 VLPs

- Immunized with Mixed MS2-L2 VLPs

$\Delta$ Immunized with Gardasil 9

Fig. 2. Buccal immunization with mixed MS2-L2 VLPs and oral protection from HPV PsVs 16, 35, 39 and 58. Mice immunized (buccal injection) thrice (at two-week intervals) with $100 \mu \mathrm{g}$ of mixed MS2-L2 VLPs, control MS2 VLPs, and $5 \mu \mathrm{g}$ of Gardasil-9 vaccine (immunized intramuscularly) were orally challenged with: A) $7 \times 10^{6} \mathrm{IU}$ of PsV16 and B) $1-7 \times 10^{6} \mathrm{IU}$ of PsVs 35, 39 and 58. Each datum represents the average radiance of an individual mouse and the lines represent the geometric mean for each group. The P-values were determined by unpaired one-tailed t-test. 


\subsubsection{Mixed MS2-L2 VLPs can be SFD without a mixture of cholera toxin/MPLA adjuvants}

To assess if mixed MS2-L2 VLPs can be SFD into a product that is thermostable at room temperature, the VLPs with or without CT/MPLA were SFD with stabilizing excipients and the integrity of the VLPs was assessed by TEM. As a control, MS2 VLPs with same adjuvants and excipients were also SFD. While mixed MS2-L2 VLPs or MS2 VLPs in the absence of adjuvants were successfully SFD (based on the integrity of the VLPs after reconstitution of the powder in PBS buffer in comparison to non-SFD VLPs), the VLPs could not be SFD with the adjuvants (Fig. 3). SFD with adjuvants caused the VLPs to agglomerate (Fig. $3 A)$. 
A)
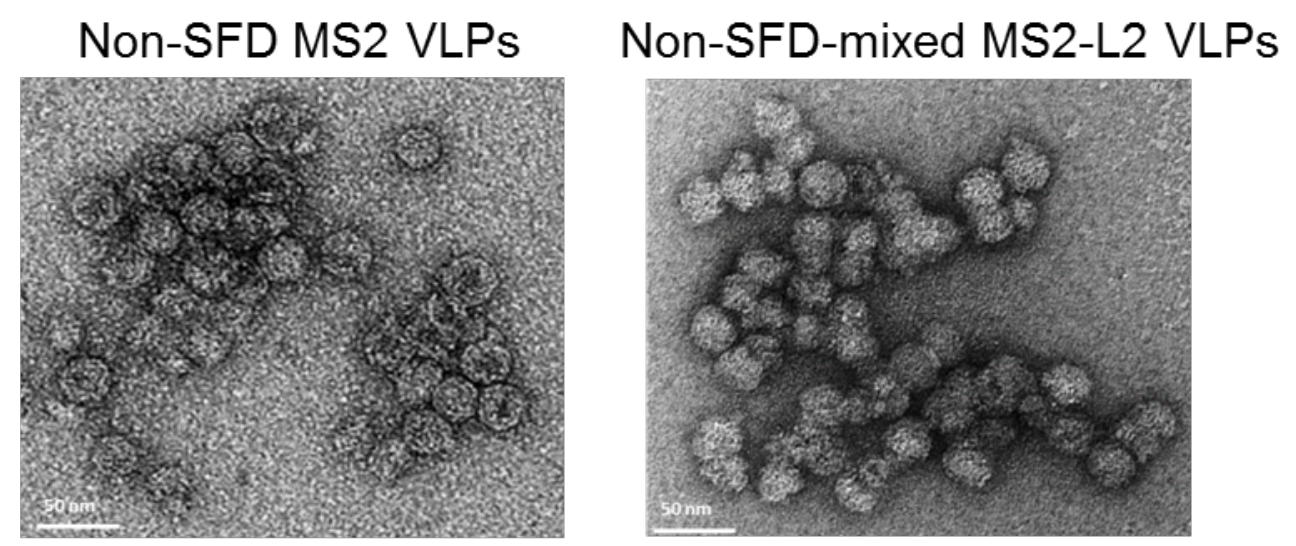

B)
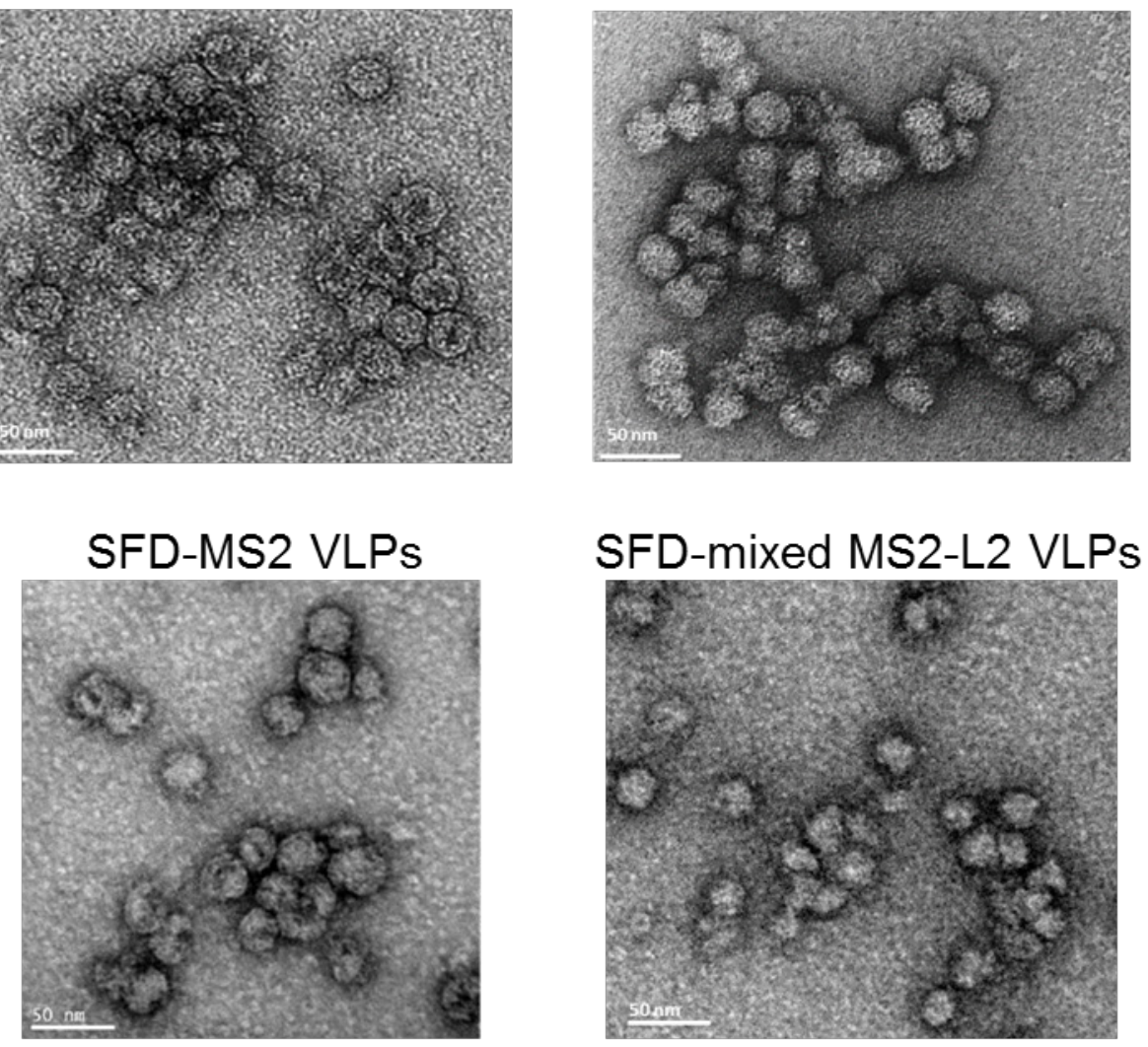

C)

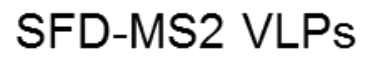
with adjuvants
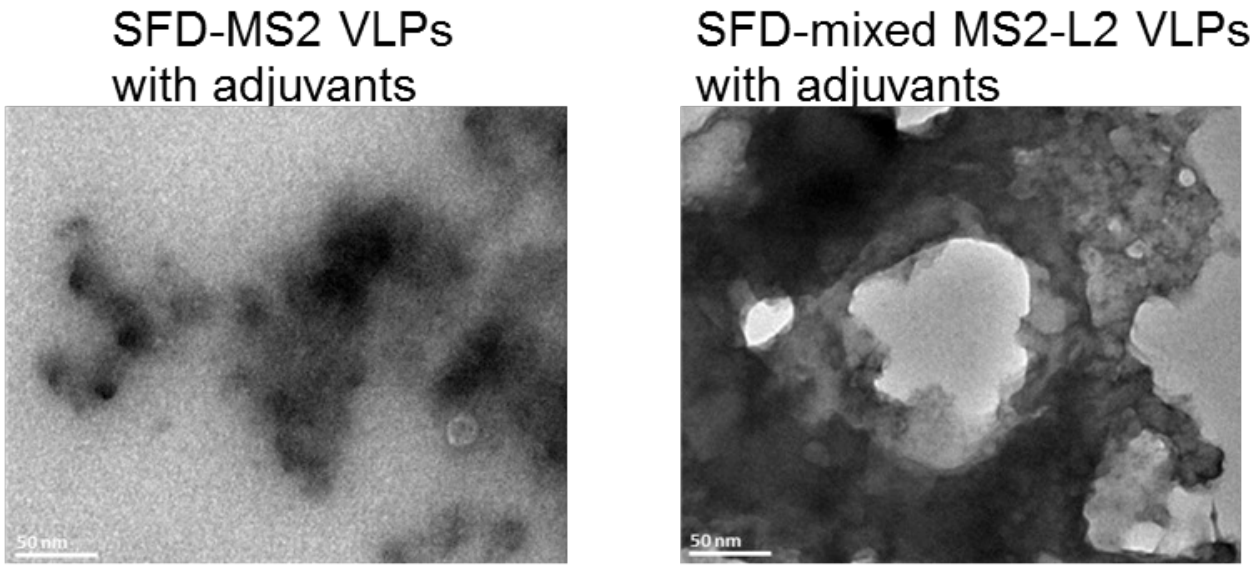
with adjuvants

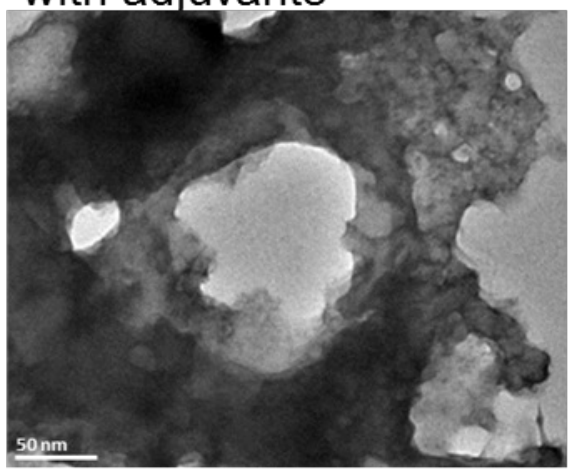

Fig. 3. Transmission electron microscopy (TEM) images of spray-freeze dried (SFD) VLPs and non-spray-freeze dried VLPs. Mixed MS2-L2 VLPs and MS2 control VLPs were SFD with/without mucosal adjuvants (CT and MPLA) and 
the dry powders were reconstituted in PBS and analyzed (in comparison with fresh liquid VLPs) using a TEM. A) TEM of spray-freeze dried VLPs with CT/MPLA, B) TEM of spray-freeze dried VLPs without CT/MPLA, and C) TEM of fresh liquid VLPs. Images were taken under 30,000X magnification.

To assess whether the SFD VLPs (those that did not agglomerate and those that agglomerated) were still immunogenic, we immunized mice (in buccal region) with the VLPs with/without additional CT/MPLA adjuvants. Mixed MS2-L2 VLPs SFD without adjuvant, but adjuvant combinations were added (+ CT/MPLA) just prior to immunization were highly immunogenic compared to the VLPs [mixed MS2-L2 VLPs (CT/MPLA)] that were SFD together with the adjuvant combinations (Fig. 4A). The addition of more adjuvant (+ CT/MPLA) to the latter [mixed MS2-L2 VLPs (CT/MPLA)] slightly enhanced the immunogenicity of the VLPs but this was not significant. The mice immunized with mixed MS2-L2 VLPs + CT/MPLA were significantly protected from vaginal infection with HPV PsV16 while mice immunized with mixed MS2-L2 VLPs (CT/MPLA) + CT/MPLA elicited suboptimal protection against PsV16 infection (Fig. 4B). Also, the group of mice (SFD mixed MS2-L2 VLPs + CT/MPLA-immunized; Fig. 4B) that showed complete protection from vaginal infection with PsV16 was completely protected from oral infection with the same PsV type (Fig. 4C). 
A)

Reactivity with HPV16 L2(17-31)

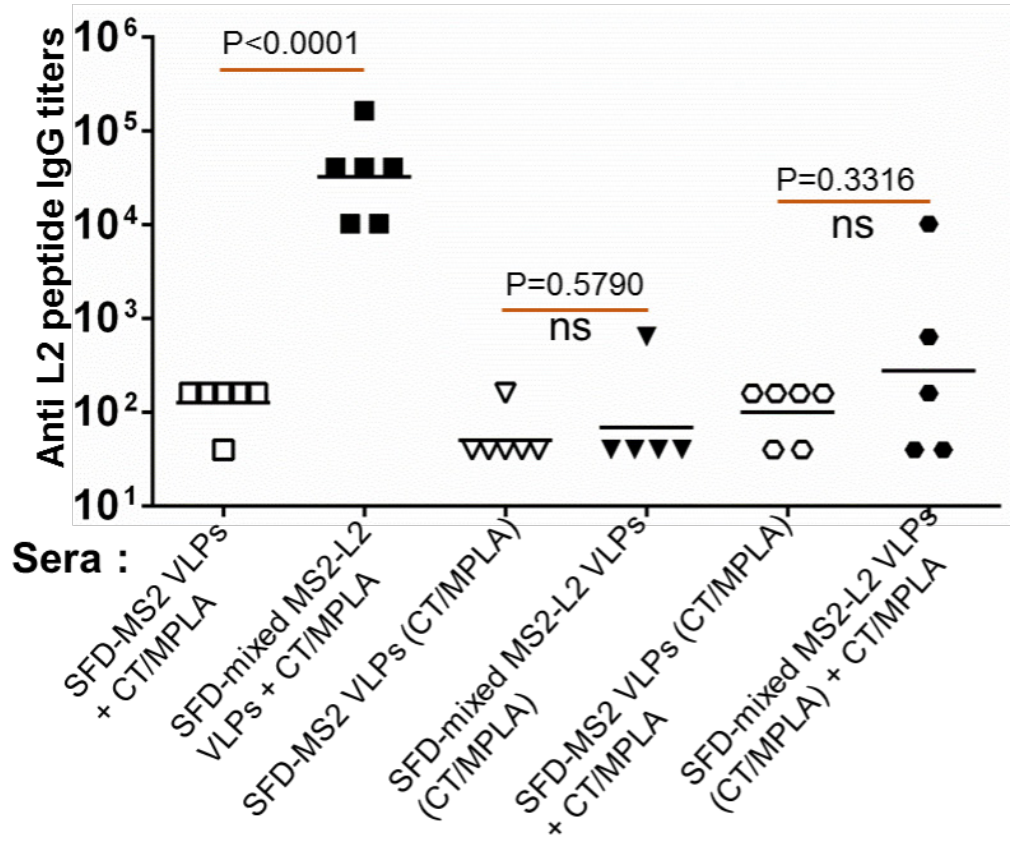

B)

Mice vaginally infected with HPV PsV16

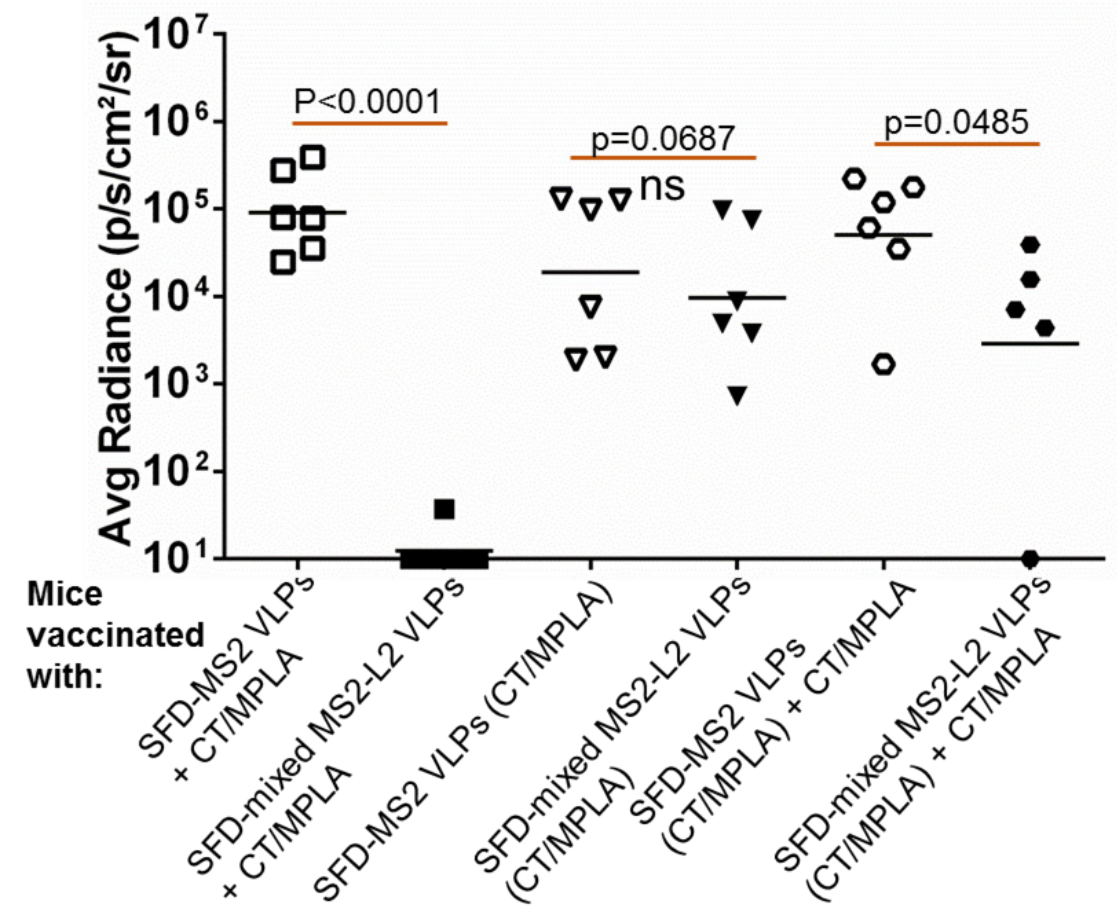


C) SFD-MS2 VLPS + CT/MPLA

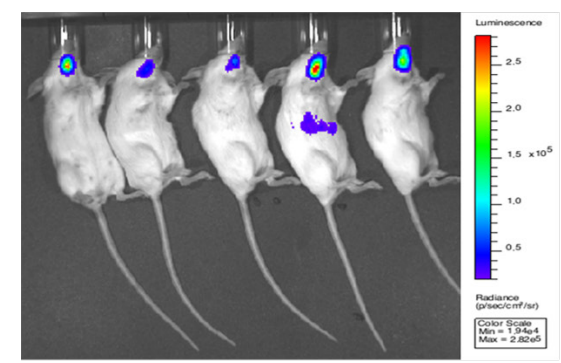

Mice orally infected with HPV PsV16

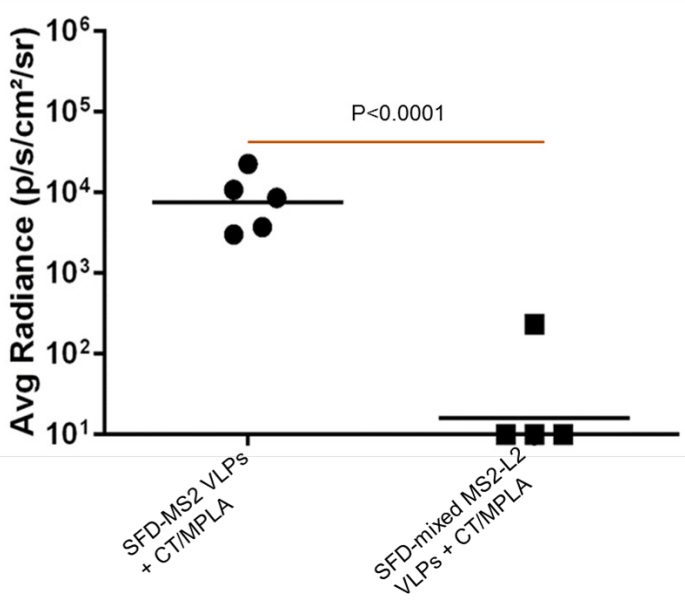

Fig. 4. Buccal immunization with reconstituted SFD mixed MS2-L2 VLPs, vaginal and oral protection from HPV PsV16. Spray-freeze dried VLPs were reconstituted in PBS and mice were immunized thrice with SFD VLPs with/out addition of fresh CT/MPLA adjuvants. A) Sera were collected two weeks after the last immunization and anti-L2 peptide IgG titers in sera were determined by endpoint dilution ELISA using 16L2 (17-31) peptide. Each datum represents antibody titer in each mouse and the black horizontal lines represent geometric mean for each group. B) The mice in (A) were vaginally challenged with $\sim 3 \times 10^{6} \mathrm{IU}$ of HPV PsV16. C) Mice immunized (buccal injection) with reconstituted SFD mixed MS2-L2 VLPs or control MS2 VLPs (in the presence of fresh CT/MPLA adjuvants) were orally challenged with $\sim 7 \times 10^{6}$ IU of PsV16. Each datum represents average radiance of an individual mouse and the lines represent the geometric mean for each group. The P-values for ELISAs and infection assays 
were determined by unpaired two-tailed t-test and unpaired one-tailed t-test, respectively.

\subsubsection{SFD mixed VLPs are thermostable at room temperature for up to 60} days and elicit protective responses

To evaluate if spray-freeze dried VLPs are thermostable, the VLPs (SFD without adjuvants; Fig. 5A) were stored at room temperature and $4^{\circ} \mathrm{C}$ for 60 days and their integrities were assessed using TEM. As shown in Figs. 5B and 5C, SFD VLPs stored at either temperature did not disintegrate during storage; their integrities look similar to freshly prepared non-SFD VLPs (Fig. 5D). Moreover, buccal immunization with the SFD mixed MS2-L2 VLPs (stored at room temperature for 60 days) protected mice from oral infection with HPV PsV16 (Fig. $6)$. 
A)
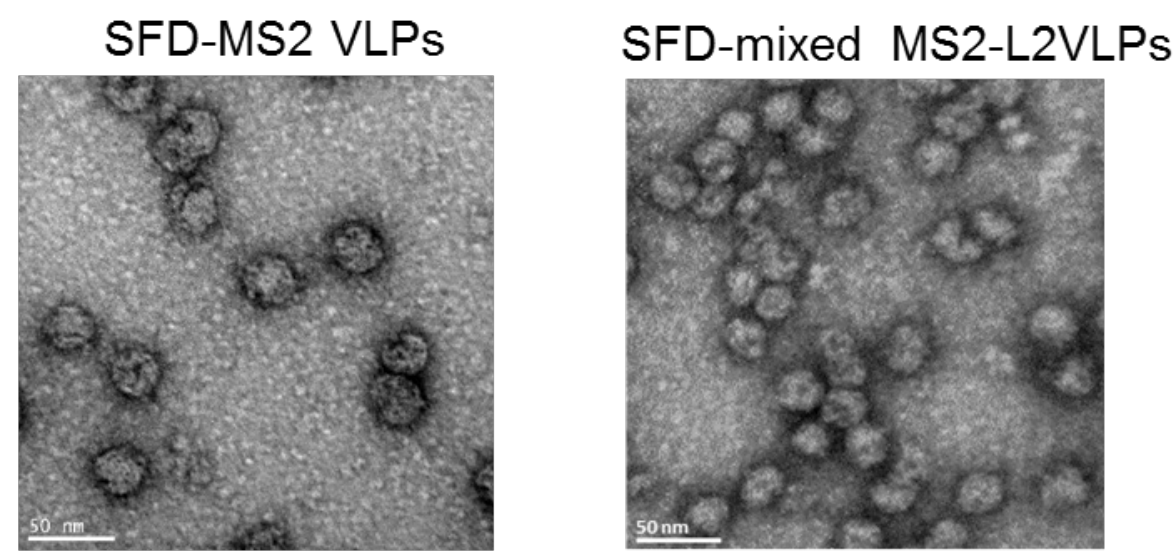

B)
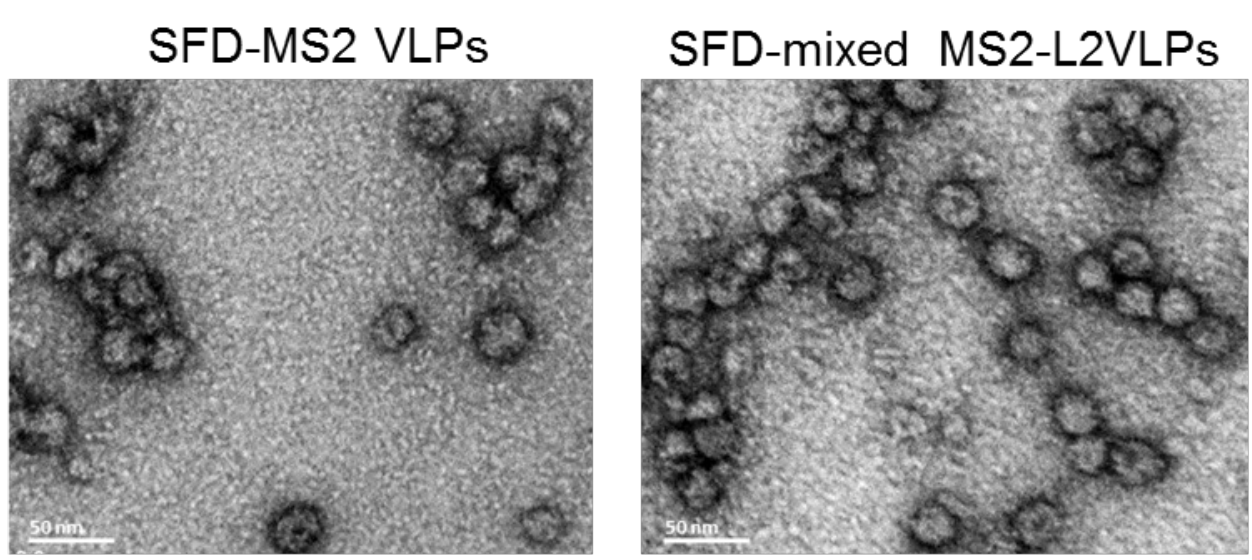

C)
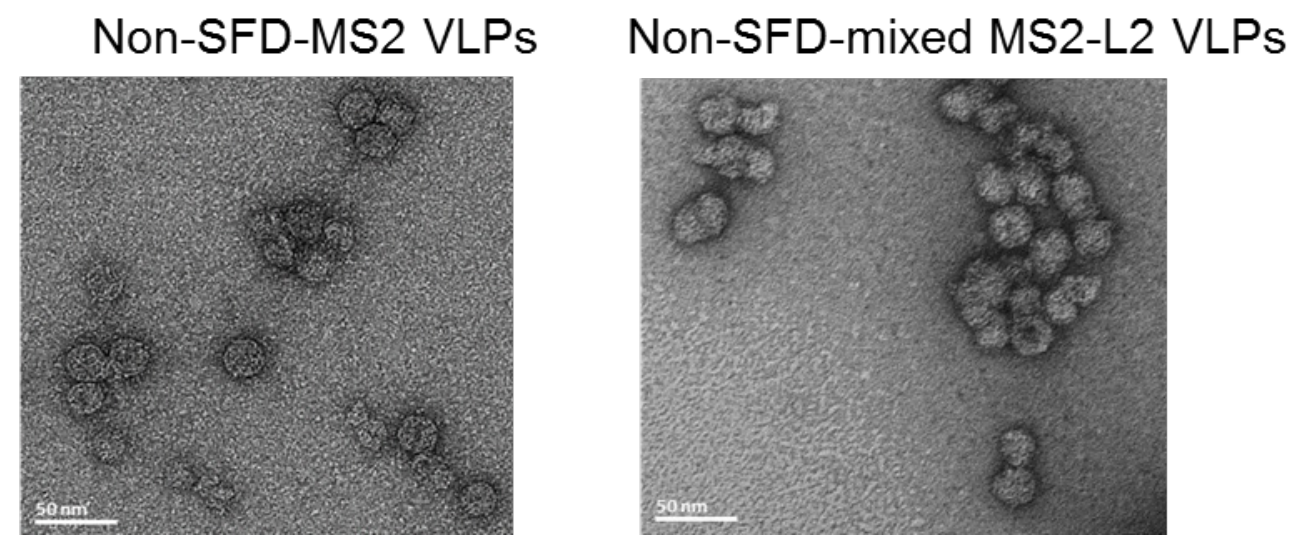

Fig. 5. TEM images of SFD VLPs after two months storage. Mixed MS2-L2 VLPs and MS2 control VLPs spray-freeze dried without adjuvants were loaded into capsules, sealed in amber-colored Wheaton glass bottles, and purged with 
nitrogen gas (A). The vials with the VLPs were stored at room temperature or 4 ${ }^{\circ} \mathrm{C}$ for 60 days. After 60 days, the spray-freeze dried VLPs were removed from the capsules, reconstituted in PBS buffer. TEM was done and images of the VLPs stored at: B) room temperature and C) $4{ }^{\circ} \mathrm{C}$ taken. The VLPs were compared to non-SFD VLPs (D). Images were taken at 30,000X magnification.

A)

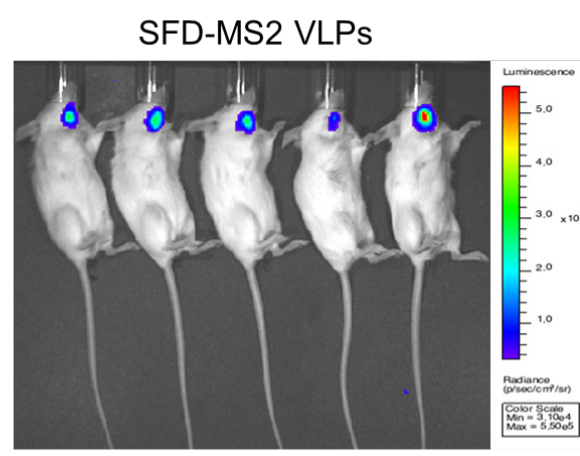

SFD-mixed MS2-L2VLPS

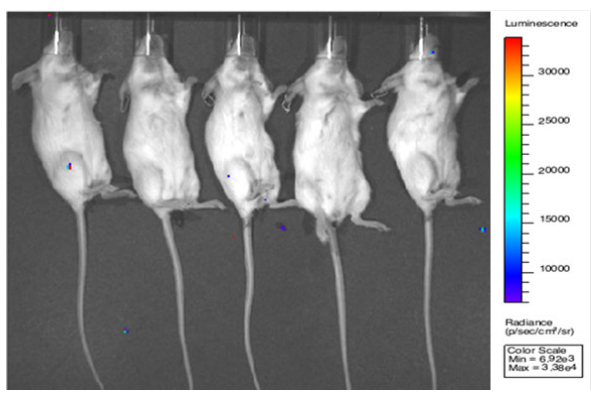

Mice orally infected with HPV PsV16

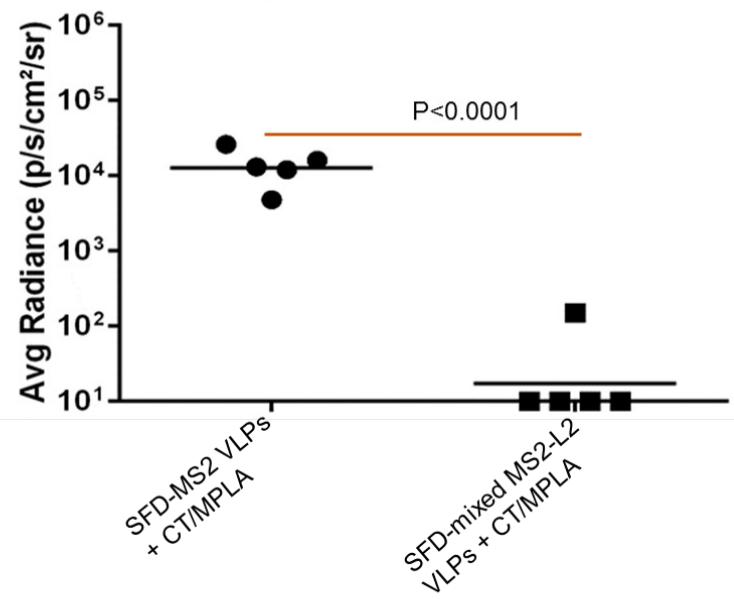

Fig. 6. Buccal immunization with reconstituted SFD mixed MS2-L2 VLPs after 60-day storage and oral protection from HPV PsV16. Spray-freeze dried VLPs were reconstituted in PBS after 60-day storage at room temperature. The reconstituted VLPS in the presence of fresh CT/MPLA adjuvants were used to immunize mice thrice. Immunized mice were orally challenged with $7 \times 10^{6} \mathrm{IU}$ of HPV PsV16. Each datum represents the average radiance of an individual 
mouse and the lines represent the geometric mean for each group. The P-values were determined by unpaired one-tailed t-test.

\subsection{Discussion}

$\mathrm{HPV}$-associated HNCs are on the rise especially oropharyngeal squamous cell carcinomas (OPSCC), a type of HPV+HNC. The number of HPV-associated OPSSCs has increased by more than $225 \%$ within the last half of the century due to an increase in the number of people engaged in oral sex (a route of transmission) $[11,13,36,37]$. It has been suggested that if the trend continues, the number of HPV+OPSCCs will surpass those of cervical cancer cases in the United States [13]. While there are validated methods (Pap smears) to screen for cervical cancer, there are no validated methods to screen for HNCs, thus making early preventive interventions for HNCs very challenging. Preventive measures therefore have to rely on preventing HPV infection of the head and neck region during oral sex.

Two prophylactic vaccines (Gardasil-9 and Cervarix; Gardasil-4 is discontinued) are currently approved to protect against HPV infection. Gardasil-4, which protected against HPV6, HPV11, HPV16 and HPV18 has been shown to elicit oral IgG antibodies [38, 39], oral antibodies neutralize/protect against HPV6, HPV16, HPV18 [40, 41], and reduce oral prevalence of vaccine types (HPV types included in the vaccine) in vaccinees [42-44]. However, a protective effect of the 
vaccine on HPV types not included in the vaccine was not observed. The second-generation HPV vaccine, Gardasil-9, has VLPs from seven oncogenic HPV types (HPV16, 18, 31, 33, 45, 52, 58) and two non-oncogenic HPV types (HPV6, 11) included in the vaccine $[6,45,46]$. Although no studies have assessed the efficacy of the vaccine against oral HPV infection, like Gardasil-4, it is anticipated that the vaccine will offer oral protection against HPV types included in the vaccine; Gardasil-9 is therefore expected to protect against $\sim 93 \%$ $\mathrm{HPV}+\mathrm{HNCs}$ and $>90 \%$ recurrent respiratory papillomatosis, respectively, based on the implication of each HPV type in HNCs $[6,16,18]$. As an alternative to Gardasil-9, we developed a bacteriophage-based MS2-L2 VLP candidate vaccine against HPVs [22]. Mixed MS2-L2 VLPs [a mixture of MS2-31L2/16L2 and MS2-consL2(69-86)] neutralized and offered vaginal protection against six oncogenic HPV pseudovirus types (HPV16, 18, 31, 33, 45 and HPV58 associated with $\sim 87 \%$ of cervical cancer) following intramuscular immunization. It has been reported that mucosal vaccines compared to injectable vaccines provide additional secretory antibody protection against pathogens at mucosal site [47]. Here, we assessed the immunogenicity of mixed MS2-L2 VLPs following oral immunization in the presence of two mucosal adjuvant combinations, cholera toxin and MPLA, that target different immune response pathways. Cholera toxin is a mucosal adjuvant that binds to ganglioside receptors (on all cells including epithelial cells, dendritic cells, macrophages, Band T-lymphocytes) [48-50] and activates the mitogen activated protein kinase (MAPK) signal transduction pathway thus activating the immune system. MPLA, 
an approved vaccine adjuvant, binds to toll-like receptors (TLR4 on B cells, dendritic cells, and macrophages) and activates the MyD88 signaling pathway, which also activates the immune system $[48,49]$. Our results show that buccal immunization of mixed MS2-L2 VLPs without adjuvant offers only suboptimal protection from vaginal infection (Fig. 1B). However, in the presence of one of the two mucosal adjuvants (cholera toxin and MPLA), the protection level was enhanced; moreover, robust protection was observed when the two-adjuvant combinations were used in immunization (Figs. 1B \& 1C); these results are consistent with previous studies, which showed that the immunogenicity of an antigen, as well as the longevity of response, can be enhanced by immunizing with more than one adjuvant combination [51-55]. These results suggest that targeting different immune signaling pathways, simultaneously, is a better strategy to enhance mucosal immune responses at the genital and the oral regions. This was further demonstrated by the level of protection observed at the oral region. Mixed MS2-L2 VLPs protected against five HPV types (HPV16, 35, 39,58 ) associated with $\sim 80 \%$ of $\mathrm{HNCs}$ (Figs. $2 \mathrm{~A}$ and $2 \mathrm{~B}$ ). The protection levels against HPV PsVs 35 \& 39 were superior to that offered by Gardasil-9 vaccine (which does not include HPV35 \& 39 virus-like particles). To the best of our knowledge, this is the first study that has assessed oral protection using diverse HPV pseudovirus types and has assessed, simultaneously, protection at the oral $\&$ the genital regions in the same mice. For example, the groups of mice infected orally with PsV35 (Fig. 2B) were simultaneously infected vaginally with PsV56 (Fig. 1C). 
In a previous study, we observed that an MS2 VLP, MS2-16L2, with an HPV L2 insertion (amino acid 17-31 from HPV16) disintegrated when stored at room temperature for 1 month [56]; this made the MS2-16L2 VLPs less suitable for developing countries with poorly developed refrigeration \& temperaturemonitoring infrastructures for transportation and storage of vaccines. To this end, we assessed the potential of formulating mixed MS2-L2 VLPs together with cholera toxin and MPLA into a dry powder, with the ultimate goal of enhancing its thermostability of the candidate vaccine. We SFD the VLPs together with the adjuvants. However, the VLPs agglomerated when SFD with the adjuvants and were not immunogenic even with the addition of more adjuvant prior to immunization (Fig. 4A). Given this setback, we tried another technique, spray drying, to formulate the VLPs into dry powder; however, similar results (agglomeration) were obtained (data not shown). These results are consistent with other studies, which showed that spray drying of vaccines with adjuvant (alum) lead to vaccine agglomeration [57]. Taken together, these results suggest that certain antigens may not be amenable to SFD or spray drying with adjuvants. Irrespective of this, the mixed MS2-L2 VLPs were successfully SFD into dry powder without the adjuvants and could be stored at room temperature, without the VLPs disintegrating, for up to 60 days (Figs. 3 and 5). Moreover, the SFD VLPs offered robust protection from oral HPV infection.

In summary, the display of a concatemer of epitope 17-31 from HPV16L2 \& epitope 20-31 from HPV31 on one VLP and the display of consensus epitope 69- 
86 on another VLP [22] is an excellent approach to elicit broad protection against diverse HPV types. Mixed MS2-L2 VLPs [MS2-31L2/16L2 VLPs and MS2consL2(69-86)] is a candidate HPV vaccine with the potential to offer protection against multiple HPV types at the oral and genital regions. In a previous study [22], we showed that the candidate vaccine offers protection from genital infection against six oncogenic HPV types (HPV16 18, 31, 33, 45, and 58). Our colleague has also shown that the candidate vaccine prevents oral infection from HPV 52 and genital infection from HPV 56 and HPV11 (data not shown). In the current study, we show that the candidate vaccine offers protection from genital with HPV PsVs 53 and protection from oral infection with HPV PsVs 16, 35, 39, 58. Although we did not assess, in the current study, protection from oral infection with HPV PsVs 18, 31, 33, 45, 53, 56 and PsV11, we expect immunized mice to offer oral protection against these viruses given the level of protection that was observed at the vaginal region with these PsVs in our previous [22]. This view is supported by the fact that mice immunized with the mixed MS2-L2 VLPs, in our previous study [22], protected the mice from vaginal infection with HPV PsV16 (at levels similar to Gardasil-9) and similar levels of protection against PsV16 were observed at the oral region in the current study. Overall, mixed MS2-L2 VLPs has the potential to orally protect against eleven oncogenic HPV types $(16,18,31,33,35,39,45,52,53,56$, and 58$)$ associated with $\sim 99 \%$ of HNCs (estimates are based on the contribution of each HPV type to HNCs [16-19]). The candidate vaccine also has the potential to protect, genitally, against the same eleven oncogenic HPV types associated with $\sim 95 \%$ of cervical 
cancer (estimates are based on the contribution of each HPV type to cervical cancer $[6,58])$. The candidate vaccine also shows protection against HPV11 associated with $19-32 \%$ of recurrent respiratory papillomatosis $[59,60]$ and $36 \%$ of genital warts [61, 62]. Thus, mixed MS2-L2 VLPs is a next generation HPV vaccine that should be evaluated further, especially for patients infected with HIV or are suffering from AIDS. HPV type distribution in HIV patients seems to be different from the normal population [6]; in addition to the other HPV types (16, $18,31,33,45,52,58)$ that are common in the normal population, HIV patients are infected or co-infected mostly with HPV35, 39, 53, 56, which are all protected by mixed MS2-L2 VLPs. 


\subsection{References}

1. Burk, R.D., A. Harari, and Z. Chen, Human papillomavirus genome variants. Virology, 2013. 445(1-2): p. 232-43.

2. Chen, Z., et al., Classification and evolution of human papillomavirus genome variants: Alpha-5 (HPV26, 51, 69, 82), Alpha-6 (HPV30, 53, 56, 66), Alpha-11 (HPV34, 73), Alpha-13 (HPV54) and Alpha-3 (HPV61). Virology, 2018. 516: p. 86-101.

3. Karolinska, I., INTERNATIONAL HUMAN PAPILLOMAVIRUS (HPV) Reference Center. Avaiable at: http://www.nordicehealth.se/hpvcenter/reference clones/. 2018.

4. Garland, S.M., et al., Human Papillomavirus Genotypes From Vaginal and Vulvar Intraepithelial Neoplasia in Females 15-26 Years of Age. Obstet Gynecol, 2018. 132(2): p. 261-270.

5. Shah, A., et al., Oral sex and human papilloma virus-related head and neck squamous cell cancer: a review of the literature. Postgrad Med J, 2017. 93(1105): p. 704-709.

6. Zhai, L. and E. Tumban, Gardasil-9: A global survey of projected efficacy. Antiviral Res, 2016. 130: p. 101-9.

7. Crow, J.M., HPV: The global burden. Nature, 2012. 488(7413): p. S2-3.

8. Boscolo-Rizzo, P., et al., New insights into human papillomavirus-associated head and neck squamous cell carcinoma. Acta Otorhinolaryngol Ital, 2013. 33(2): p. 77-87.

9. Leslie, S.W. and S. Kumar, Genital Warts, in StatPearls. 2018: Treasure Island (FL).

10. Berman, T.A. and J.T. Schiller, Human papillomavirus in cervical cancer and oropharyngeal cancer: One cause, two diseases. Cancer, 2017. 123(12): p. 22192229.

11. D'Souza, G., et al., Differences in the Prevalence of Human Papillomavirus $(H P V)$ in Head and Neck Squamous Cell Cancers by Sex, Race, Anatomic Tumor Site, and HPV Detection Method. JAMA Oncol, 2016.

12. Gelwan, E., et al., Nonuniform Distribution of High-risk Human Papillomavirus in Squamous Cell Carcinomas of the Oropharynx: Rethinking the Anatomic 
Boundaries of Oral and Oropharyngeal Carcinoma From an Oncologic HPV Perspective. Am J Surg Pathol, 2017. 41(12): p. 1722-1728.

13. Chaturvedi, A.K., et al., Human papillomavirus and rising oropharyngeal cancer incidence in the United States. J Clin Oncol, 2011. 29(32): p. 4294-301.

14. Fortes, H.R., et al., Recurrent respiratory papillomatosis: A state-of-the-art review. Respir Med, 2017. 126: p. 116-121.

15. Sanchez, G.I., et al., Human papillomavirus genotype detection in recurrent respiratory papillomatosis (RRP) in Colombia. Head Neck, 2013. 35(2): p. 22934.

16. Kreimer, A.R., et al., Human papillomavirus types in head and neck squamous cell carcinomas worldwide: a systematic review. Cancer Epidemiol Biomarkers Prev, 2005. 14(2): p. 467-75.

17. Ndiaye, C., et al., HPV DNA, E6/E7 mRNA, and p16INK4a detection in head and neck cancers: a systematic review and meta-analysis. Lancet Oncol, 2014. 15(12): p. 1319-31.

18. Castellsague, X., et al., HPV Involvement in Head and Neck Cancers: Comprehensive Assessment of Biomarkers in 3680 Patients. J Natl Cancer Inst, 2016. 108(6): p. djv403.

19. de Martel, C., et al., Worldwide burden of cancer attributable to HPV by site, country and HPV type. Int J Cancer, 2017. 141(4): p. 664-670.

20. Administration, U.S.F.a.D., Gardasil 9. 2018.

21. Administration, U.S.F.a.D., Cervarix. 2018.

22. Zhai, L., et al., A novel candidate HPV vaccine: MS2 phage VLP displaying a tandem HPV L2 peptide offers similar protection in mice to Gardasil-9. Antiviral Res, 2017. 147: p. 116-123.

23. Gambhira, R., et al., A protective and broadly cross-neutralizing epitope of human papillomavirus L2. J Virol, 2007. 81(24): p. 13927-31.

24. Kondo, K., et al., Neutralization of HPV16, 18, 31, and 58 pseudovirions with antisera induced by immunizing rabbits with synthetic peptides representing segments of the HPV16 minor capsid protein L2 surface region. Virology, 2007. 358(2): p. 266-72.

25. Schellenbacher, C., R.B.S. Roden, and R. Kirnbauer, Developments in L2-based human papillomavirus (HPV) vaccines. Virus Res, 2017. 231: p. 166-175. 
26. Tumban, E., et al., VLPs displaying a single L2 epitope induce broadly crossneutralizing antibodies against human papillomavirus. PLoS One, 2012. 7(11): p. e49751.

27. Cuburu, N., et al., Sublingual immunization with nonreplicating antigens induces antibody-forming cells and cytotoxic T cells in the female genital tract mucosa and protects against genital papillomavirus infection. J Immunol, 2009. 183(12): p. 7851-9.

28. Maseda, Y., et al., Mucosal and systemic immune response to sublingual or intranasal immunization with phosphorylcholine. Auris Nasus Larynx, 2018. 45(2): p. 273-280.

29. Baldridge, J.R., et al., Monophosphoryl lipid A enhances mucosal and systemic immunity to vaccine antigens following intranasal administration. Vaccine, 2000. 18(22): p. 2416-25.

30. Childers, N.K., et al., Adjuvant activity of monophosphoryl lipid A for nasal and oral immunization with soluble or liposome-associated antigen. Infect Immun, 2000. 68(10): p. 5509-16.

31. Tonnis, W.F., et al., Improved storage stability and immunogenicity of hepatitis $B$ vaccine after spray-freeze drying in presence of sugars. Eur J Pharm Sci, 2014. 55: p. 36-45.

32. Ali, M.E. and A. Lamprecht, Spray freeze drying for dry powder inhalation of nanoparticles. Eur J Pharm Biopharm, 2014. 87(3): p. 510-7.

33. Kunda, N.K., et al., A stable live bacterial vaccine. Eur J Pharm Biopharm, 2016. 103: p. 109-117.

34. Tumban, E., et al., A pan-HPV vaccine based on bacteriophage PP7 VLPS displaying broadly cross-neutralizing epitopes from the HPV minor capsid protein, L2. PLoS One, 2011. 6(8): p. e23310.

35. Roberts, J.N., et al., Genital transmission of HPV in a mouse model is potentiated by nonoxynol-9 and inhibited by carrageenan. Nat Med, 2007. 13(7): p. 857-61.

36. Chaturvedi, A.K., et al., Worldwide trends in incidence rates for oral cavity and oropharyngeal cancers. J Clin Oncol, 2013. 31(36): p. 4550-9.

37. D'Souza, G., et al., Oral sexual behaviors associated with prevalent oral human papillomavirus infection. J Infect Dis, 2009. 199(9): p. 1263-9. 
38. Pinto, L.A., et al., Quadrivalent Human Papillomavirus (HPV) Vaccine Induces HPV-Specific Antibodies in the Oral Cavity: Results From the Mid-Adult Male Vaccine Trial. J Infect Dis, 2016. 214(8): p. 1276-83.

39. Parker, K.H., et al., Evaluation of HPV-16 and HPV-18 specific antibody measurements in saliva collected in oral rinses and merocel $(R)$ sponges. Vaccine, 2018. 36(19): p. 2705-2711.

40. Handisurya, A., et al., Human papillomavirus vaccination induces neutralising antibodies in oral mucosal fluids. Br J Cancer, 2016. 114(4): p. 409-16.

41. Ahn, J., et al., Prophylactic immunization with human papillomavirus vaccines induces oral immunity in mice. Laryngoscope, 2018. 128(1): p. E16-E20.

42. Hirth, J.M., et al., Prevalence of oral human papillomavirus by vaccination status among young adults (18-30years old). Vaccine, 2017. 35(27): p. 3446-3451.

43. Chaturvedi, A.K., et al., Effect of Prophylactic Human Papillomavirus (HPV) Vaccination on Oral HPV Infections Among Young Adults in the United States. J Clin Oncol, 2018. 36(3): p. 262-267.

44. HPV Vaccine Slashes Rates of Oral Infection. Cancer Discov, 2017. 7(7): p. OF6.

45. Cuzick, J., Gardasil 9 joins the fight against cervix cancer. Expert Rev Vaccines, 2015. 14(8): p. 1047-9.

46. Zhang, Z., et al., Expanded strain coverage for a highly successful public health tool: Prophylactic 9-valent human papillomavirus vaccine. Hum Vaccin Immunother, 2017. 13(10): p. 2280-2291.

47. Rhee, J.H., S.E. Lee, and S.Y. Kim, Mucosal vaccine adjuvants update. Clin Exp Vaccine Res, 2012. 1(1): p. 50-63.

48. Freytag, L.C. and J.D. Clements, Mucosal adjuvants. Vaccine, 2005. 23(15): p. 1804-13.

49. Cox, E., et al., Adjuvants modulating mucosal immune responses or directing systemic responses towards the mucosa. Vet Res, 2006. 37(3): p. 511-39.

50. Bharati, K. and N.K. Ganguly, Cholera toxin: a paradigm of a multifunctional protein. Indian J Med Res, 2011. 133: p. 179-87.

51. Song, J.H., et al., Sublingual vaccination with influenza virus protects mice against lethal viral infection. Proc Natl Acad Sci U S A, 2008. 105(5): p. 1644-9. 
52. Zhang, C., B. Wang, and M. Wang, GM-CSF and IL-2 as adjuvant enhance the immune effect of protein vaccine against foot-and-mouth disease. Virol J, 2011. 8: p. 7.

53. Toubaji, A., et al., The combination of GM-CSF and IL-2 as local adjuvant shows synergy in enhancing peptide vaccines and provides long term tumor protection. Vaccine, 2007. 25(31): p. 5882-91.

54. Ma, X., et al., The effects of GM-CSF and IL-5 as molecular adjuvants on immune responses and contraception induced by mZP3 DNA vaccination. Am J Reprod Immunol, 2012. 68(6): p. 476-85.

55. O'Neill, E., et al., Protection by SIV VLP DNA prime/protein boost following mucosal SIV challenge is markedly enhanced by IL-12/GM-CSF coadministration. J Med Primatol, 2002. 31(4-5): p. 217-27.

56. Tumban, E., et al., Preclinical refinements of a broadly protective VLP-based $H P V$ vaccine targeting the minor capsid protein, L2. Vaccine, 2015. 33(29): p. 3346-53.

57. Maa, Y.F., et al., Stabilization of alum-adjuvanted vaccine dry powder formulations: mechanism and application. J Pharm Sci, 2003. 92(2): p. 319-32.

58. de Sanjose, S., et al., Human papillomavirus genotype attribution in invasive cervical cancer: a retrospective cross-sectional worldwide study. Lancet Oncol, 2010. 11(11): p. 1048-56.

59. Omland, T., et al., Recurrent respiratory papillomatosis: HPV genotypes and risk of high-grade laryngeal neoplasia. PLoS One, 2014. 9(6): p. e99114.

60. Kocjan, B.J., et al., Identical human papillomavirus (HPV) genomic variants persist in recurrent respiratory papillomatosis for up to 22 years. J Infect Dis, 2013. 207(4): p. 583-7.

61. Sturegard, E., et al., Human papillomavirus typing in reporting of condyloma. Sex Transm Dis, 2013. 40(2): p. 123-9.

62. Chang, L., et al., Distribution of genital wart human papillomavirus genotypes in China: a multi-center study. J Med Virol, 2013. 85(10): p. 1765-74. 


\section{Chapter 3}

\section{Novel Expression of Coat Proteins from Thermophilic}

\section{Bacteriophage ФIN93 and Evaluation for Assembly into}

\section{Virus-like Particles}

\subsection{Abstract}

The structural proteins of viruses can spontaneously assemble to form virus-like particles (VLPs) without the viral genome. VLPs are empty viral shells without the whole viral genome and not infectious. Overexpression of viral coat or envelope proteins in a suitable host cell allows the proteins to self-assemble into VLPs. VLP vaccines such as human papillomaviruses (HPVs) and hepatitis $B$ virus (HBV), have been approved to protect against HPVs and HBV infections, respectively. In addition to this, a large group of researchers are working on adopting VLPs as a display platform to develop chimeric VLPS vaccines displaying heterologous antigens from other viruses, bacteria, parasites and even tumor-associated antigens. However, there are some challenges/limitations using current VLP display platform. For example, there are limitations on the size of a heterologous peptide that can be displayed on a VLP, the VLP not thermostable at room temperature, and pre-existing antibody to the VLP platforms my limit their use to elicit antibodies against heterologous antigens. To address some of these questions, especially thermostability and pre-existing antibodies, we 
decided to explore if two coat proteins, open reading frame (ORF) 13 and ORF14, from a thermophilic bacteriophage, $\Phi$ IN93, can be expressed in E. coli and if the coat proteins can assemble into VLPs. Here, we co-expressed and purified ORF13 and ORF14 proteins from E. coli. Our results seem to suggest that co-expression of two truncated versions of the coat proteins have potential to form structures that resemble VLPs. To the best of our knowledge, this is the first attempt to develop a new thermophilic VLP platform based on $s$ thermophilic bacteriophage.

\subsection{Introduction}

Viral genomes code for structural and non-structural proteins. Non-structural proteins include enzymes required for viral replication while structural proteins are protein components assembled around the viral genome to form a virus particle (virion) and include capsid (coat) proteins and in some cases envelope

proteins [1]. The structural proteins by themselves can also assemble, naturally during the life cycle of a virion, without the viral genome to form structures, known as virus-like particles (VLPs) (reviewed in [2]). VLPs are therefore empty viral shells without the viral genome. VLPs can be generated by cloning and expression of the coat protein(s) or envelope proteins in a suitable host cell. Overexpression of coat proteins or envelope proteins in a host cell allows the proteins to spontaneously self-assemble into VLPs [3, 4]. 
VLPs can be derived from animal viruses, plant viruses, human viruses, and even from bacterial viruses (bacteriophages). VLPs have so many applications in science and in medicine; they can be used in pre-clinical studies to deliver drugs/cargo to specific cancer cells, to develop armored RNA (positive controls for diagnostic tests for infectious diseases), and for in vivo imaging (VLPs loaded with fluorophores). Furthermore, because VLPs resemble viruses in terms of size, multivalency of coat proteins on capid, inability to replicate, and in terms of immunogenicity, they have can also be used to develop vaccines [5-9]. Two VLPs-based vaccines, derived from human papillomaviruses (HPVs) and hepatitis B virus (HBV), have been approved by the Food and Drug Administration (FDA) to protect against HPVs [10, 11] and HBV [2] infections, respectively; other VLPs-based vaccines against viruses are under development or in clinical trials $[12,13]$. VLPs cannot only be used to develop vaccines against viruses from which the structural proteins are derived from but they can also be used as display platforms to develop chimeric VLPs vaccines displaying heterologous antigens from other viruses [14-18], bacteria [19], parasites [20, 21] and even tumor-associated antigens [22]. The goal of chimeric VLPs is to elicit immune response against the heterologous antigens on the platform. Thus, VLPs have been applied to develop candidate vaccines against both microbial and non-microbial diseases [23] ranging from allergy, hypotension, cholesterol [24], to cancer [22]. 
Despite the success of using VLPs as platforms to develop candidate vaccines, there are some challenges associated with current VLPs platforms. Some coat proteins have limitations on the size and the type of heterologous antigens that can be genetically inserted on the coat proteins without affecting the ability of the coat proteins to assemble into VLPs $[5,25,26]$. Additionally, some VLPs are not thermostable; in some cases, thermostability decreases with the insertion of heterologous antigens [27, 28]. Furthermore, most VLPs platforms used for peptide display (chimeric VLPs) including vector platforms, for vaccine design, are derived from viruses that infect humans and/or humans had previously been immunized with VLPs or antigens derived from these viruses. Thus, pre-existing antibodies against the VLPs display platforms in the general population, may compromise the immunogenicity of the display platforms and ultimately that of heterologous antigens displayed on the platforms. [29, 30]. To address some of these challenges, we assessed whether the coat proteins from a bacteriophage, $\Phi I N 93$, can assemble into VLPs. Bacteriophage $\Phi I N 93$ is a thermophilic virus isolated from a thermophilic bacterium, Thermus aquaticus with optimum growth temperature of $75^{\circ} \mathrm{C}$ [31].

Bacteriophage $\Phi \mathrm{IN93}$ is a double-stranded DNA virus with a circular genome size of $\sim 19.4 \mathrm{kbp}$. Two putative coat proteins, open reading frame (ORF) 13 and ORF14, have been identified in the bacteriophage based on sequence homology with the major coat proteins (VP16 and VP17) of another thermophilic bacteriophage, P23-77 [32]. ORF13 and ORF14 of thermophilic bacteriophage 
ФIN93 are $80 \%$ and $73 \%$ identical, respectively, to VP16 and VP17 of P23-77 (Fig. 1). It has been shown that a mixture of VP16, VP17, and VP11 (a minor capsid protein) of P23-77 can form complexes in vitro [33], which is a prelude to assembly/VLPs formation. However, no studies have ever assessed the expression of ORF13 and ORF14 from bacteriophage $\Phi$ IN93 or assessed the ability of these coat proteins to assemble into VLPs. Here, we assessed for the first time, the expression of ORF13 and ORF14 in a bacterial expression system and assessed the potentials of the coat proteins to assemble into VLPS with the long-term goal of developing a novel thermophilic bacteriophage VLPs platform for vaccine design. 
A.

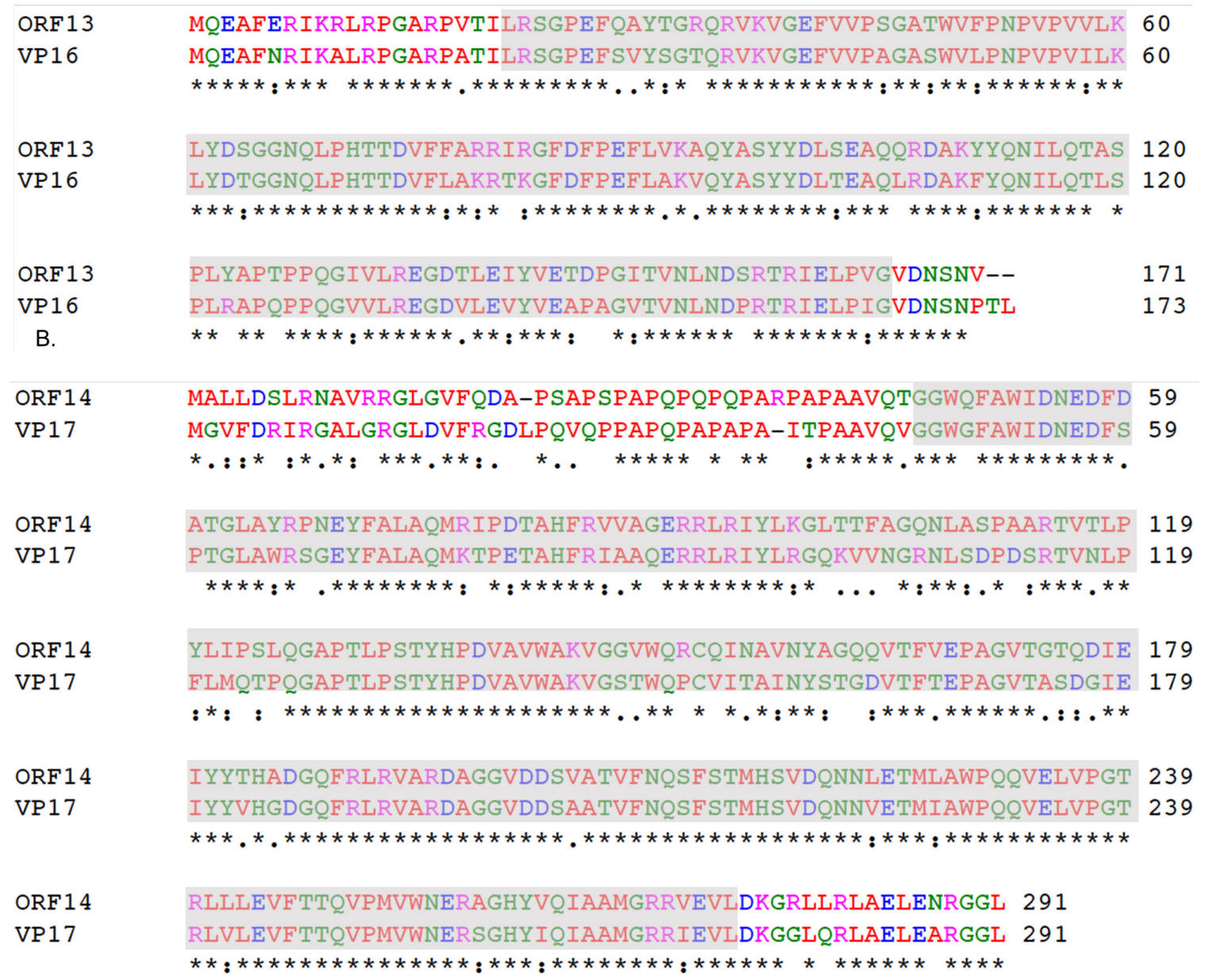

Fig. 1. Sequence alignments of coat proteins of bacteriophages $\Phi I N 93$ and P23-77. Sequence alignment of: A) ORF13 of bacteriophage $\Phi I N 93$ \& VP16 of bacteriophage P23-77 and B) ORF14 of bacteriophage IIN93 \& VP17 of bacteriophage P23-77. Alignments were done using Clustal Omega. Asterisk (*) denotes identical amino acids, colon (:) denotes amino acids with similar properties and period (.) denotes amino acids with weak similar properties. 
Amino acids highlighted in gray-background were used in model structures in Figure 4.

\subsection{Materials and methods}

\subsubsection{Generation of expression vectors}

The genes encoding potential coat proteins (ORF13 and ORF14) of bacteriophage ФIN93 were codon-optimized for high-level protein expression in E coli bacteria and were synthesized by Epoch Life Science. The complete sequence of each gene was separately amplified by polymerase chain reaction (PCR) and cloned into pET28a plasmid (Kanamycin resistance) and pET15b plasmid (Ampicillin resistance) using $\mathrm{Ncol}$ and $\mathrm{BamHI}$ restricted sites; this gave rise to four plasmids, namely: pET15b-ORF14, pET28a-ORF13, pET15b-ORF13, and pET28a-ORF14.

In addition to cloning the complete sequences of ORF13 and OFR14, we also generated truncated versions of each of the two genes. To generate truncated ORF13 and ORF14 genes, DNA sequences representing amino acids (aa) 21-165 and aa 46-271, respectively, were separately amplified by PCR and each truncated gene was cloned into the pET28a and pET15b using the same restriction sites above; this gave rise to four additional plasmids, namely: pET15b-ORF13-trunc with aa 21-165, and pET15b-ORF14-trunc with aa 46-271, 
pET28a-ORF13-trunc with aa 21-165, and pET28a-ORF14-trunc with aa 46-271. In all cases, the genes in each of the constructs were sequenced across restriction sites to confirm the cloning.

\subsubsection{Coat protein expression and purification}

For coat protein expression, C41 E. coli cells were transformed separately with each plasmid and single colonies were screened for protein expression as follows. Bacterial cultures from colonies were grown in Luria-Bertani (LB) medium at $37^{\circ} \mathrm{C}$ until the culture reached an optical density (OD)600 of 0.6 . Coat protein expression was induced with $0.5 \mathrm{mM}$ Isopropyl $\beta$-D-1thiogalactopyranoside (IPTG) overnight at the same temperature. For coexpression of ORF13 and ORF14 in the same bacteria, equal concentrations of pET15b-ORF14 and pET28a-ORF13 or pET28a-ORF14 and pET15b-ORF13 or pET28a-ORF13-trunc and pET15b-ORF14-trunc or pET15b-ORF13-trunc and pET28a-ORF14-trunc were mixed and used to transform C41 cells. Transformed cells were grown in LB medium with $30 \mu \mathrm{g} / \mathrm{ml}$ of kanamycin plus $50 \mu \mathrm{g} / \mathrm{ml}$ of ampicillin at the same temperature until the culture reached an $\mathrm{OD}_{600}$ of 0.6 . Coat protein expression was induced with $1 \mathrm{mM}$ IPTG under the same conditions and time as above. To screen for coat protein expression, bacterial cells were pelleted, resuspended in 8M urea, sonicated and resolved on SDS-PAGE gel. 
Cultures, which showed protein expression, were used to grow large volume cultures $(100 \mathrm{ml}$ or $250 \mathrm{ml})$ for large-scale protein expression and purification. The cultures were grown and induced as above. Cell pellets were then lysed using $0.2 \%$ lysozyme solution (100 mM NaCl, $10 \mathrm{mM}$ EDTA, $50 \mathrm{mM}$ Tris-HCl PH

8.5 plus $0.05 \%$ deoxycholate) and sonicated to help lyse the bacteria. Two ng/ul of DNase and $2 \mathrm{mM}$ of $\mathrm{MgCl}_{2}$ were added to the lysates and the lysates were incubated for 1 hour at $37^{\circ} \mathrm{C}$. Lysates were spun at $3,700 \mathrm{rpm}\left(4^{\circ} \mathrm{C}\right)$ for 30 minutes and the supernatants collected and resuspended in $50 \%$ ammonium sulfate to precipitate coat proteins. The supernatants with precipitated coat proteins were spun at $10,000 \mathrm{rpm}\left(4^{\circ} \mathrm{C}\right)$ for 10 minutes. The pellets were resuspended in sepharose column buffer (SCB: $10 \mathrm{mM}$ Tris-HCl PH 7.4, $100 \mathrm{mM}$ $\mathrm{NaCl}, 0.1 \mathrm{mM} \mathrm{MgSO}_{4}$ ), spun at the same time and conditions. Supernatants were then loaded on sepharose cross-linked CL-4B column and factions were collected. Fractionation tubes containing coat proteins were combined and the SCB buffer was exchange with PBS (1x phosphate buffered saline) using Millipore Amicon ${ }^{\mathrm{TM}}$ Ultra-4 Centrifugal Filter Units (100K MWCO).

\subsubsection{Generation of bacteriophage $\Phi$ IN93}

ФIN93 was amplified and purified as previously described [31]. Briefly, $100 \mathrm{ul}$ of overnight culture $\left(70^{\circ} \mathrm{C}\right)$ of Thermus thermophilus bacterial strain TZ2 was used to inoculate a fresh $\mathrm{A} 2$ medium $(0.1 \%$ tryptone, $0.1 \%$ yeast extract, and 
Castenholtz basal salts $\mathrm{pH} 7.5)$. The culture was grown at $70{ }^{\circ} \mathrm{C}$ for 4 hours and was subsequently inoculated with a plaque of bacteriophage $\Phi I N 93$. Then, the culture was shaking for another 2.5-3 hours until the media became clear (Lysis). The culture was spun down at $3000 \mathrm{rpm}$ for $10 \mathrm{~min}$ and the supernatant which contained phage was saved.

\subsubsection{Transmission electron microscopy (TEM)}

To assess the potential of coat proteins to assemble into VLPs, TEM was conducted as follows. Purified coat proteins of bacteriophage $\Phi I N 93$ or the virus were loaded onto glow-discharged carbon grids for 2 minutes and then grids were stained with $2 \%$ uranyl acetate for 2 minutes. Samples were visualized at a magnification of $10,000 \mathrm{X}$.

\subsubsection{Generation of sera for immunoassays}

To generate sera that can react with both ORF13 and ORF14, we expressed ORF13 and ORF14 in pET28a as a recombinant protein with three amino acids, glycine-serine-serine, linker sequence in-between the two proteins. Expression and purification were done as described above. To generate sera, 3-4 week-old female Balb/c mice were immunized three times, intramuscularly, with $10 \mu \mathrm{g}$ of 
purified recombinant protein (ORF13 + ORF14); all immunizations were done at two-week intervals in the presence of alum adjuvant. Two weeks after the last immunization, sera were collected and used for western blots against ORF13 and ORF14 coat proteins. Animal work was conducted in accordance with Michigan Tech Institutional Animal Care and Use Committee (IACUC) guidelines.

\subsubsection{Western blots}

One hundred ng of purified $\Phi I N 93$ coat proteins, bacteriophage $\Phi I N 93$, and control MS2 coat proteins were resolved on an SDS-PAGE gel and transferred to polyvinylidene fluoride (PVDF) membranes. The membranes were then blocked overnight with $5 \%$ non-fat milk followed by the addition of 1:1,000 dilution antiORF13 + ORF14 sera. The membranes were incubated for 2 hours at room temperature, washed, and 1:5,000 dilution of horseradish peroxide (HRP)conjugated goat anti-mouse IgG antibodies were added for 1 hour at the same temperature. The membranes were then washed, developed with enhanced chemiluminescent substrate, and scanned using Luminescent Image Analyzer (LAS-4000). 


\subsection{Results}

\subsubsection{ORF13 and ORF14 can be successfully expressed in E. coli}

To assess whether ORF13 and ORF14 coat proteins can be expressed in E. coli, given the fact that the coat proteins are derived from a thermophilic bacteriophage, we first generated expression vectors, pET15b-ORF14 and pET28a-ORF13, each with complete sequences of ORF14 and ORF13, respectively (Fig. 2). As shown in Fig. 2A, the coat proteins were successfully expressed in C41 E. coli cells. However, the expression level of ORF13 in pET28a seemed to be high compared to that of ORF14 in pET15b. To assess if the difference in expression level was due to the expression vectors used or the genes cloned to the expression vectors, we swapped the genes in the expression vectors by cloning ORF13 gene into pET15b and ORF14 gene into pET28a (Fig. 2B). The expression level of ORF14 from pET28a vector was still low compared to that of ORF13 from pET15b vector (Fig. 2A), suggesting that the gene and not the expression vector was associated with the differences in expression levels. 
A.

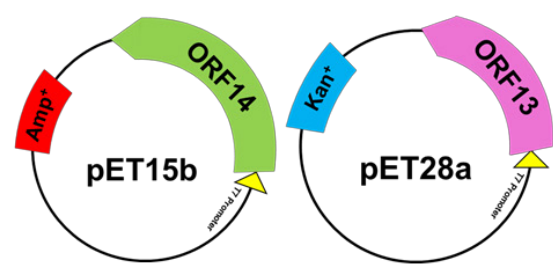

pET15b-ORF14 pET28a-ORF13

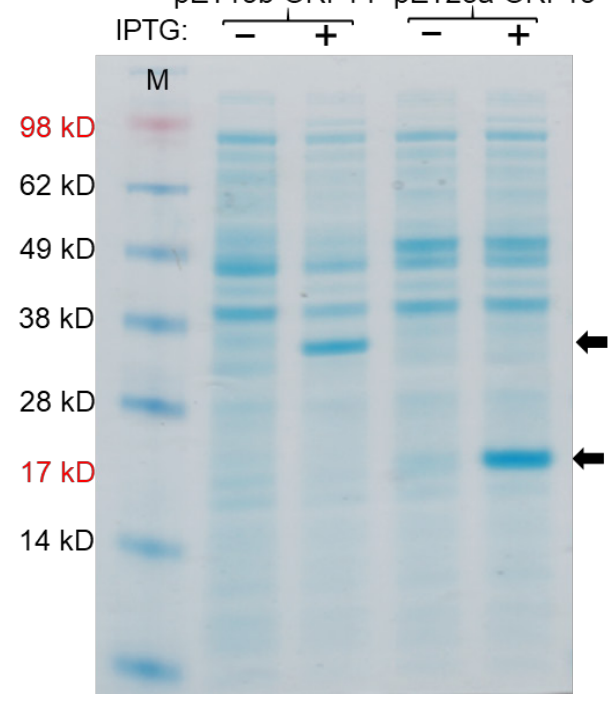

B.

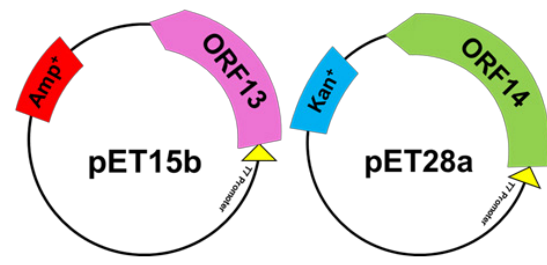

pET15b-ORF13 pET28a-ORF14

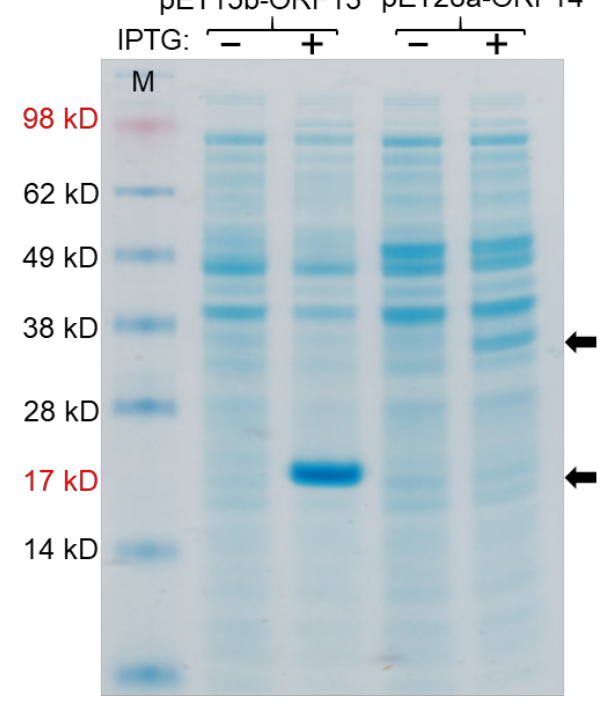

Fig. 2. Expression of coat proteins, ORF13 and ORF14, in pET15b and pET28a vectors in C41 cells. A) Plasmids pET15b-ORF14 or pET28a-ORF13 and B) plasmids pET15b-ORF13 or pET28a-ORF14 were used to transformed C41 E. coli cells. The bacteria were grown at $37^{\circ} \mathrm{C}$ and protein express was induced with $0.5 \mathrm{mM} \mathrm{IPTG}$. Cell pellets were lysed with $8 \mathrm{M}$ Urea and loaded on SDS-PAGE gel for analysis. Gels were stained with Coomassie blue. Arrows indicate coat protein bands of ORF13 (18.81 KD) and ORF14 (32.01 KD). (-) is uninduced culture and (+) is induced IPTG culture. M=Molecular weight marker.

To assess whether ORF13 and ORF14 coat proteins can be expressed in the same bacteria, on the assumption that the two are required for assembly into 
VLPs, we co-transformed C41 cells with two different combinations of expression vectors, pET15b-ORF14 and pET28a-ORF13 or pET28a-ORF14 and pET15bORF13. Both proteins were co-expressed in bacteria regardless of the combinations used (Fig. 3A). However, in pET15b-ORF14 and pET28a-ORF13 combination, ORF13 was expressed at high levels compared to ORF14 (results are similar to expression of the proteins, separately, above). In pET28a-ORF14 and pET15b-ORF13 combination, both proteins seemed to be expressed at similar levels (with ORF14 expression slightly higher). To assess whether ORF13 and ORF14 coat proteins (complete sequences) can assemble into VLPs, TEM analysis was conducted using co-expressed coat proteins. Unfortunately, none of the expressed coat proteins from the plasmid combinations, pET15b-ORF14 and pET28a-ORF13 or pET28a-ORF14 and pET15b-ORF13, assembled into VLPs. To confirm that the purified coat proteins were proteins of interest, we did a western blot using anti-ORF13 + ORF14 antibodies. As shown in Fig. 3B, the antibodies reacted with both proteins as well as with our positive controls, ORF13 and ORF14, from the bacteriophage $\Phi I N 93$. 
A. Co-transformation-1
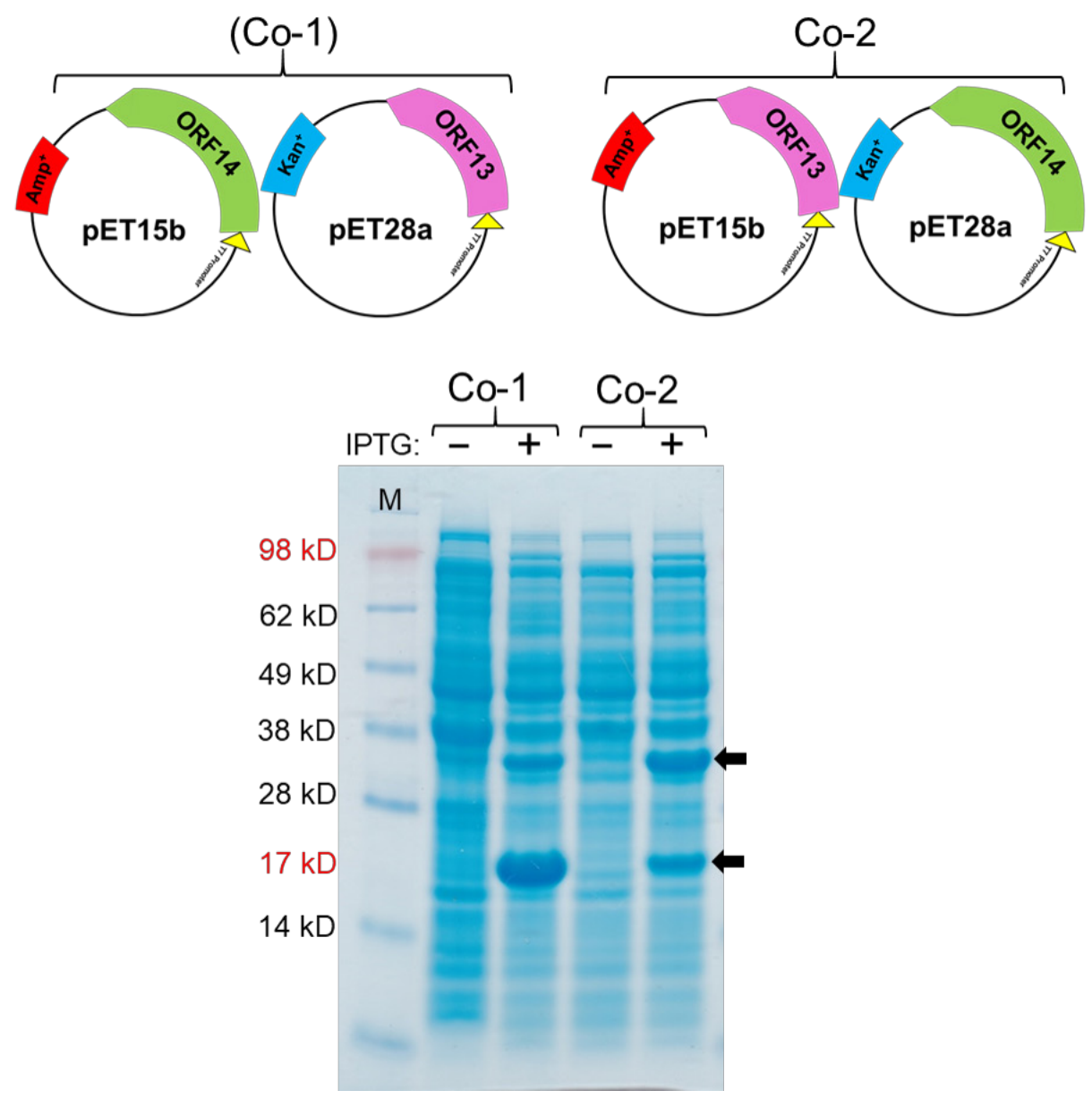

B.

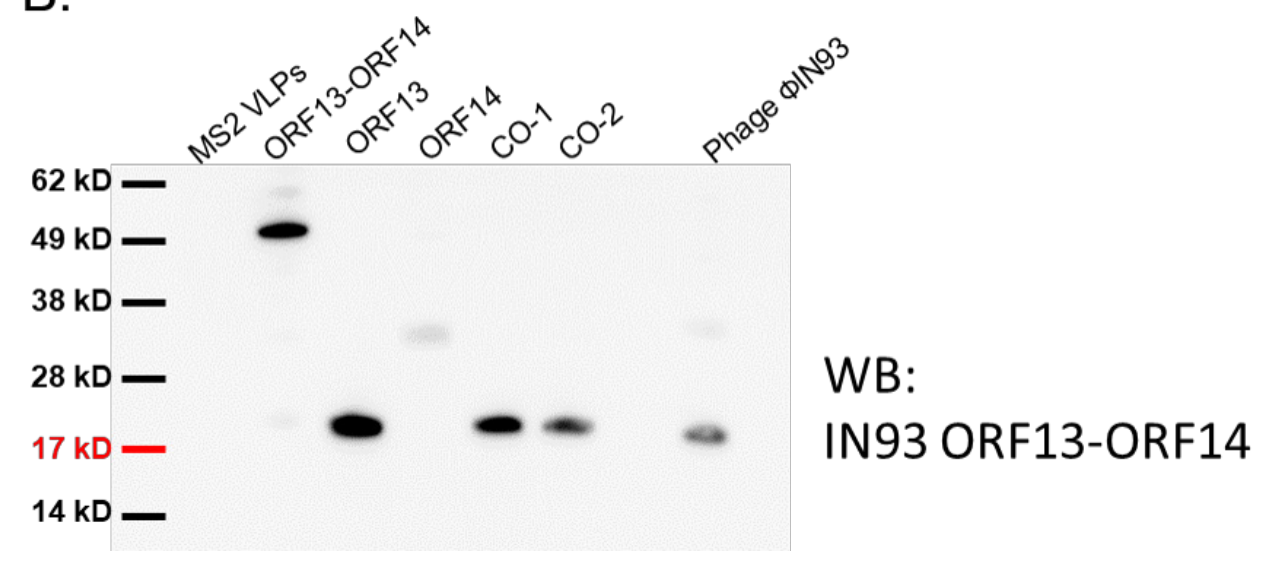


Fig. 3. Co-expression of ORF13 and ORF14 proteins in C41 cells. A) Equal concentrations of pET15b-ORF14 and pET28a-ORF13 (Co-1) or pET15b-ORF13 and pET28a-ORF14 (Co-2) were mixed together and the mixtures were then used to separately transform $\mathrm{C} 41 \mathrm{E}$. coli. The bacteria were grown at $37^{\circ} \mathrm{C}$ and co-protein expression was induced with 1 mM IPTG. Cell pellets were lysed with 8 M Urea and loaded on SDS-PAGE gel for analysis. Gels were stained with Coomassie blue. Arrows indicate coat protein bands of ORF13 (18.81 KD) and ORF14 (32.01 KD). (-) is uninduced culture and (+) is induced IPTG culture. M=Molecular weight marker. B) Western Blots: ORF13, ORF14 and coexpressed proteins (ORF13 and ORF14) were prepared for SDS-PAGE gel and detected by serum raised from mice immunized with ORF13 + ORF14 proteins. Bacteriophage MS2 VLPs were used as a negative control while the purified ORF13-ORF14 recombinant proteins were set as positive control.

\subsubsection{Truncated ORF13 and ORF14 can be co-expressed and purified from E coli}

As mentioned above, ORF13 and ORF14 is $80 \%$ and $73 \%$ identical, in terms of amino acid, to VP16 and VP17 of bacteriophage P23-77, respectively. The 3D structure of VP16-VP17 complex has been predicted; VP16 forms a homodimer in the complex and VP17 coat protein interacts with at least one monomer of VP16 in the complex [34]. Given this information, we decided to 
predict the 3D structure of ORF13-ORF14 complex, based on structure of VP16VP17 complex, using SWISS-MODEL and Cn3D [35, 36]. As shown in Fig. 4, the 3D structure of ORF13-ORF14 complex is similar to that of VP16-VP17; the software predicted the structure using only amino acids number 21-165 from ORF13 and amino acids 46-271 from ORF14 (the same range of amino acids for VP16-VP17 complex). Because the structure was predicted using only amino acids 21-165 and 46-271 but not the complete sequences, we generated truncated versions of ORF13 (aa 21-165) and ORF14 (aa 46-271) and assessed the potential of the coat proteins to assemble into VLPs. ORF13-trunc and ORF14-trunc were successfully expressed, as single proteins or co-expressed proteins, regardless of whether pET15b or pET28a was used as the expression vectors (Figs. 5A and B). Purified single-expressed ORF13-trunc coat protein but not the single-expressed ORF14-trunc reacted with the recombinant ORF13ORF14 antibodies (Fig. 5C); these results including those of co-expressed ORF13-trunc and ORF14-trunc are consistent with the results of coat proteins expressed with complete sequences above (Fig. 3B). 

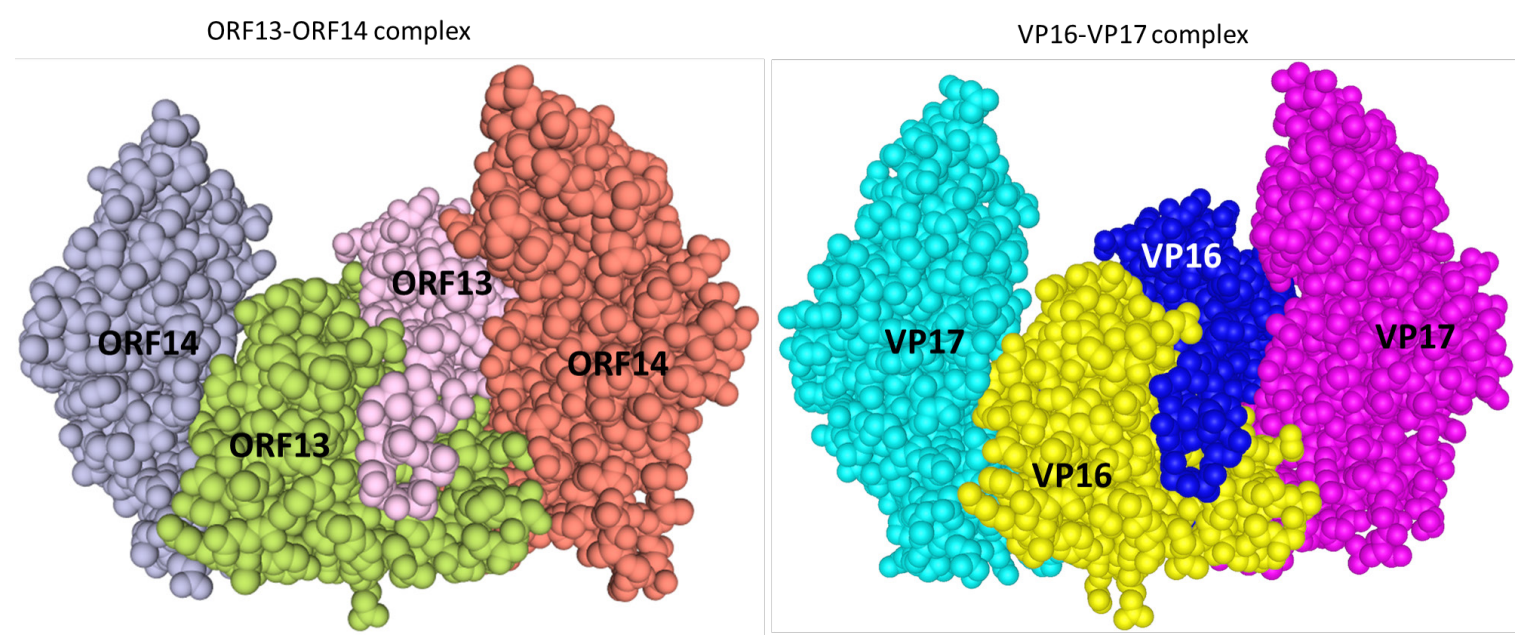

Fig. 4. Three dimensional (3D) structures of coat proteins of bacteriophages $\Phi$ IN93 and P23-77. The 3D structure of ORF13-ORF14 complex (left) from bacteriophage $\Phi I N 93$ was modeled, based on sequences and the 3D structure of VP16-VP17 complex (right; Cn3D view) from bacteriophage P23-77 as template, using Swiss-Model software. Homodimers of ORF13 (middle) and VP16 (middle) interact with each of the two copies of ORF14 and VP17, respectively. Both structures were modeled using amino acids 21-165 from ORF13 or VP16 and amino acids 46-271 from ORF14 or VP17 (highlighted in gray-background in Figure 1). 
A.
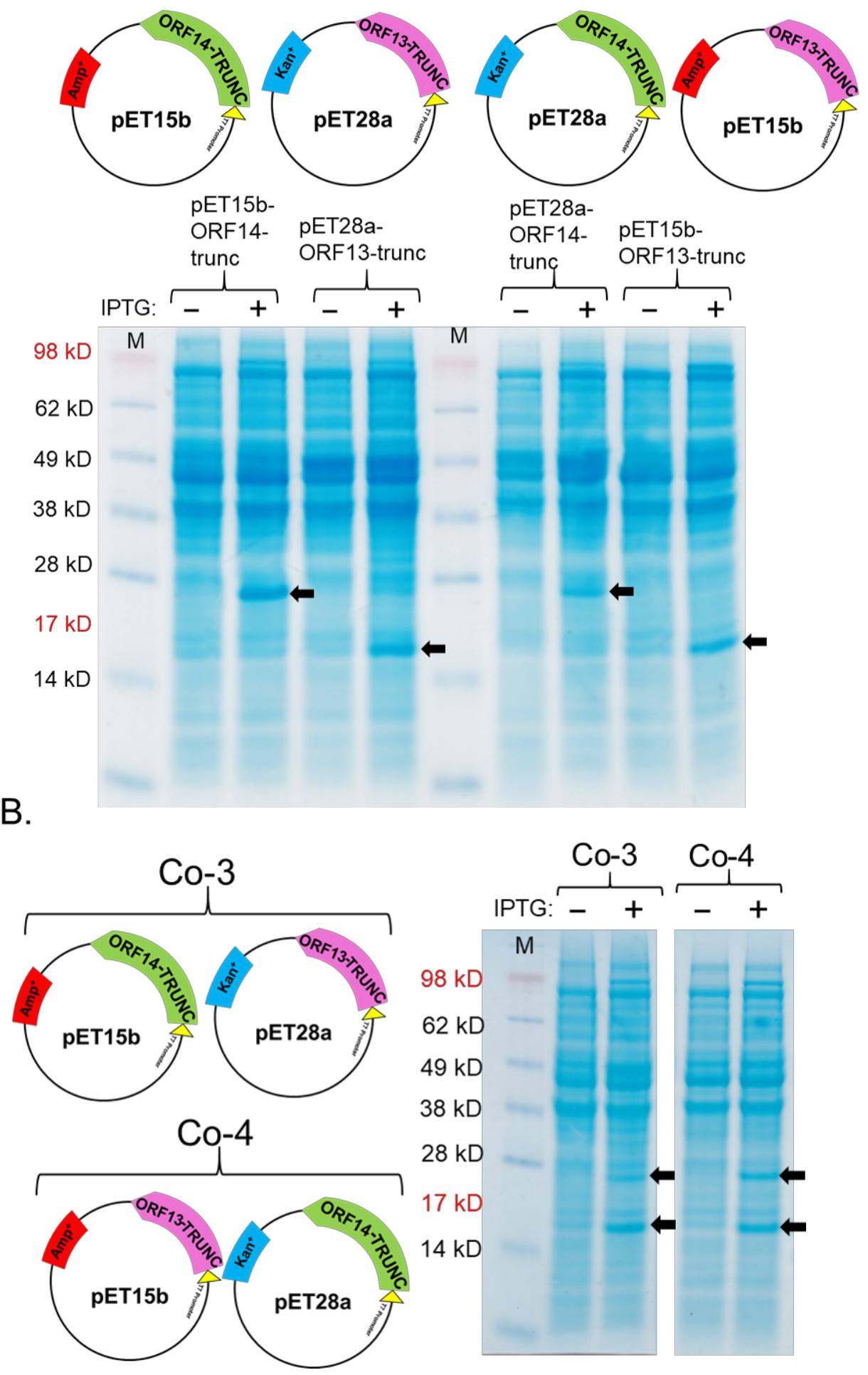


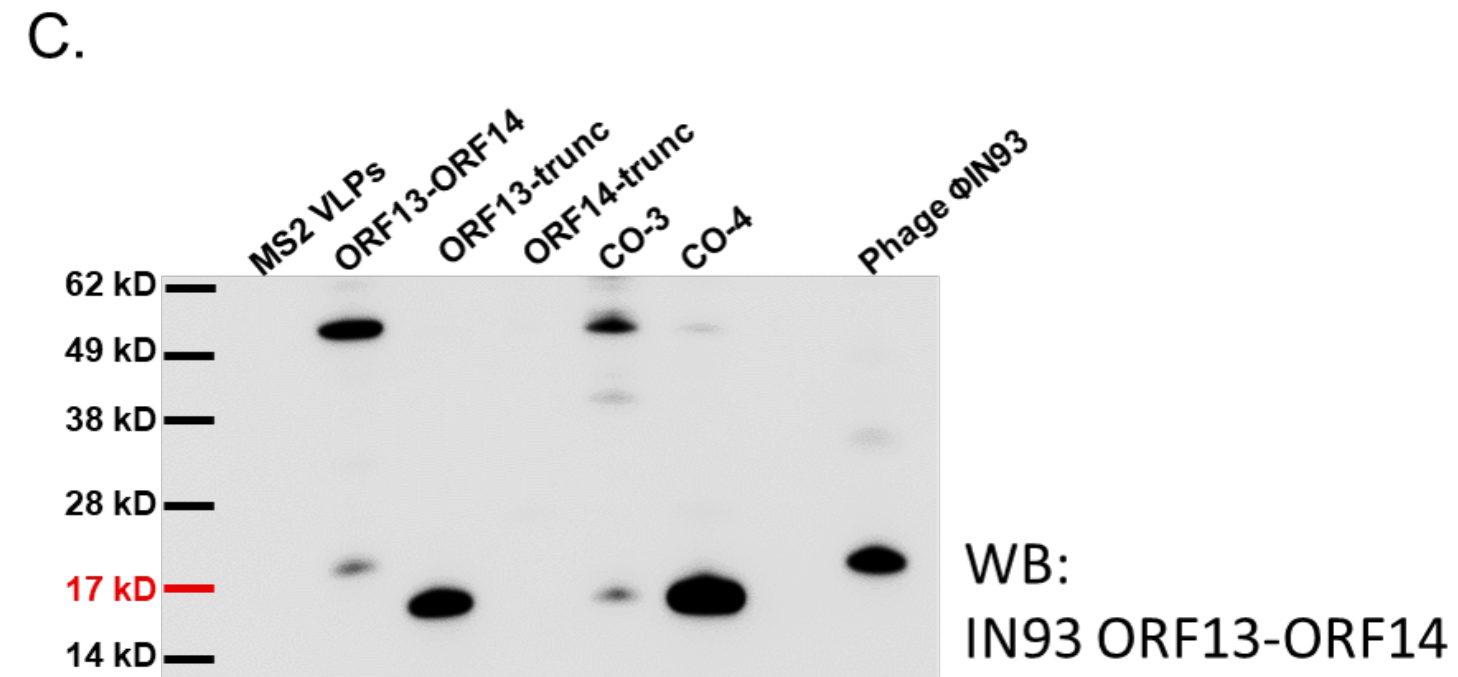

Fig. 5. Single-expression and co-expression of truncated ORF13 (ORF13-trunc) and truncated ORF14 (ORF14-trunc) proteins in C41 cells. A) Plasmids pET15bORF14-trunc or pET28a-ORF13-trunc were used to separately transform C41 E. coli cells and the bacteria were grown at $37^{\circ} \mathrm{C}$. Protein expression was induced with $0.5 \mathrm{mM}$ IPTG. B) Equal concentrations of plasmids pET15b-ORF14-trunc and pET28a-ORF13trunc (Co-3) or pET15b-ORF13-trunc and pET28a-ORF14-trunc (Co-4) were mixed and used to transformC41 E. coli cells. The bacteria were grown at $37{ }^{\circ} \mathrm{C}$ and co-protein expression was induced with $1 \mathrm{mM}$ IPTG. Cell pellets were lysed with $8 \mathrm{M}$ Urea and loaded on SDS-PAGE gel for analysis. Gels were stained with Coomassie blue. Arrows indicate protein bands, ORF13-trunc (16.06 kD) and ORF14-trunc (24.97 kD). (-) is uninduced culture and (+) is induced IPTG culture. M=Molecular weight marker. C) Western blots: ORF13-trunc, ORF14-trunc and co-expressed proteins (ORF13trunc and ORF14-trunc) were prepared for SDS-PAGE gel and detected by serum raised from mice mentioned above. The phage MS2 VLPs were used as a 
negative control while the purified ORF13-ORF14 recombinant proteins and the phage $\Phi$ IN93 were used as the positive controls.

\subsubsection{Truncated ORF13 and ORF14 form structures that resemble VLPs}

To assess whether the expressed coat proteins can assemble into viruslike particles, TEM analyses were conducted using purified coat proteins. As shown in Fig. 6A, single-expressed ORF13-trunc or ORF14-trunc gave rise to very small oval structures. The co-expressed version of the truncated coat proteins seemed to formed structures that resemble VLPs (Fig. 6 B); their sizes ( $75 \mathrm{~nm}$ to $\sim 100 \mathrm{~nm}$ ) were closer to those of bacteriophage ФIN93 (Fig. 6C). 

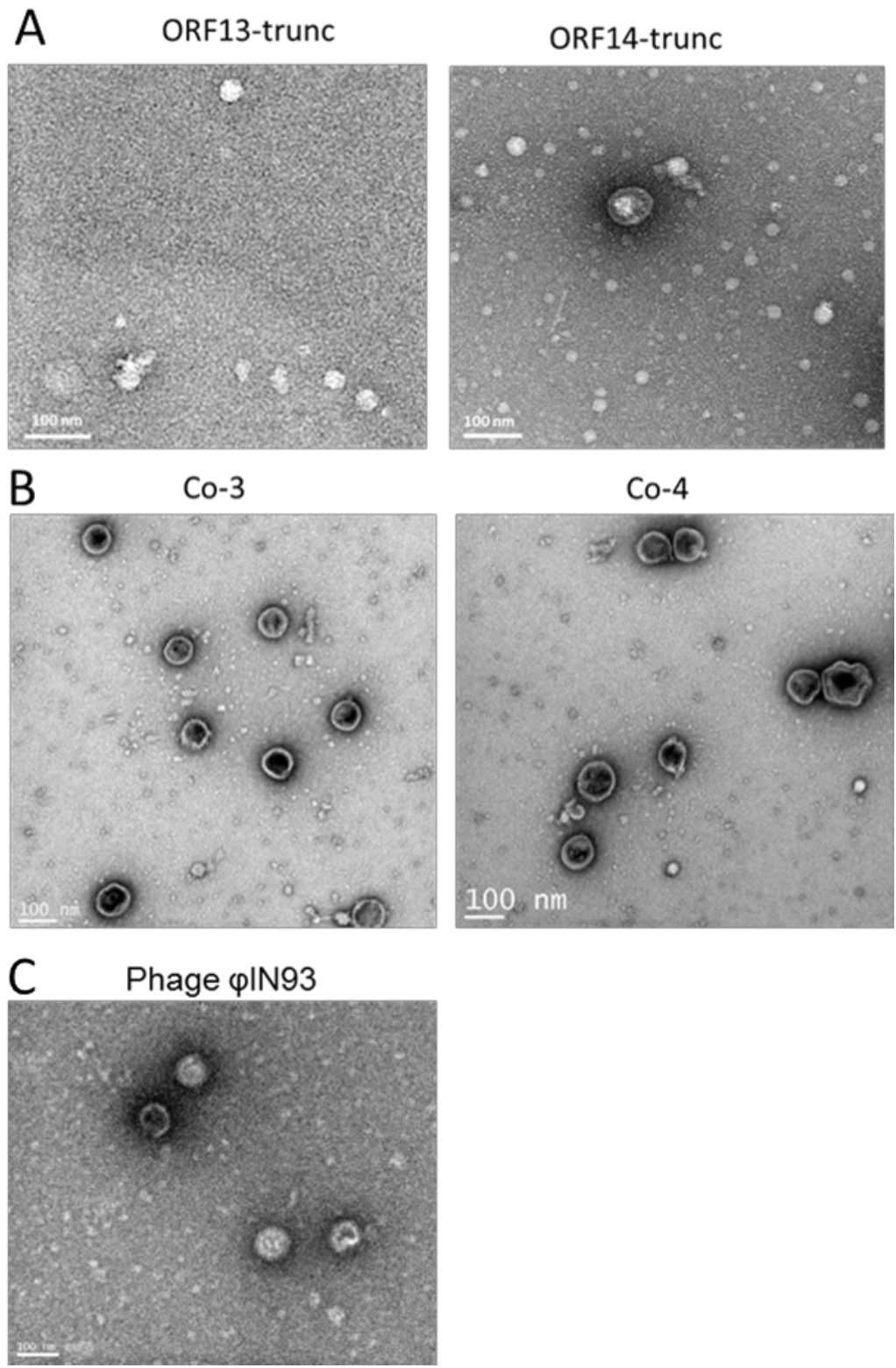

Fig. 6. Assessing the assembly of Coat proteins of single-expressed and co-expressed ORF13-trunc and ORF14-trunc. A) TEM of purified ORF13-trunc and purified ORF14-trunc. B) TEM of purified co-expressed truncated coat proteins (Co-3: ORF13-trunc and ORF14 trunc expressed from pET28a and pET15b, respectively) or (Co-4; ORF13-trunc and ORF14 trunc expressed from 
pET15b and pET28a, respectively). C) TEM of bacteriophage $\Phi I N 93$. TEM were conducted at $25,000 \times$ magnification.
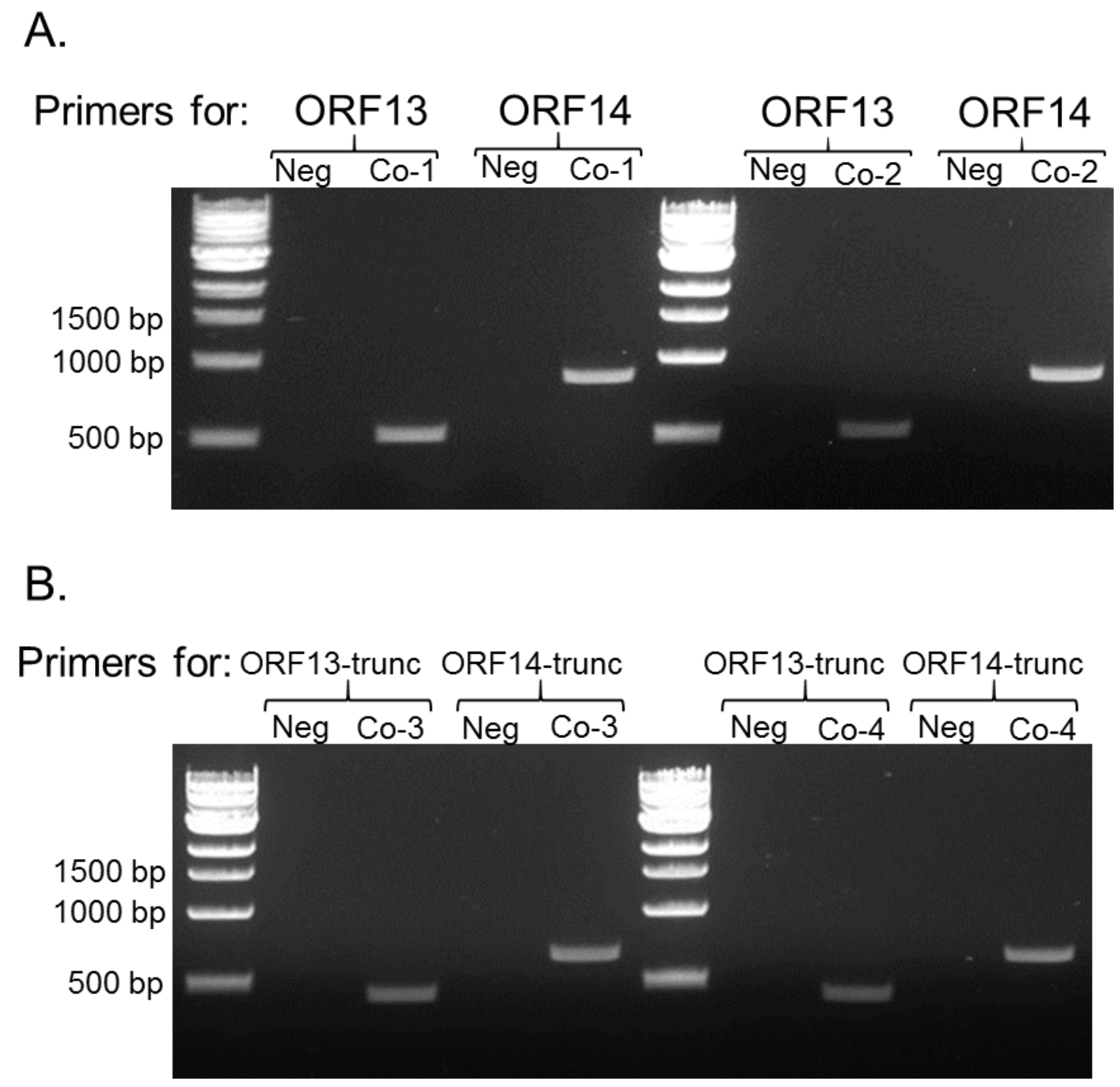

Fig. 7. PCR amplifications of co-expressed ORF13 \& ORF14 (complete gene sequences and truncated versions). A) Induced cultures from Figure 3A (Co-1 and Co-2 with complete gene sequences) were use as templates for PCR. The presence of ORF13 or ORF14 was tested using primers for each gene. Sizes of 
ORF13 and ORF14 are $\sim 579$ base pairs and $\sim 876$ base pairs, respectively. B) Induced cultures from Figure 5B (Co-3 and Co-4 with truncated versions of genes) were used as templates for PCR. The presence of ORF13 or ORF14 was tested using primers for each gene. Neg: untransformed E. coli culture negative control. Sizes of ORF13-trunc and ORF14-trunc are $\sim 441$ base pairs and $\sim 684$ base pairs, respectively.

\subsection{Discussion}

Two coat proteins, ORF13 and ORF14, from a thermophilic bacteriophage ФIN93 have $80 \%$ and $73 \%$ amino acid identity, respectively, with two major coat proteins, VP16 and VP17, of thermophilic bacteriophage P23-77 [32]. While VP16 and VP17 coat proteins have been expressed in previous studies [33, 34]. The expressions of ORF13 and ORF14 have never been explored. Here we cloned and assessed the expression of ORF13 and ORF14 individually and in combination (co-expression) in E. coli $\mathrm{C} 41$ cells with the long term-goal of assessing the potential of the coat proteins to assemble into virus-like particles (VLPs). ORF13 and ORF14 coat proteins were successfully expressed, as separate proteins, in C41 cells. Moreover, the coat proteins could also be coexpressed in the same bacteria by using two plasmids that are incompatible ( $p E T 28 a$ and $p E T 15 b$; have the same origin of replication, pBR322) by simply applying two different selective pressures (two antibiotics resistance; kanamycin 
and ampicillin) on the bacterial cells for 24 hours. The co-expression of ORF13 and ORF14 using two incompatible plasmids are consistent with previous studies that have shown that two proteins can be co-expressed from incompatible plasmids by using different antibiotic to the vectors [37, 38]. While ORF13 and ORF13 were successfully expressed (individually or together), the expression of ORF14 in all cases was less compared to that of ORF13, regardless of whether the protein was expressed using $\mathrm{pET} 28$ a plasmid or $\mathrm{pET} 15 \mathrm{~b}$ plasmid. In the coexpression study, especially Co-1 with pET28a expressing ORF13 and pET15b expressing ORF14, we initially thought the expression bacteria might only have pET28a-ORF13 plasmid (i.e. pET15b-ORF14 plasmid might have been lost from the bacteria due to plasmid incompatibility). To assess if both expression plasmids were maintained in the bacteria during expression, bacterial cultures expressing the coat proteins were induced and aliquots (equal volumes) of the cultures were used as templates for polymerase chain reaction (PCR). As shown in Fig. 7A, the band intensities suggest that both plasmid combinations (pET15bORF14 and pET28a-ORF13 or pET15b-ORF13 and pET28a-ORF14) were maintained in the bacteria. These data suggest that ORF14 expression may be normally low on the virus. This view is supported by our Western blot data using ФIN93 virus. In our Western blot data (Figs. 3B and 5C), ORF14 band in the lane with positive control $\Phi$ IN93 virus is very faint compared to ORF13 band. The view (low expression) is further supported by data from a related coat protein, VP17 from P23-77, which is $73 \%$ identical to ORF14; in a Master's Thesis, 
University of Jyväskylä (Finland), it was observed that VP17 was expressed at low levels compared to VP16 (80\% identical to ORF13) following co-expression of VP17 and VP16 using a bicistronic VP16-VP17 transcription unit [39]. Taken together, our data suggest that ORF14 is expressed at low levels compared to ORF13. It is likely that less proportion of ORF14 may be required for viral assembly compared to ORF13 as has been suggested for related proteins, VP17 (540 copies) and VP16 (1080 copies) in bacteriophage P23-77 [33, 34]. We assessed whether ORF13 and ORF14 can assemble to VLPs. As mentioned in the introduction, a mixture of VP16, VP17, and VP11 (a minor capsid protein) of P23-77 has been shown to form complexes in vitro suggesting that these coat proteins may form VLPs. However, a sequence in bacteriophage $\Phi$ IN93 that is homologous to VP11 (minor capsid protein of P23-77) has not be identified, suggesting that the capsid protein of $\Phi$ IN93 may be composed of only two coat proteins, ORF13 and ORF14. This may be not surprising given the fact that in some viruses (e.g. adeno-associated virus type 2), only two coat proteins out of 3 or more coat proteins are sufficient to form VLPs $[4,40]$. Unfortunately, none of the expressed ORF13 and ORF14 coat proteins (individually or together) assembled into VLPs.

Given the fact the expressed ORF13 and ORF14 coat proteins did not assemble into VLPs, we generated truncated forms of the proteins based on regions of the proteins (amino acid sequence ranges) that were used by SwissModel software to predict ORF13-ORF14 structure in Fig. 4 (left). To our 
surprise, the truncated versions of the proteins (individually or co-expressed) seemed to be expressed at low levels compared to the full-length proteins. PCR result based on band intensities (Fig. 7B) showed that the expression plasmids for ORF13 and ORF14 were both maintained in the bacteria. We assessed whether the truncated versions of ORF13 and ORF14 can assemble to VLPs. We observed structures that look like VLPs but future studies need to confirm if these are actually $\Phi I N 93$ VLPs. 


\subsection{References}

1. Howley, M. and M. Knipe, Fields virology. 6 ed. Vol. 1. 2013: Philadelphia : Wolters Kluwer Health/Lippincott Williams \& Wilkins. 2664.

2. Gerlich, W.H., Medical virology of hepatitis B: how it began and where we are now. Virol J, 2013. 10: p. 239.

3. Zeltins, A., Construction and characterization of virus-like particles: a review. Mol Biotechnol, 2013. 53(1): p. 92-107.

4. Palucha, A., et al., Virus-like particles: models for assembly studies and foreign epitope carriers. Prog Nucleic Acid Res Mol Biol, 2005. 80: p. 135-68.

5. $\quad$ Pumpens, P., et al., The True Story and Advantages of RNA Phage Capsids as Nanotools. Intervirology, 2016. 59(2): p. 74-110.

6. Chroboczek, J., I. Szurgot, and E. Szolajska, Virus-like particles as vaccine. Acta Biochim Pol, 2014. 61(3): p. 531-9.

7. Tao, P., et al., Bacteriophage T4 nanoparticles for vaccine delivery against infectious diseases. Adv Drug Deliv Rev, 2018.

8. Shirbaghaee, Z. and A. Bolhassani, Different applications of virus-like particles in biology and medicine: Vaccination and delivery systems. Biopolymers, 2016. 105(3): p. 113-32.

9. Yan, D., et al., The application of virus-like particles as vaccines and biological vehicles. Appl Microbiol Biotechnol, 2015. 99(24): p. 10415-32.

10. Tyler, M., E. Tumban, and B. Chackerian, Second-generation prophylactic HPV vaccines: successes and challenges. Expert Rev Vaccines, 2014. 13(2): p. 247-55.

11. Zhai, L. and E. Tumban, Gardasil-9: A global survey of projected efficacy. Antiviral Res, 2016. 130: p. 101-9.

12. ClinicalTrials.gov. ClinicalTrials.gov-virus-like particles. [cited 2018 June 11]; Available from: https://www.clinicaltrials.gov/ct2/results?cond=virus$\underline{\text { like }+ \text { particles } \& \text { term }=\& \text { cntry }=\& \text { state }=\& \text { city }=\& \text { dist }}=$.

13. Zhao, C., Z. Ao, and X. Yao, Current Advances in Virus-Like Particles as a Vaccination Approach against HIV Infection. Vaccines (Basel), 2016. 4(1). 
14. Wei, S., et al., Neutralization effects of antibody elicited by chimeric HBV S antigen viral-like particles presenting HCV neutralization epitopes. Vaccine, 2018. 36(17): p. 2273-2281.

15. Basu, R., et al., Immunization with phage virus-like particles displaying Zika virus potential B-cell epitopes neutralizes Zika virus infection of monkey kidney cells. Vaccine, 2018. 36(10): p. 1256-1264.

16. Zhai, L., et al., A novel candidate HPV vaccine: MS2 phage VLP displaying a tandem HPV L2 peptide offers similar protection in mice to Gardasil-9. Antiviral Res, 2017. 147: p. 116-123.

17. Berkower, I., et al., Assembly, structure, and antigenic properties of virus-like particles rich in HIV-1 envelope gp120. Virology, 2004. 321(1): p. 75-86.

18. Ramasamy, V., et al., A tetravalent virus-like particle vaccine designed to display domain III of dengue envelope proteins induces multi-serotype neutralizing antibodies in mice and macaques which confer protection against antibody dependent enhancement in AG129 mice. PLoS Negl Trop Dis, 2018. 12(1): p. e0006191.

19. Daly, S.M., et al., VLP-based vaccine induces immune control of Staphylococcus aureus virulence regulation. Sci Rep, 2017. 7(1): p. 637.

20. Collins, K.A., et al., Enhancing protective immunity to malaria with a highly immunogenic virus-like particle vaccine. Sci Rep, 2017. 7: p. 46621.

21. Crossey, E., et al., Identification of an Immunogenic Mimic of a Conserved Epitope on the Plasmodium falciparum Blood Stage Antigen AMA1 Using VirusLike Particle (VLP) Peptide Display. PLoS One, 2015. 10(7): p. e0132560.

22. Ong, H.K., W.S. Tan, and K.L. Ho, Virus like particles as a platform for cancer vaccine development. PeerJ, 2017. 5: p. e4053.

23. Chackerian, B. and K.M. Frietze, Moving towards a new class of vaccines for non-infectious chronic diseases. Expert Rev Vaccines, 2016. 15(5): p. 561-3.

24. Crossey, E., et al., A cholesterol-lowering VLP vaccine that targets PCSK9. Vaccine, 2015. 33(43): p. 5747-5755.

25. Schellenbacher, C., R. Roden, and R. Kirnbauer, Chimeric L1-L2 virus-like particles as potential broad-spectrum human papillomavirus vaccines. J Virol, 2009. 83(19): p. 10085-95. 
26. Tyler, M., et al., Immunization with a consensus epitope from human papillomavirus L2 induces antibodies that are broadly neutralizing. Vaccine, 2014. 32(34): p. 4267-74.

27. Tumban, E., et al., Preclinical refinements of a broadly protective VLP-based $H P V$ vaccine targeting the minor capsid protein, L2. Vaccine, 2015. 33(29): p. 3346-53.

28. Edstam, J.S., et al., Exposure of hepatitis B vaccine to freezing temperatures during transport to rural health centers in Mongolia. Prev Med, 2004. 39(2): p. 384-8.

29. Knuchel, M.C., et al., Relevance of a pre-existing measles immunity prior immunization with a recombinant measles virus vector. Hum Vaccin Immunother, 2013. 9(3): p. 599-606.

30. Zak, D.E., et al., Merck Ad5/HIV induces broad innate immune activation that predicts CD8(+) T-cell responses but is attenuated by preexisting Ad5 immunity. Proc Natl Acad Sci U S A, 2012. 109(50): p. E3503-12.

31. Matsushita, I. and N. Yamashita, Isolation and Characterization of Bacteriophage Induced from a New Isolate of Thermus aquaticus. Microbiol. Cult. Coll., 1995. 11(2): p. 133-138.

32. Pawlowski, A., et al., Gammasphaerolipovirus, a newly proposed bacteriophage genus, unifies viruses of halophilic archaea and thermophilic bacteria within the novel family Sphaerolipoviridae. Arch Virol, 2014. 159(6): p. 1541-54.

33. Pawlowski, A., et al., The Minor Capsid Protein VP11 of Thermophilic Bacteriophage P23-77 Facilitates Virus Assembly by Using Lipid-Protein Interactions. J Virol, 2015. 89(15): p. 7593-603.

34. Rissanen, I., et al., Bacteriophage P23-77 capsid protein structures reveal the archetype of an ancient branch from a major virus lineage. Structure, 2013. 21(5): p. 718-26.

35. Wang, Y., et al., Cn3D: sequence and structure views for Entrez. Trends Biochem Sci, 2000. 25(6): p. 300-2.

36. SWISS-MODEL. Available from: https://swissmodel.expasy.org/interactive.

37. Yang, W., et al., A new method for protein coexpression in Escherichia coli using two incompatible plasmids. Protein Expr Purif, 2001. 22(3): p. 472-8. 
38. Johnston, K., et al., Coexpression of proteins in bacteria using T7-based expression plasmids: expression of heteromeric cell-cycle and transcriptional regulatory complexes. Protein Expr Purif, 2000. 20(3): p. 435-43.

39. Rissanen, I., Purification and crystallization of the two major coat proteins of bacteriophage P23-77 for X-ray crystallography 2009.

40. Backovic, A., et al., Capsid protein expression and adeno-associated virus like particles assembly in Saccharomyces cerevisiae. Microb Cell Fact, 2012. 11: p. 124. 


\section{Summary}

Most of our work focused on developing HPV L2 candidate vaccines based on bacteriophage MS2 VLP platform and we also spent time assessing the thermostability of the candidate vaccine by using spray-freeze drying technique; furthermore, we assessed the potential of developing a novel VLP display platform based on a thermophilic bacteriophage $\Phi I$ N93. In chapter 1, we showed that inserting a concatemer of two L2 peptides (HPV31 L2 20-31 and HPV16 L2 17-31) on bacteriophage MS2 VLPs does not affect the ability of MS2 coat proteins to form VLPs. Mixed MS2-L2 VLPs (MS2 VLPs displaying the concatemer L2 epitope and MS2 VLPs displaying a consensus L2 epitope) elicited antibodies that cross-protected/neutralized selected HR-HPV pseudovirus types (HPV16, 31, 45, 58, 33 and 18), suggesting that this is an excellent approach to achieve broader protection against more HPV types. In chapter 2, we continued with the assessment of cross-protection of candidate vaccine against additional HPV types (HPV35, 39, 53, and 58). We showed that the candidate vaccine offers protection from genital infection with more HPV PsVs (HPV53) and protection from oral infection with selected high-risk HPV PsVs (HPV35, 39 and 58). Overall, in Chapters 1 and 2, the candidate vaccine showed superior protection, especially with HPVs (HPV35 and HPV39) compared to Gardasil 9. In Chapter 2, the candidate vaccine without adjuvants was successfully spray-freeze dried into powder for thermostability test. SFD did not affect VLP assembly and the immunogenicity. Moreover, after 60 days 
storage in room temperature, the candidate vaccine still elicited high immunogenicity and protection against oral infection of HPV16 PsV. In the future, more high-risk HPVs types should be tested to assess the cross-protection potential of this candidate vaccine. Also, longer storage time such as six months to 1 year (at room temperature or higher) should be done to assess the thermostability of the VLPs. The longevity of immune responses of the candidate vaccine should also be tested.

In chapter 3 , we successfully co-expressed and purified full-length and truncated coat proteins of $\Phi I N 93$ phage. VLP-like structures were observed in the coexpression of truncated coat proteins. However, this result needs to be further confirmed. One possible way is the gold nanoparticle staining. In brief, the VLPlike structures should be immuno-stained with serum (recombinant ORF13ORF14) mentioned above in chapter 3 and then incubated with the secondary antibodies conjugated with gold nanoparticles. If they are VLPs formed by $\Phi$ IN93 coat proteins, the VLPs-primary antibody complex will be bound by the gold particles. This can be observed using a TEM. A positive control can be phage ФIN93 which is supposed to be bound properly, while a negative control can be HPV pseudovirus 16 VLPs which is not expected to be bound by the antibody. However, if they fail to form VLPs in E. coli, another expression system, thermophilic bacterium (Thermus aquaticus), can be used to co-express and assess VLP assembly. The thermophilic bacterium might have some "elements" 
to help the coat protein fold and re-assemble given the fact that this is the natural host of phage $\Phi I N 93$. 


\section{A Copyrights}

Chapter 1 and Chapter 2 involve texts and figures originally published in

the journal, Antiviral Research, by Lukai Zhai et al. in 2016, 2017 and 2019. This dissertation does not need to be published online.

\section{Copyright}

Clearance

Center

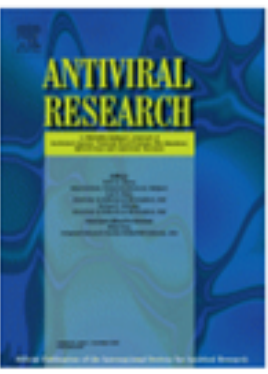

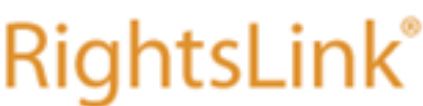

Title:

Author:

Gardasil-9: A global survey of projected efficacy

Publication: Antiviral Research

Publisher: Elsevier

Date: June 2016

을 2016 Elsevier B.V. All rights reserved.

\section{Home}

Account

Info

Please note that, as the author of this Elsevier article, you retain the right to include it in a thesis or dissertation, provided it is not published commercially. Permission is not required, but please ensure that you reference the journal as the original source. For more information on this and on your other retained rights, please visit: https://www.elsevier.com/about/our-

business/policies/copyright\#Author-rights

\section{BACK}

CLOSE WINDOW

Copyright (4) 2019 Copyright Clearance Center, Inc. All Rights Reserved. Privacy statement. Terms and Conditions. Comments? We would like to hear from you. E-mail us at customercare@copyright.com 


\section{Copyright Clearance

Center

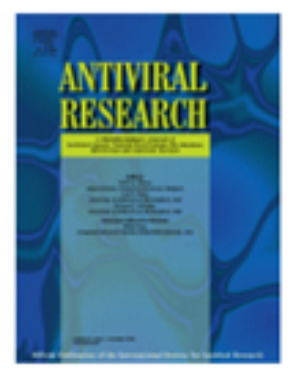

Title:

A novel candidate HPV vaccine:

Logged in as: MS2 phage VLP displaying a tandem HPV L2 peptide offers LUKAI ZHAI similar protection in mice to LOGOUT Gardasil-9

Author: Lukai Zhai,Julianne Peabody,Yuk-Ying Susana Pang,John Schiller,Bryce Chackerian,Ebenezer Tumban

Publication: Antiviral Research

Publisher: Elsevier

Date: November 2017

Published by Elsevier B.V.

Please note that, as the author of this Elsevier article, you retain the right to include it in a thesis or dissertation, provided it is not published commercially. Permission is not required, but please ensure that you reference the journal as the original source. For more information on this and on your other retained rights, please visit: https://www.elsevier.com/about/ourbusiness/policies/copyright:\#Author-rights

\section{BACK \\ CLOSE WINDOW}

Copyright \& 2019 CeRvright Clearance Center, Inc, All Rights Reserved. Privacy statement. Ierms and Conditions. Comments? We would like to hear from you. E-mail us at customercare 9 cepyright.cem 


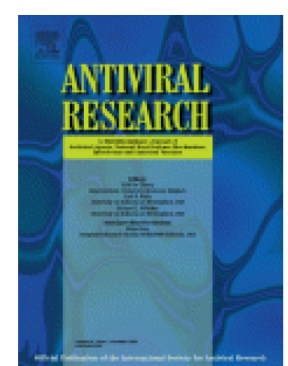

Title:

Oral immunization with bacteriophage MS2-L2 VLPs protects against oral and genital Logged in as: LUKAI ZHAI infection with multiple HPV Account \#: types associated with head \& neck cancers and cervical cancer 3001424735 Lukai Zhai,Rashi Yadav,Nitesh

Author:

K. Kunda,Dana

Anderson,Elizabeth

Bruckner,Elliott K. Miller,Rupsa

Basu,Pavan Muttil,Ebenezer

Tumban

Publication: Antiviral Research

Publisher: Elsevier

Date: $\quad$ Available online 26 March 2019

(c) 2019 Elsevier B.V. All rights reserved.

Please note that, as the author of this Elsevier article, you retain the right to include it in a thesis or dissertation, provided it is not published commercially. Permission is not required, but please ensure that you reference the journal as the original source. For more information on this and on your other retained rights, please visit: https://www.elsevier.com/about/ourbusiness/policies/copyright\#Author-rights

\section{BACK}

CLOSE WINDOW

Copyright (c) 2019 Copyright Clearance Center, Inc. All Rights Reserved. Privacy statement. Terms and Conditions. Comments? We would like to hear from you. E-mail us at customercare@copyright.com 